علاقـة الـذكـاء الانـفـعـالـي بــاستـر اتـيـجيـات إد ارة

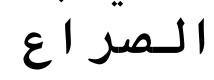

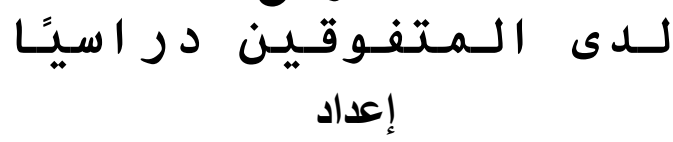

أ. أحمد جمال طه أحمد

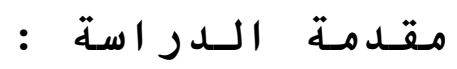

للاككاء الانفعالي دور مهم في حياة كل فرد، مما يدعو إلى ضرورة الاهتمام

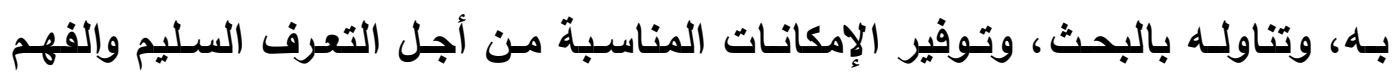

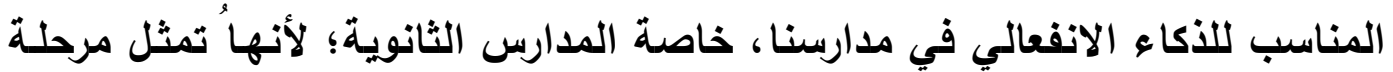

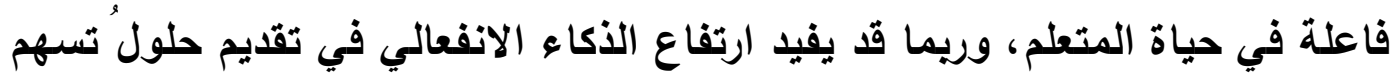

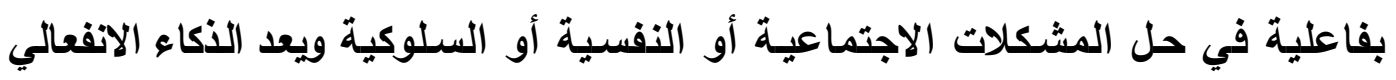

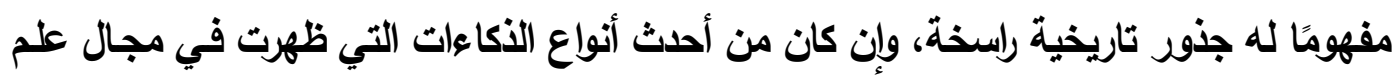

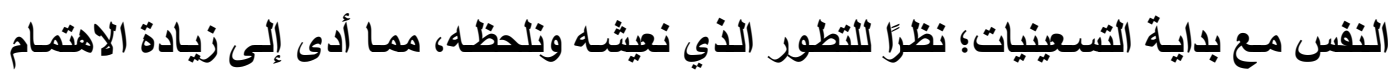
بالذكاء الانفعالي، وتزليد أعداد البحوث المنشورة في الدوريات والمجلات العربية والأجنبية التي لئي

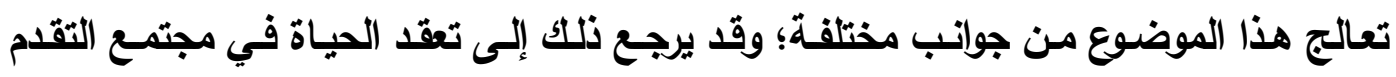

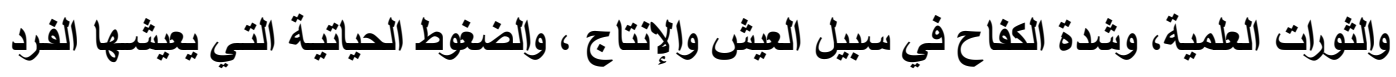

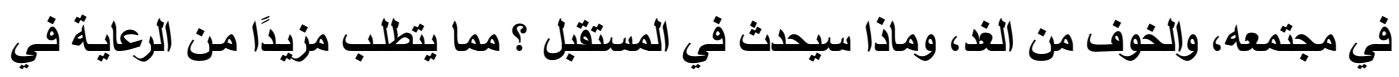

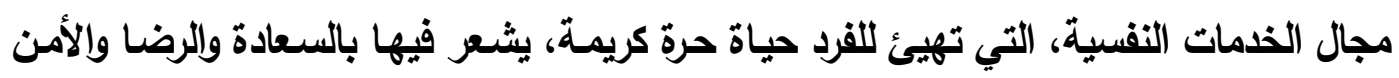

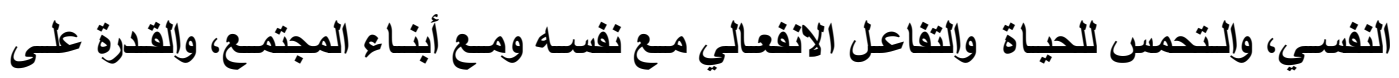

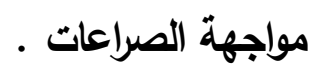

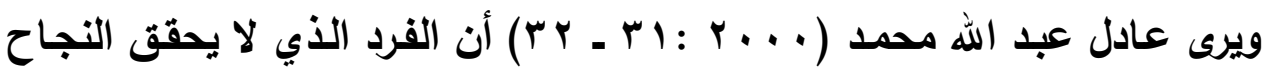
في حياته ولا يكون له حظ في موافقة الآخرين له، فإنه يدين نفسه، ويحط من قدر نفسـه

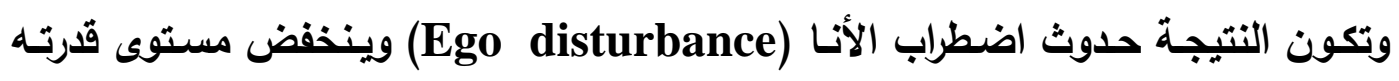

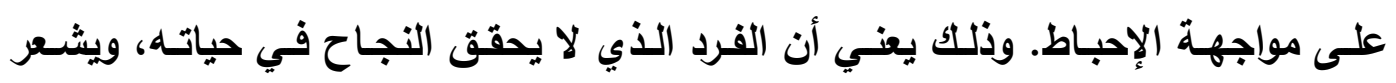

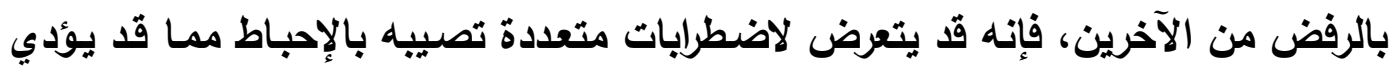
إلى عدم القدرة على مواجهة الصراع أو إدارته.

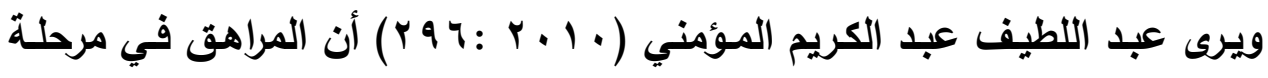

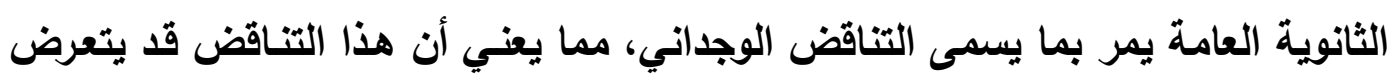


المتعلم من خلاله للصراع، وقد يزداد كلما ازداد طموح الفرد وتطلع إلى المستقبل، ولكي

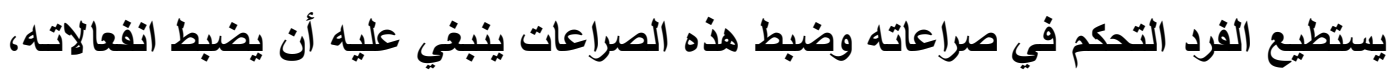

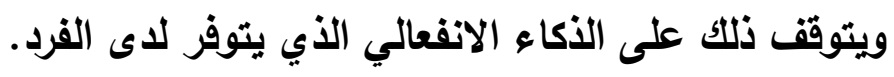

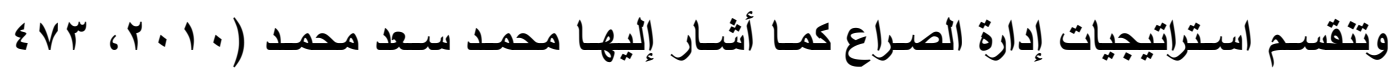

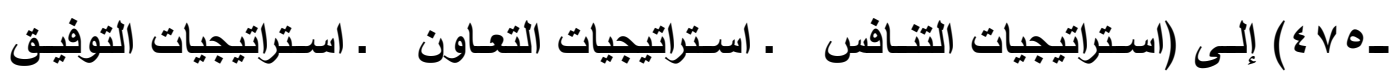

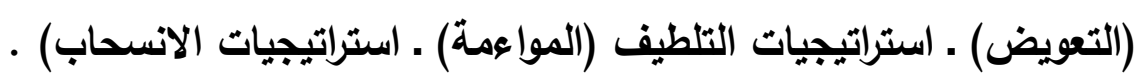

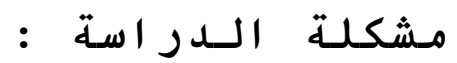

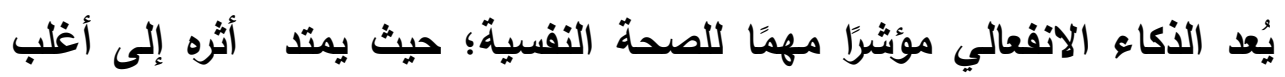

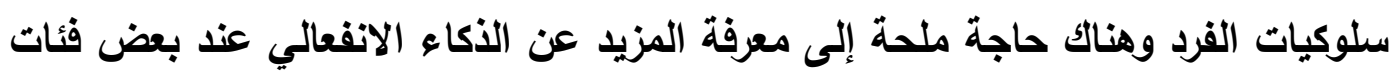

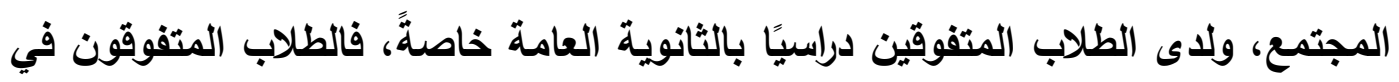
مرحلة الثانوية العامة قد يعيثون الصراع في مواقف كثيرة .

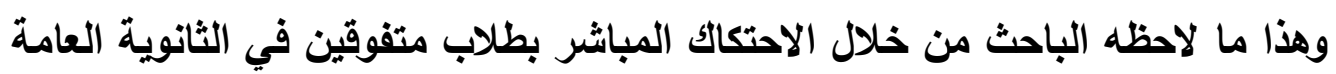
والاحتكاك ببعض معلمي الثانوية العامة ويعض الموجهين، والاستفادة من خبراتهم حيث أيدوا :

1 ـ ـ عدم توفر قدر كاف من المطلومات عن الذكاء الانفعالي؛ وأن الذكاء الانفعالي لا

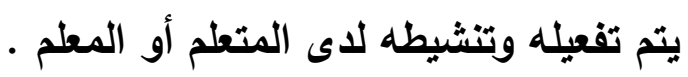

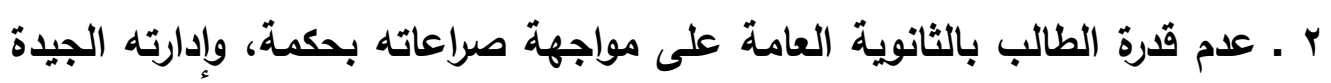
لتلك الصراعات، والطالب المتفوق قد يتوفر لايه قر كاف من الذكاء الانفعالي إلا أنه رغم ذلك قد لا يستطيع استخدام استراتيجيات إدارة الصراع بكفاءة وفاعلية .

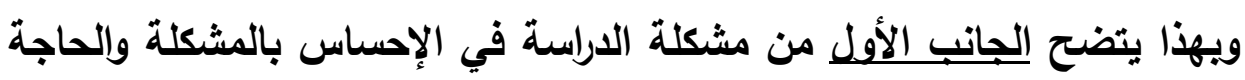
الملحة للها من خلال التعرف على العلاقة بين الذكاء الانفعالي واستراتيجيات إدارة الصراع لاى المتفوقين بالمرحلة الثانوية بالمنيا.

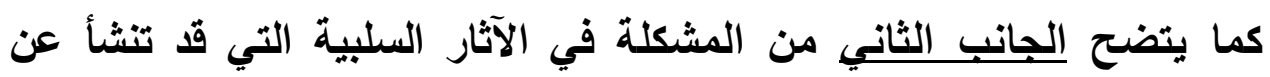

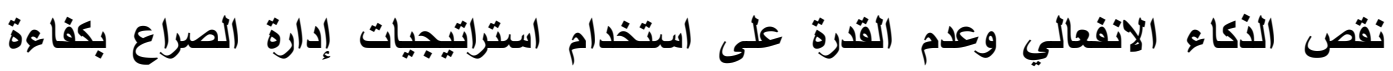

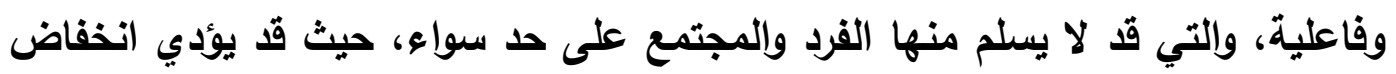

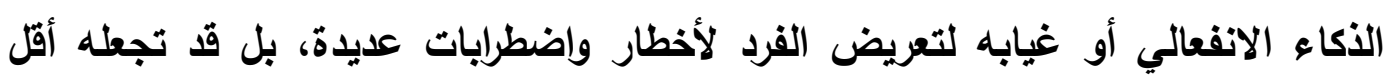

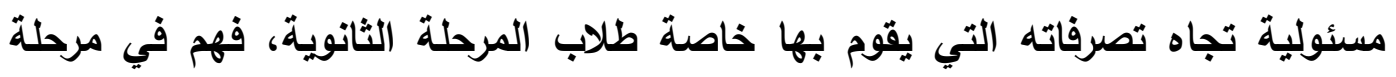


مهمة وخطيرة، يحتاجون فيها إلى زيادة الوعي بالذكاء الانفعالي في كل ما يحيط بهم في

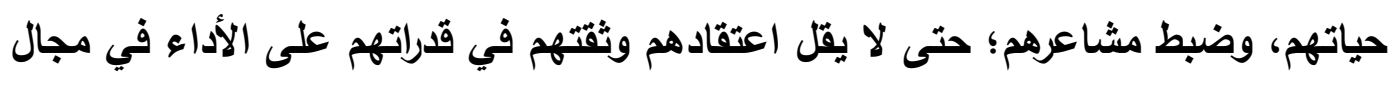

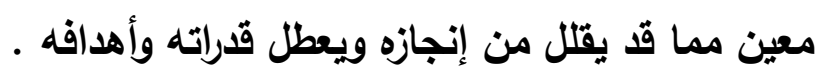

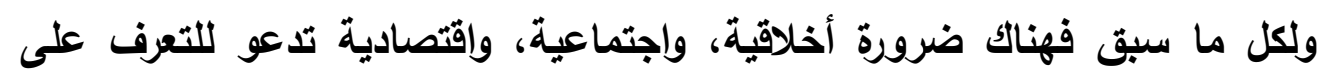
العلاقة بين الذكاء الانفعالي واستراتيجيات إدارة الصراع عند المتفوقين دراسيًا من طلاب

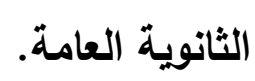

أما الجانب الثالث من مشكلة الدراسة الحالية فيتضح في النقاط الآتية :

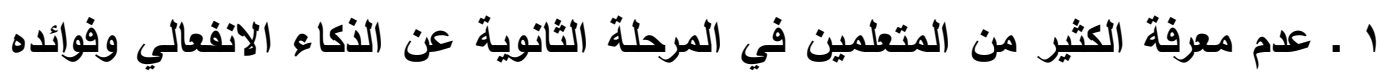

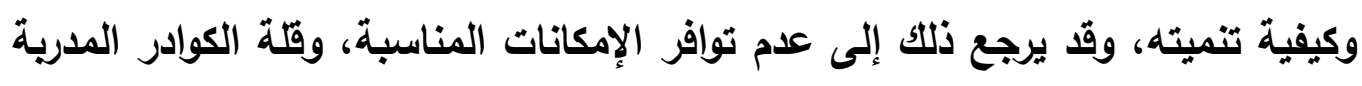
على تفعيل وتنثيط الذكاء الانفعالي .

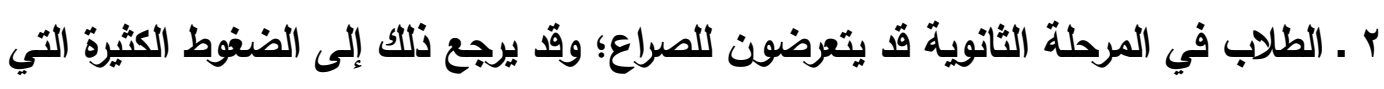

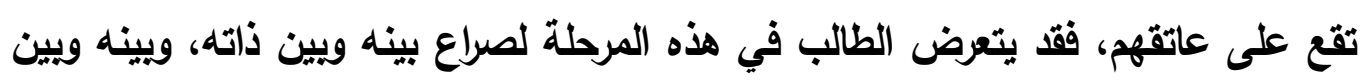

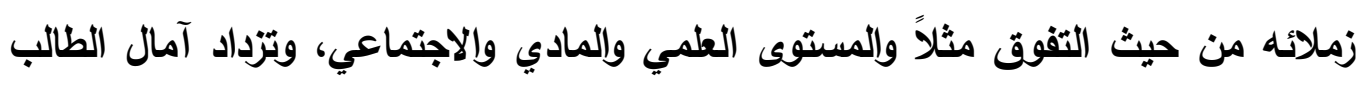

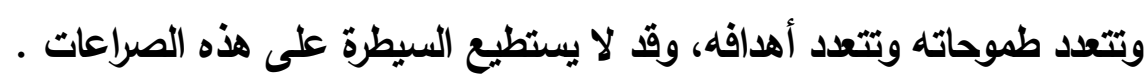

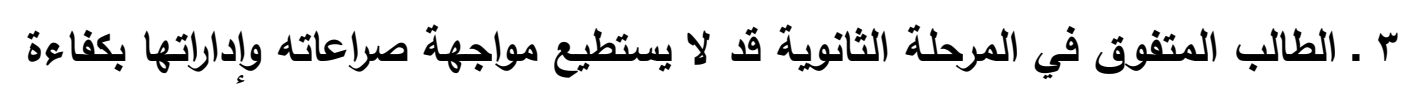
وفاعلية . الماب.

؛. قلة اللارسات . في حدود علم الباحث ـ التي حاولت التعرف على علاقة الذكاء الانفعالي

باستراتيجيات إدارة الصراع لدى عينة من المتفوقين دراسيًا بمرحلة الثانوية العامة بالمنيا.

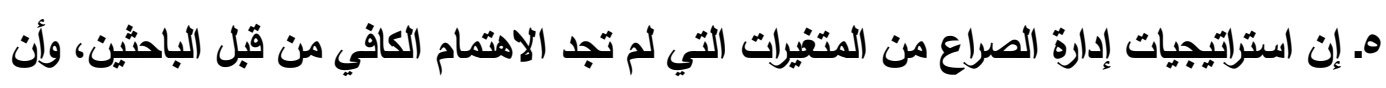

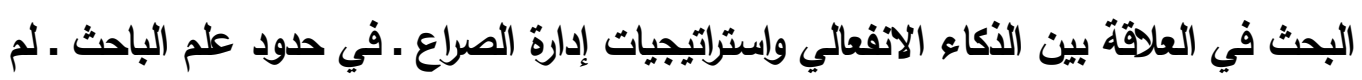

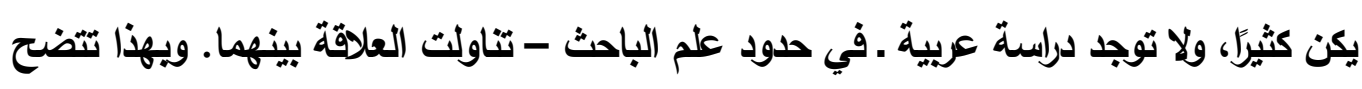
مشكلة الدراسة في الإحساس بها والحاجة الملحة لحلها.

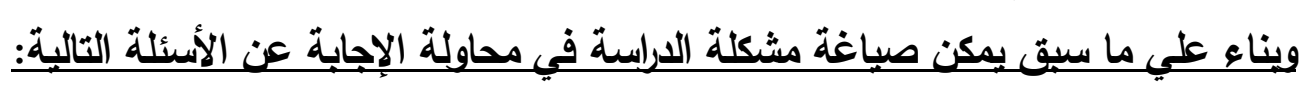

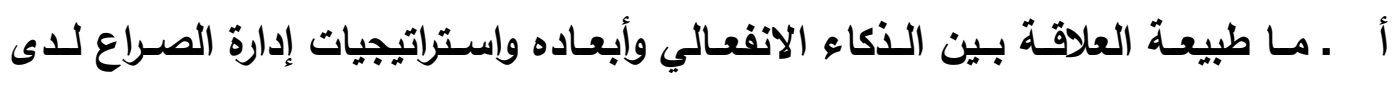

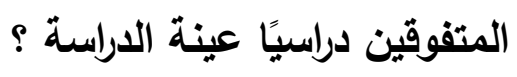
ب ـ هل تختلف درجات الذكور ودرجات الإنات في الذكاء الانفعالي وأبعاده؟ ج ـ هل تختلف درجات الذكور ودرجات الإناث في استراتيجيات إدارة الصراع ؟ 


$$
\begin{aligned}
& \text { ج - مـتغيـر ات الـدراسة : الأفعالي : } \\
& 1 \text { - الأكاء الانفعالي : }
\end{aligned}
$$

تتصف مرحلة المراهقة بتغيرات فسيولوجية، وعقلية واجتماعيـة وخلقية، وتختلف

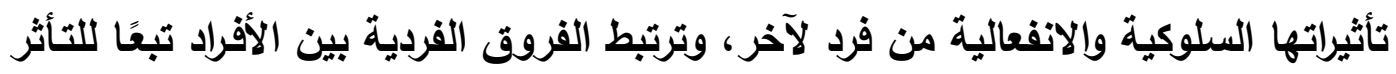

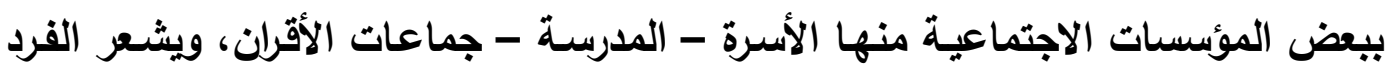

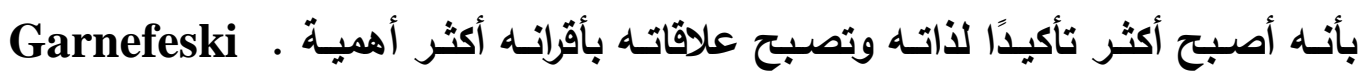
.(2000:1175-1180)

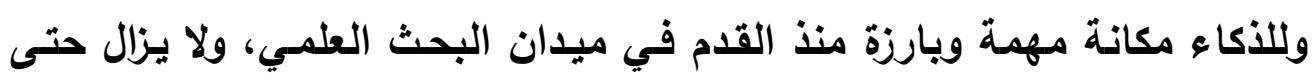

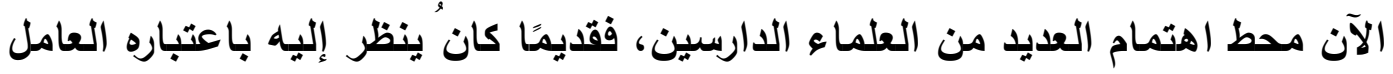

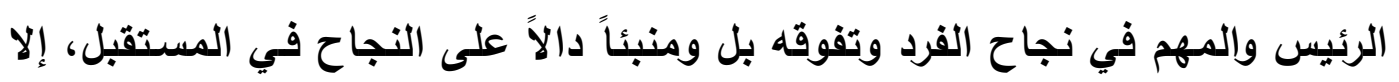

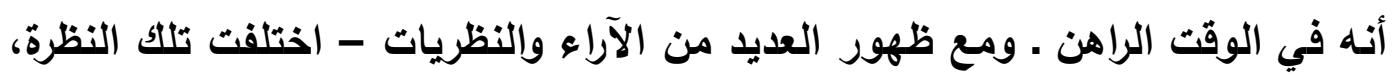

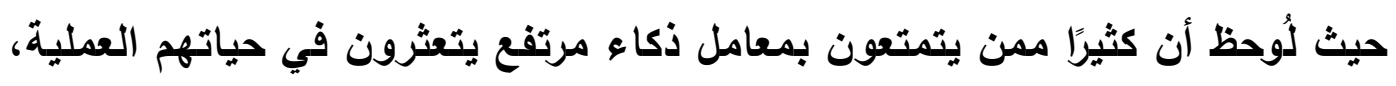

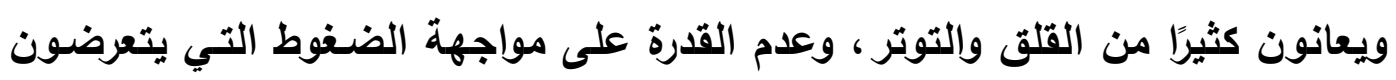

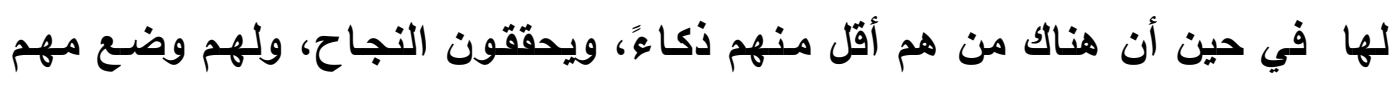

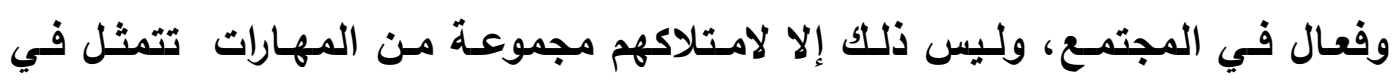

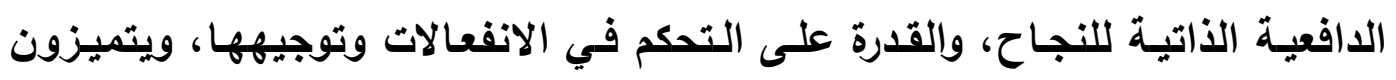

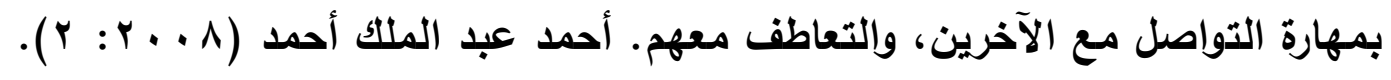
ويـرى (Kazdin,(2000:528 أن التعـاطف يمثل استجابة انفعاليـة عاطفيـة ترتكز على فهم حالة الانفعال للآخرين، ويتضمن مشاعر الحب والثفقة والأسى والاهتمام

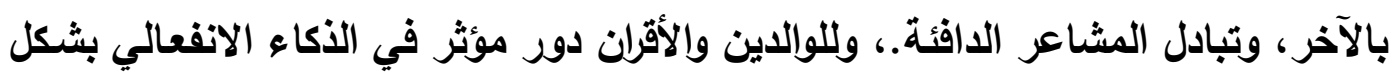

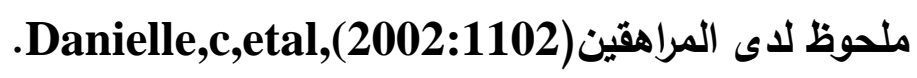
وغذاما يستطيع الفرد الأي يتمتع بالذكاء الانفعالي القدرة على التحكم في عواطقه وكيفية

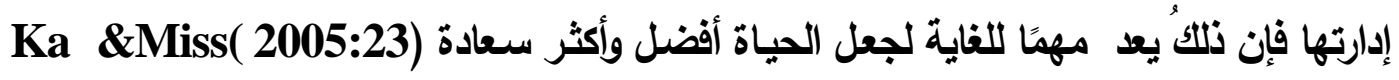
، Wai,

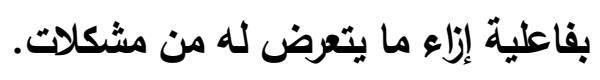
وعلى النقيض من ذلك فإن انخفاض الأكاء الانفعالي لاى الفرد يزيلد من إمكانية تعرض الفرد للمخاطر النفسية والتعرض للأمراض الجسمية، وإنخفاض القدرات العقلية، 
ويعيق التطلم من الناحية الاجتماعية، ويتصف أيضًا ذوو الذكاء الانفعالي المنففض بأنهر

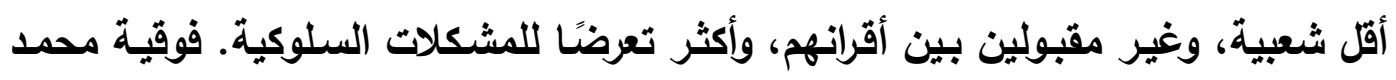

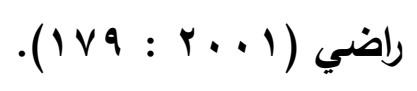

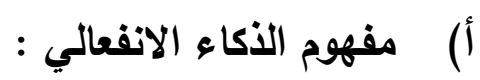

اختلف العماء فيما بينهم عند تناولهم لمفهوم الذكاء الانفعالي إلى ثلاثة أقسام :

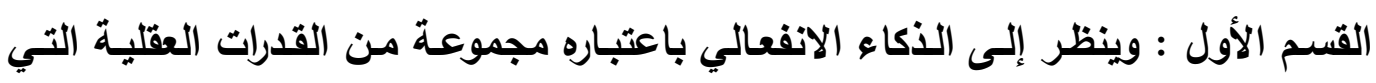

يمتلكها الفرد ومن رواد هذا الفكر " Mayer\& Salvoey " ومن التعريفات العديثة لهذا الاتجاه : تعريف Mayer\& Salvoey,(1993:433 للأكاء الانفعالي بأنها:" نوع

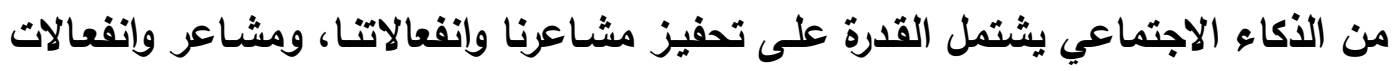

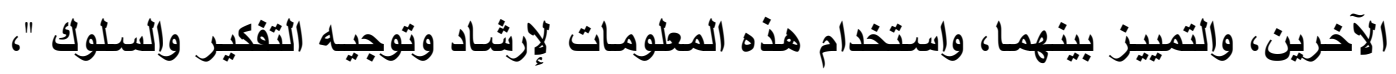

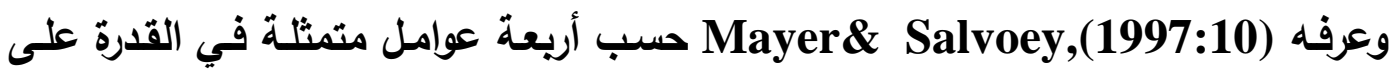
فهم الانفعالات بدقة وتقييمها والتعبير عنها وتوليد مشاعر جديدة وكنلك القدرة على فهم

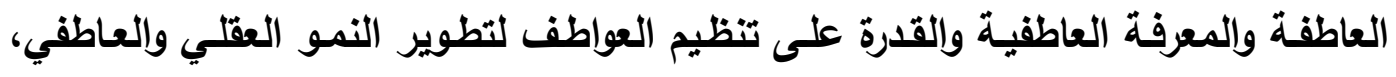

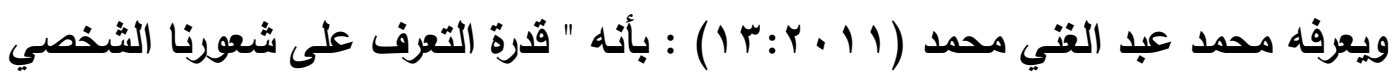

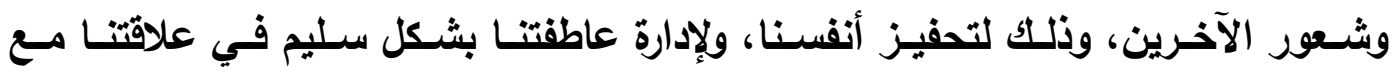
الآخرين"، أو "هو مجموعة من العناصر التي تلدعم القدرة على قيام الفرد بالتحكم في فئي

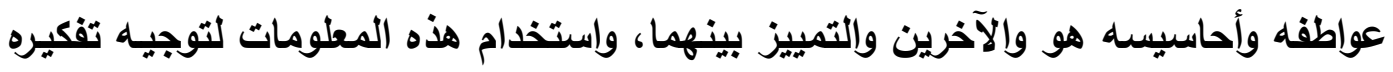
وأعماله أو تصرفاته".

القسم الثاني : ينظر إلى الذكاء الانفعالي باعتباره مجموعة من المهارات التي يمكن

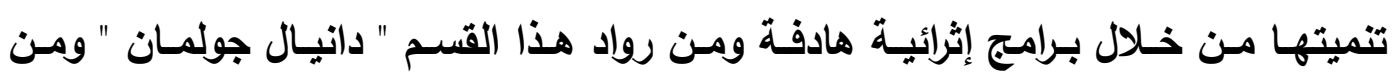
التعريفات الحديثة لهذا الاتجاه : يعرف (1995:43), Goleman الذكاء الانفعالي بأنها. "وعي الفرد بانفعالاته، وتنظيم هذه الانفعالات وتحفيز الذات، وإدراك انفعالات الآخرين،

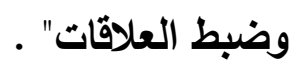

ويعرفه (Greenberg \&Bar-on, (2000: 119) "بأنه كمفهوم يشتمل على

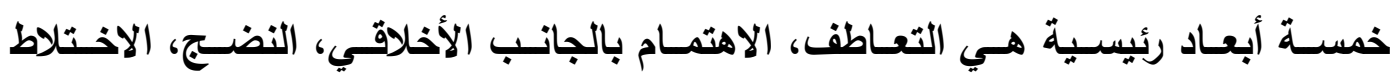

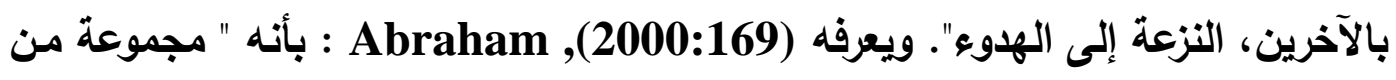
المهارات تساعد الفرد على أن يكون دقيقًا في تقدير مشاعر الذات واكتثـاف الملامسح 
الانفعاليـة للآخرين، واستخذامها في تحقيق الدافعيـة والإنجاز في حياة الفرد"، ويعرفهـ الانفعالات Mehrabian,(2003:9)

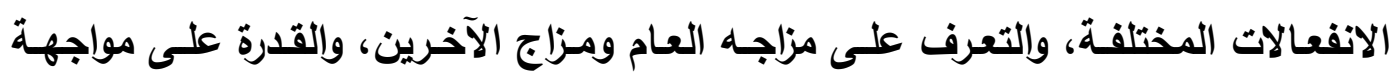

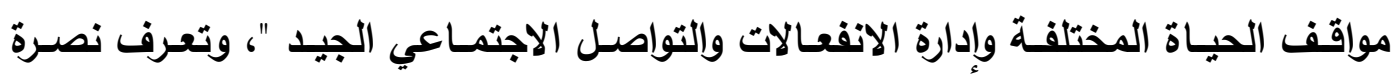

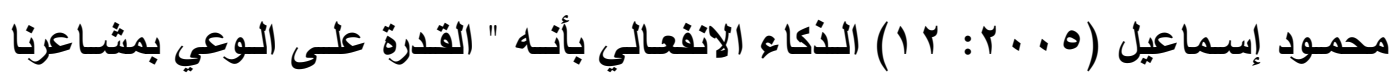

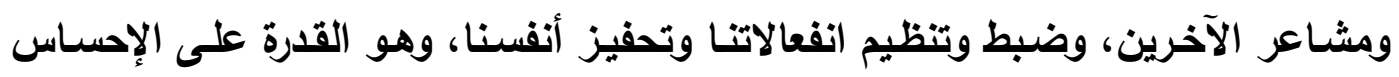

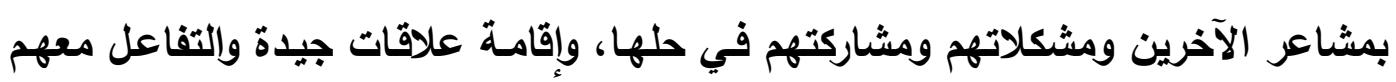
بذفء" بمناع

القسم الثالث: اهتم العلماء في هذا القسم بالتوسط بين وجهتي النظر السابقتين وذلك

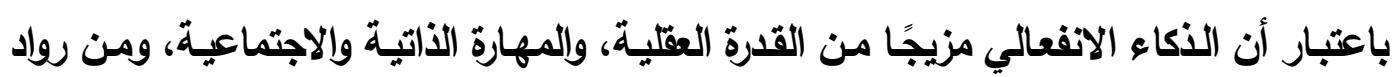

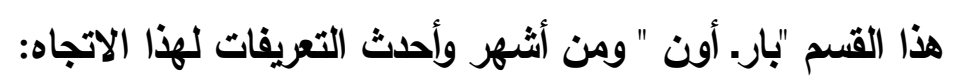
يعرف (2000:364), Bar - on الذكاء الانفعالي بأنه "القدرة على توليد

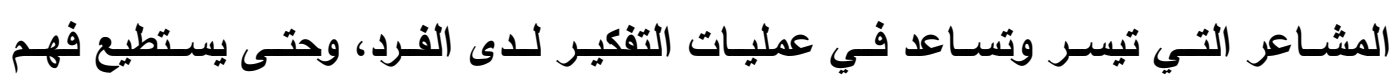

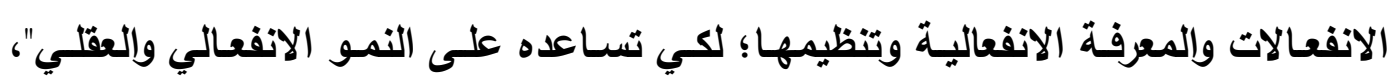
ويعرفه (Petrides \& Furnham,2004:278) بأنه " مجموعة من الأنماط السلوكية

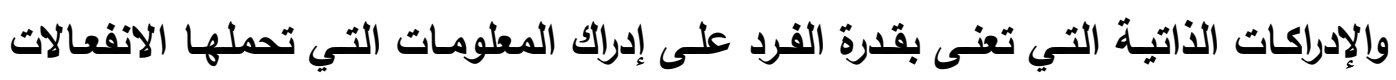

$$
\text { واستثمارها في الحياة ". }
$$

ويميل الباحث إلى وجهة نظر علماء القسم الثاني والذين عرفوا الذكاء الانفعالي

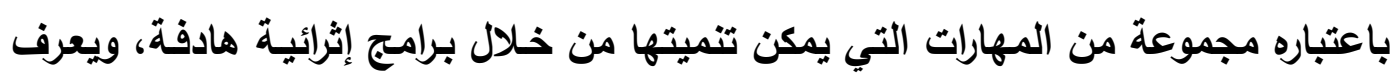

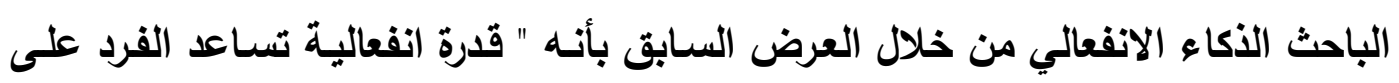

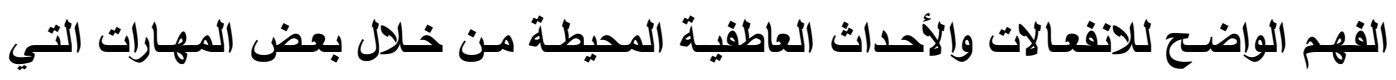
يكتسبها الفرد في حياته، فتتكون لايه القدرة على التعرف على مشاعره وإنفعالاته والتمييز

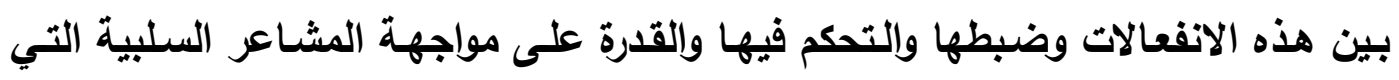

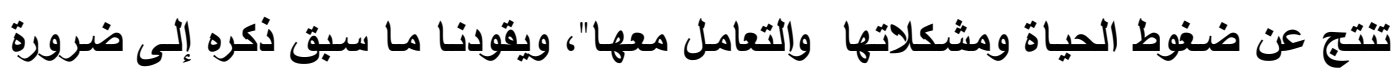
التعرف على أهمية الذكاء الانفعالي. ب) أهمية دراسة الأكاء الانفعالي : الأفعاي. 
يشتمل الذكاء الانفعالي على مجموعة من السمات المزاجية والاجتماعية التي سئ

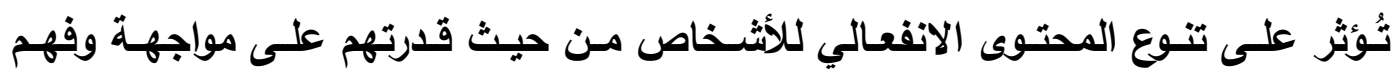

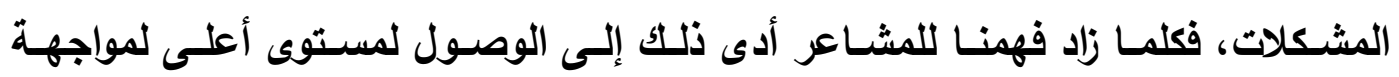

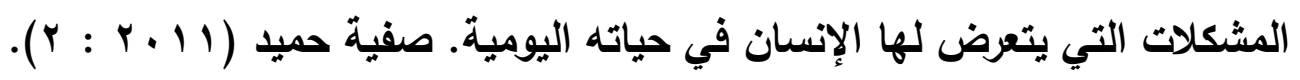

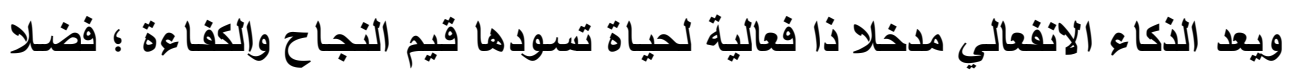

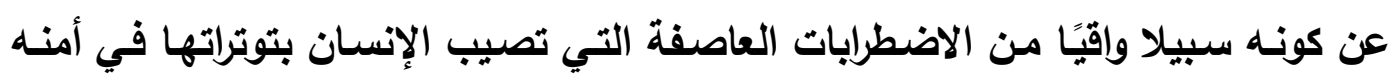

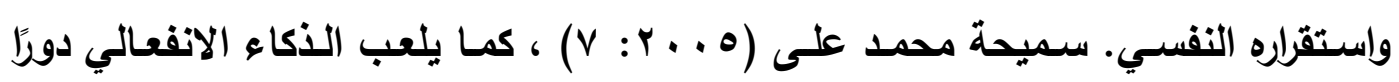

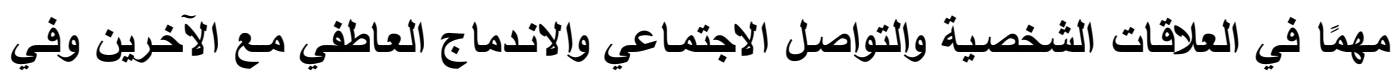

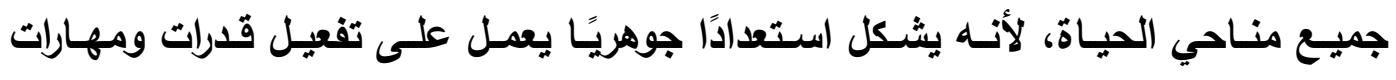

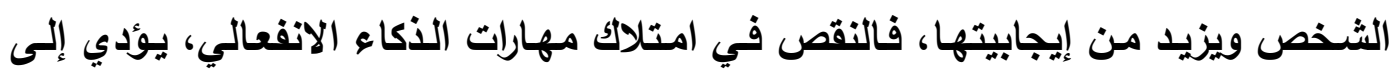
تفاقم المشكلات لاى الفرد من حيث عدم القدرة على التعاطف أو تفهم انفعالات الآخرين،

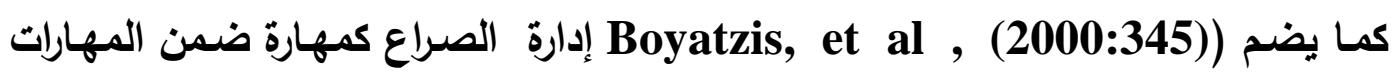

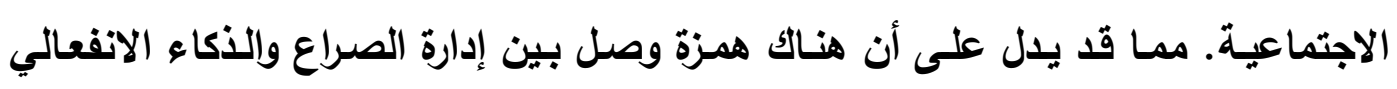
باعتباره يضم الكثير من المهارات الاجتماعية.

ويرى (Maurice,2004:40) أن العوامل الانفعالية والانفعالية تلعب دورًا مهمًا

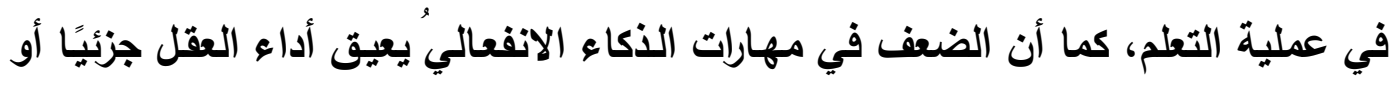

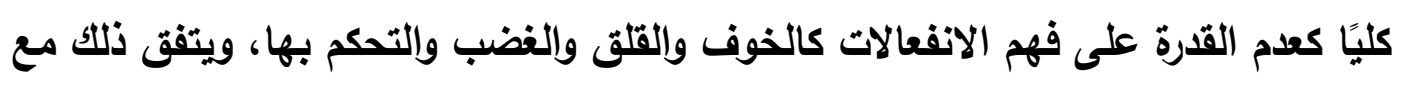

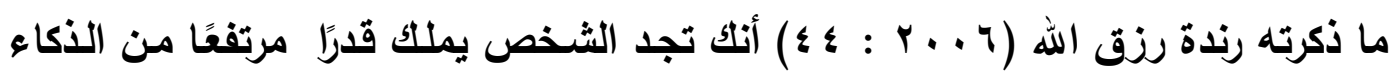

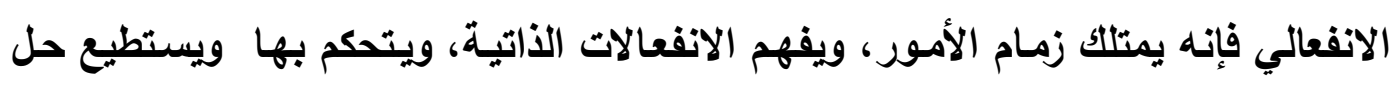

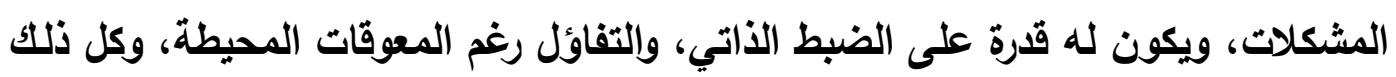
يساعد العقل على العمل بأقصى طاقاته الإبداعية. ج) أبعاد الذكاء الانفعالي : يتكون الذكاء الانفعالي من مجموعة من الخصائص التي تميز الأفراد الأكثر

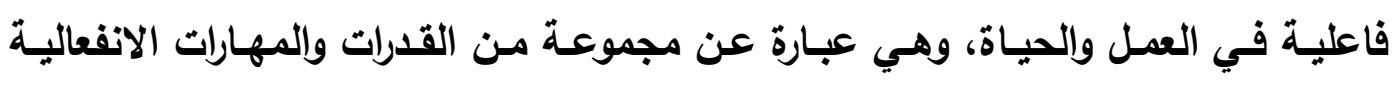

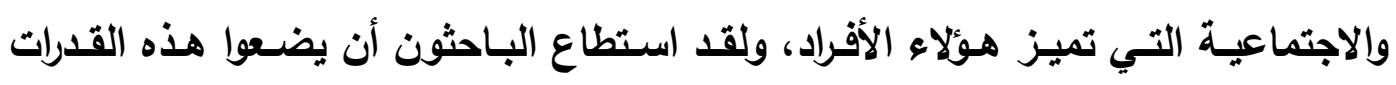
والمهارات ضمن أبعاد مثل (إدراك الانفعالات وضـبطها، التعاطف، والأمسل، والتفــاؤل، 
والتواصل الاجتماعي)، وفيما يلي يعرض الباحث أهم مكونـات الذكاء الانفعالي ومهاراتهـ وأبعاده ضمن بعض النماذج : 1) أبعاد الأكاء الانفعالي لماير وسالوفي :

يتضمن نموذج القدرات Mayer \& Selovey(,1997:3 الأبعاد الآتية : (أ ) الوعي الانفعالي والمعرفة الانفعالية : ويشتمل قدرة الفرد على إدارة الانفعالات بطريقة

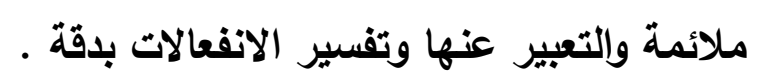

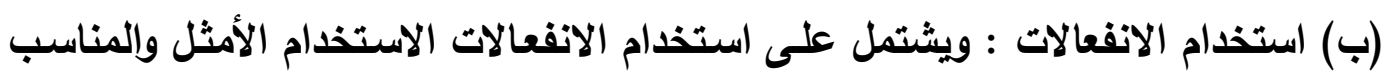

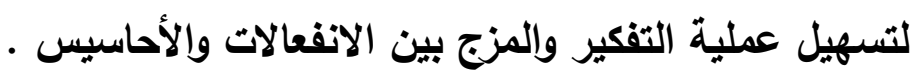

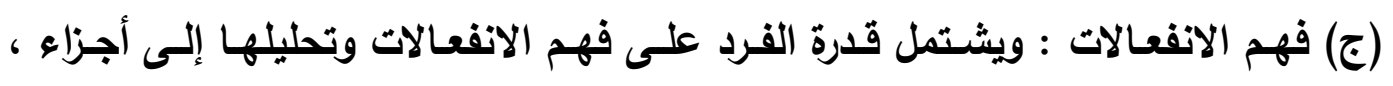

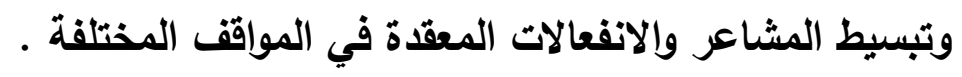

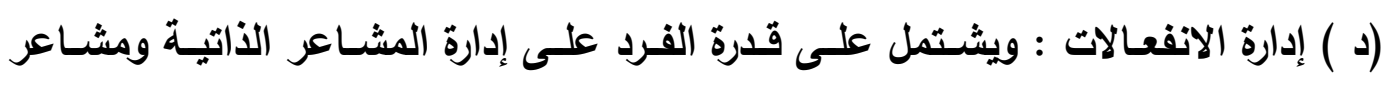

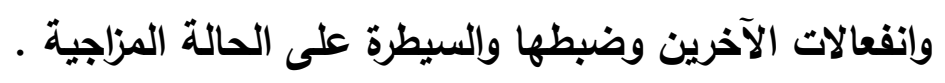

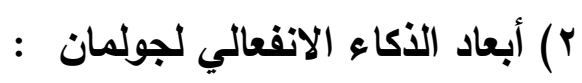

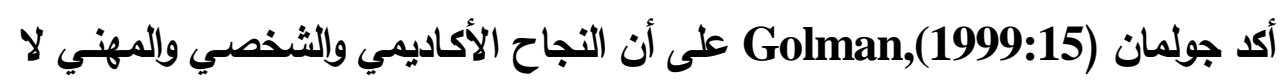

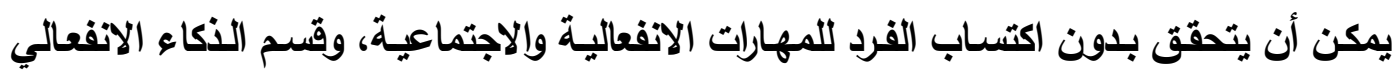

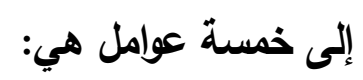

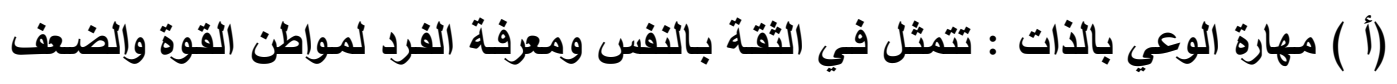

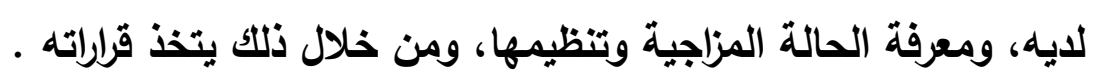

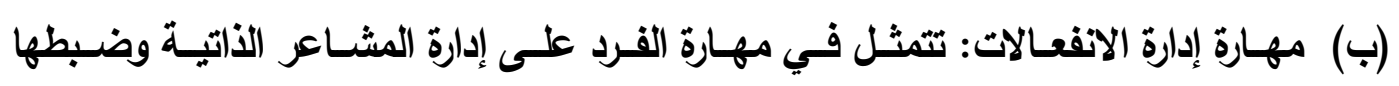

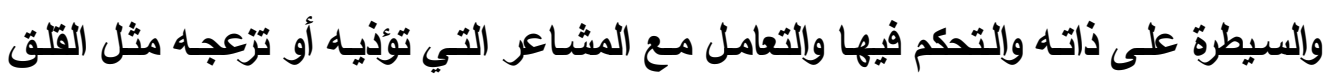
والمخاوف والغضب والحزن وهذه المعالجة هي أساس النكاء الانفعالي.

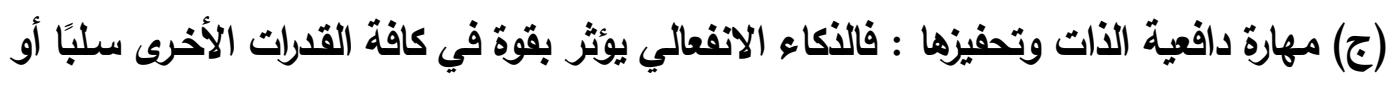

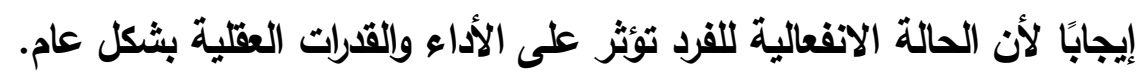

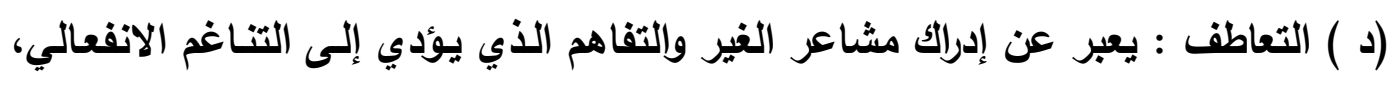

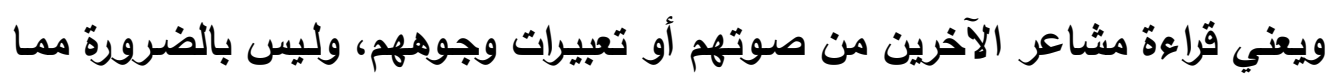

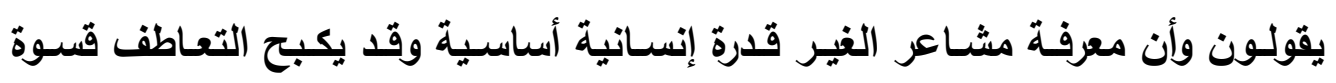
الإنسان ويحافظ على تحضره. 
(ه) مهارة الوعي الاجتماعي (المهارات الاجتماعية) : تتمثل في مهارة الفرد على التفاعل

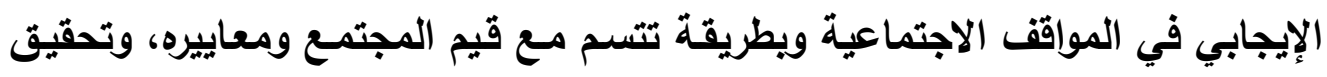

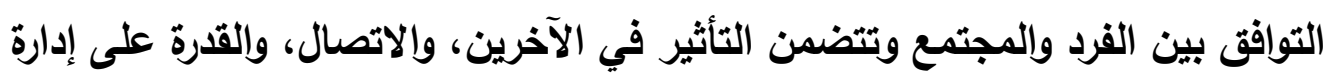
الصراعات، والقيادة، والتُعاون والعمل الجماعي. (ץ) أبعاد الذكاء الانفعالي لبار. أون:

ويتضمن النكاء الانفعالي Bar - on, R \& etal,(2000:1108 الأبعاد الآتية:

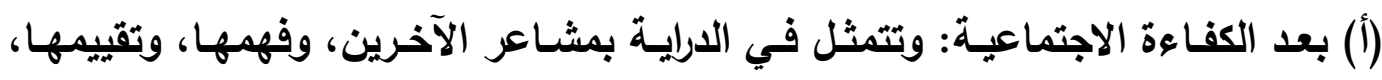

وتدعيم العلاقات الاجتماعية والحفاظ عليها، والتعاطف، والمسئولية الاجتماعية.

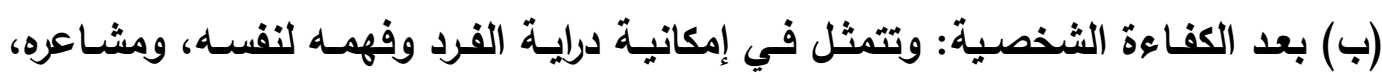

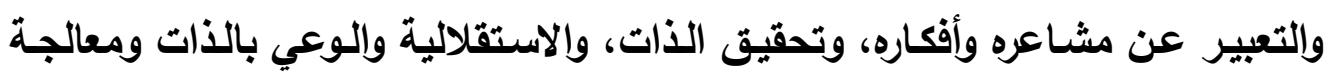
الانفعالات.

(ج) بعد التكيف : ويتمثل في مرونة الفرد وحل مشكلاته والقدرة على مواءمة مشاعر

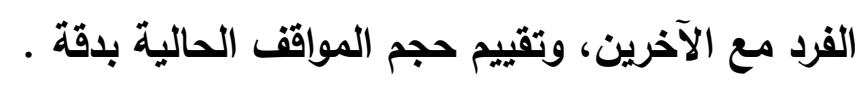

(د ) بعد إدارة الضـغوط : وتتمثل في قدرة الفرد على السيطرة على الانفعال وتحمل لكل

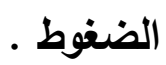

(هـ) بعد المزاج العام: ويتمثل في تفاؤل الفرد وسعادته ونظرته الإيجابية للأمور في الحياة ، والثعور بالمشاعر الموجبة والتعبير عنها. خلاصة وتسعقيب :

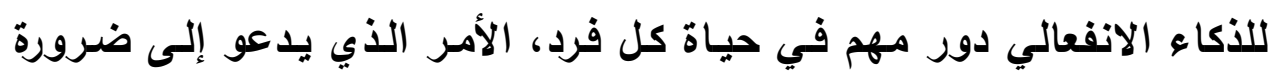

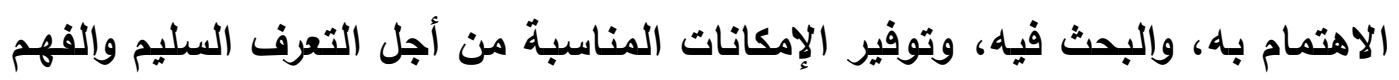

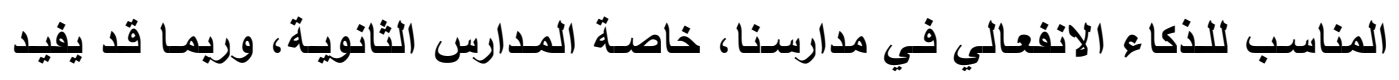

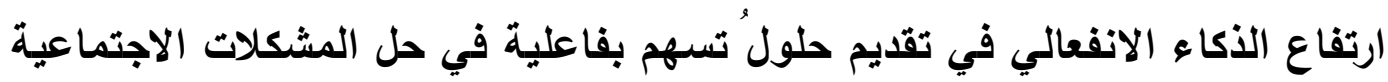

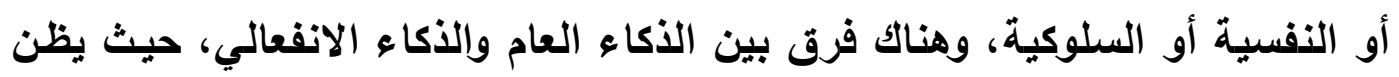

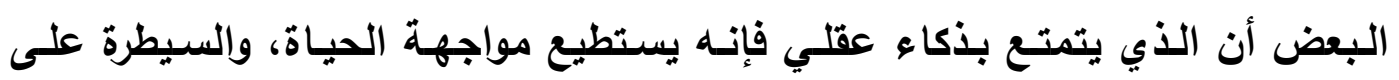

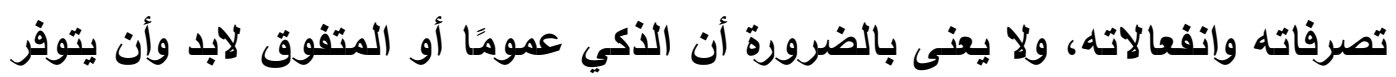

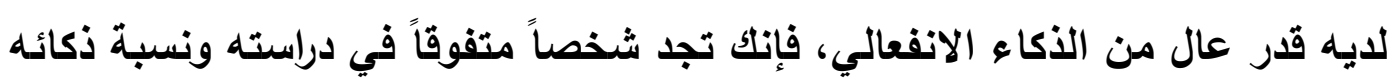

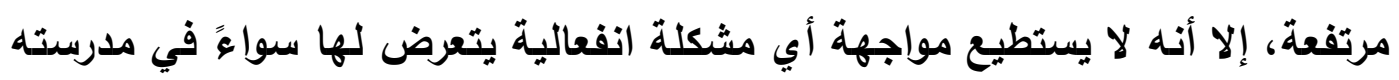


أو في حياته، ويعجز عن التصرف، وقد لا يستطيع أيضًًا مواجهة الصراعات التي

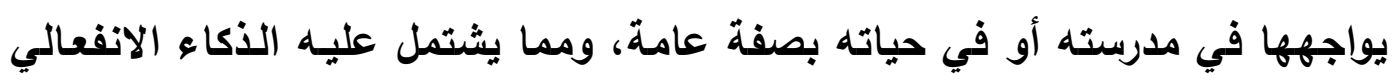

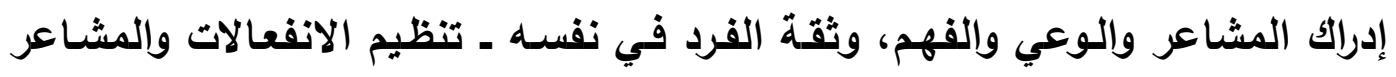

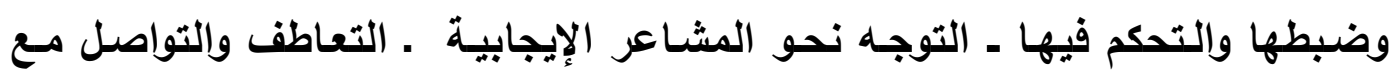

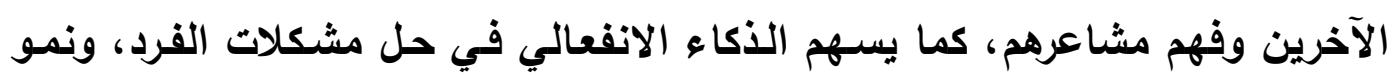

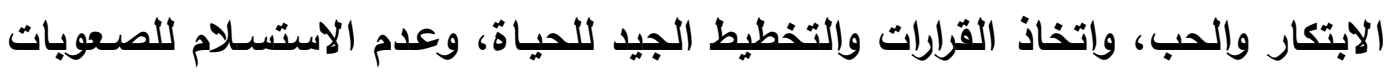

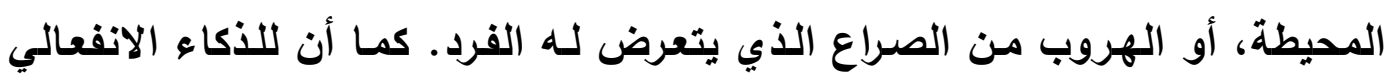

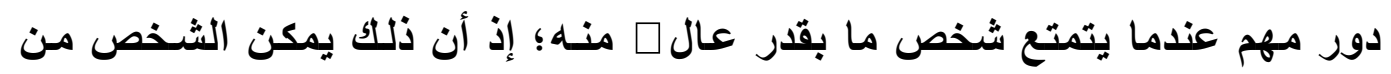

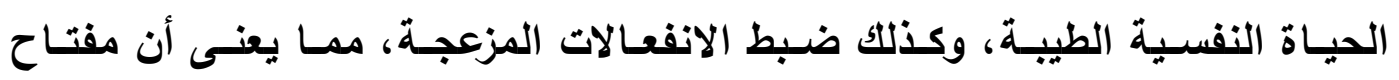

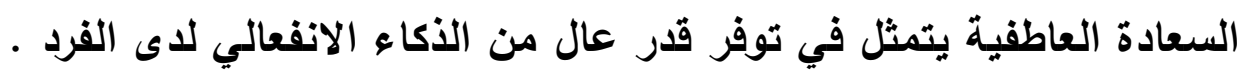

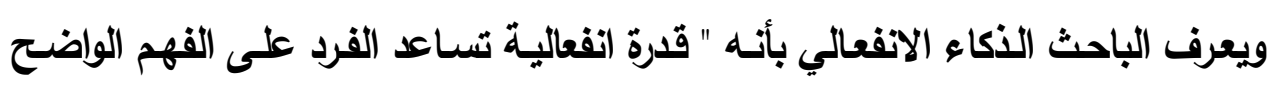

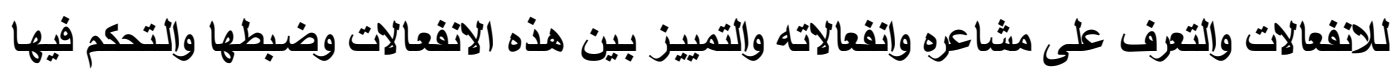

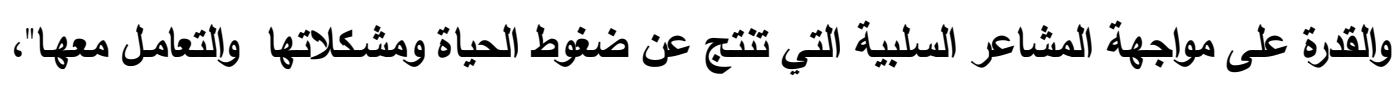
والفرد ذو الذكاء الانفعالي المرتفع يتسم بالقدرة على صنع المواقف الإنسانية وإدارتها، وحل

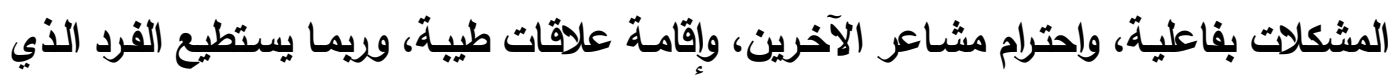

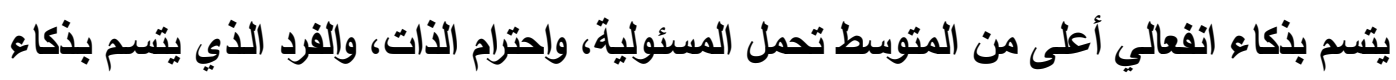

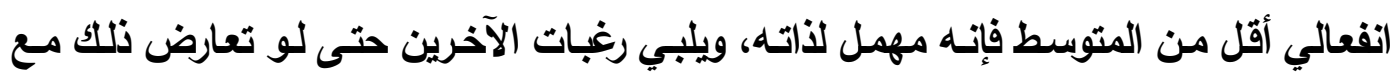

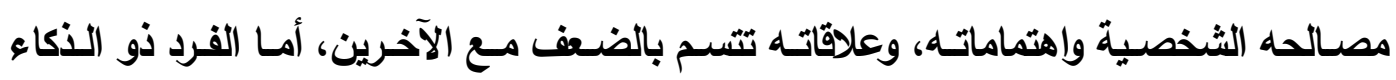

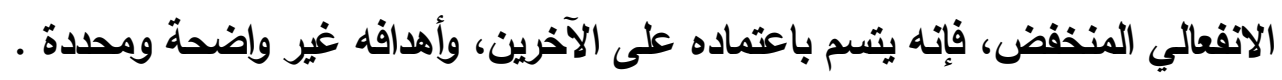

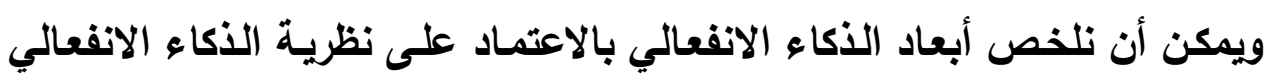

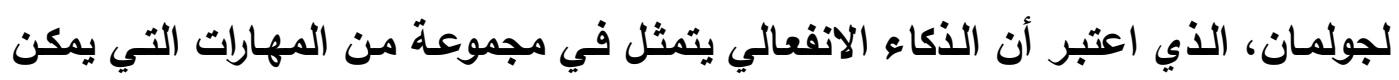

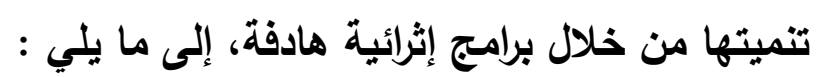

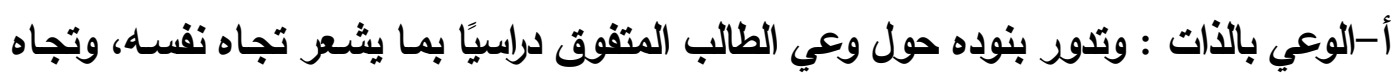

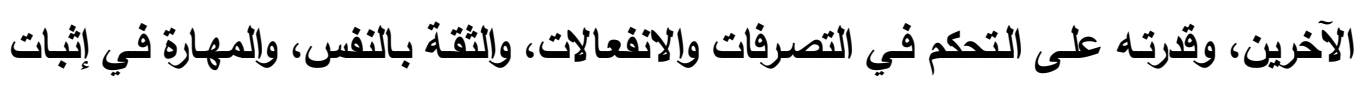

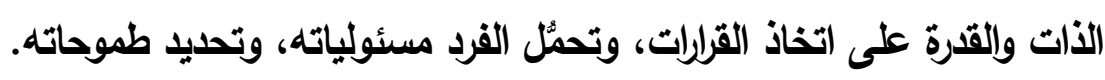

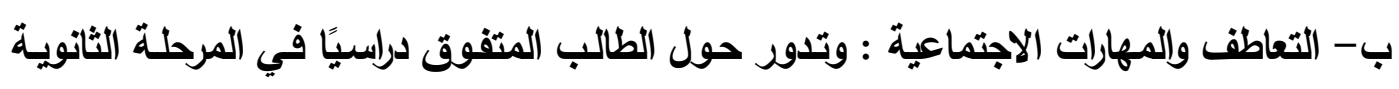

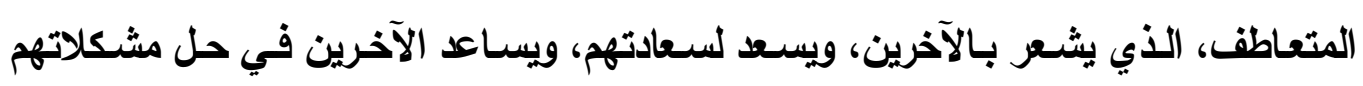


والتواصل معهم، ولايسه القدرة على إدرالك انفعالات الآخرين، والتوحد معهم انفعاليًا وفهم

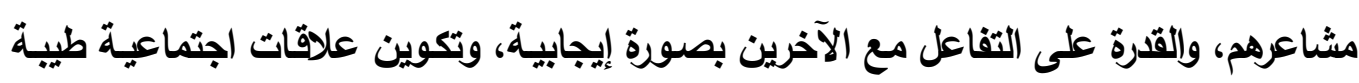
قائمة على الصدق والأمانة وإلتقاهم . ج - إدارة الانفعالات: وتدور حول قدرة الطالب المتفوق دراسيًا على إدارة انفعالاتهـ بحكمة، والتعامل معها بما يضمن التعامل الإيجابي مـع الآخرين، والتكيف الملائم

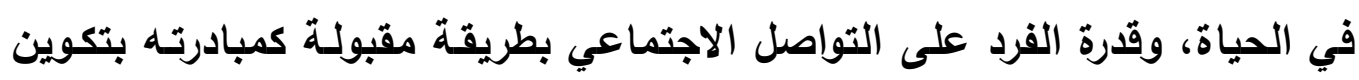

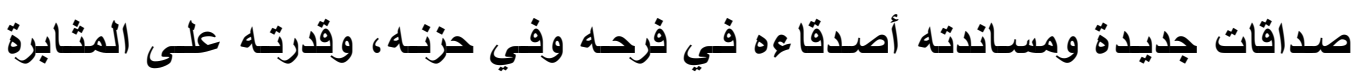

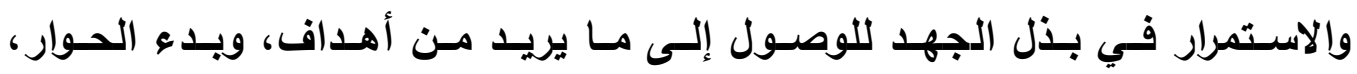
والمشاركة الانفعالية لأبناء مجتمعه.

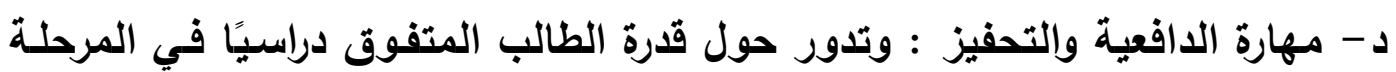

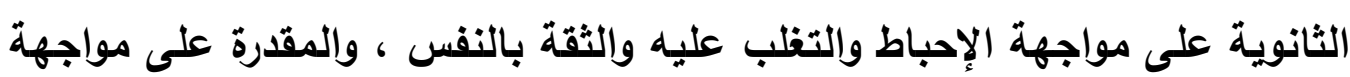

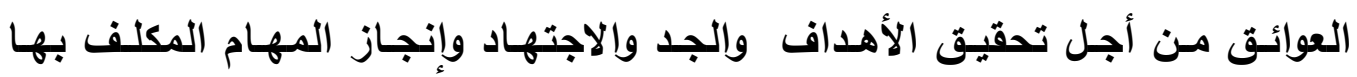

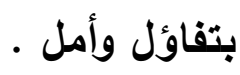

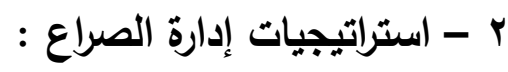

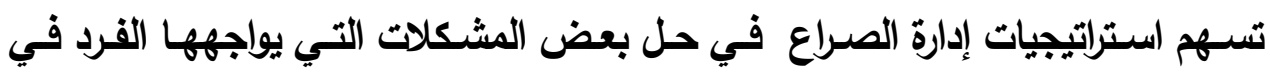

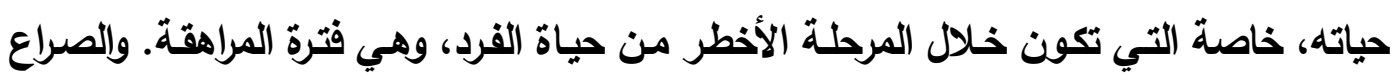

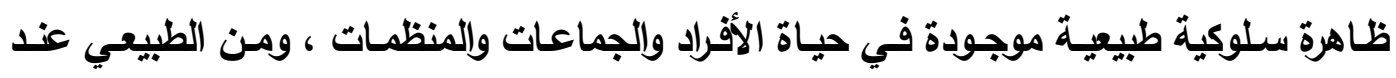

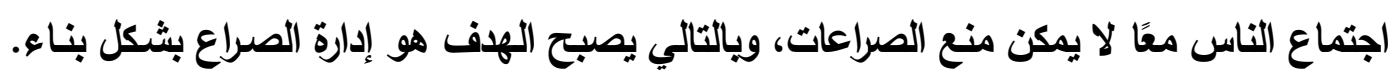

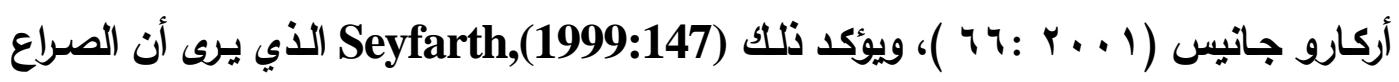

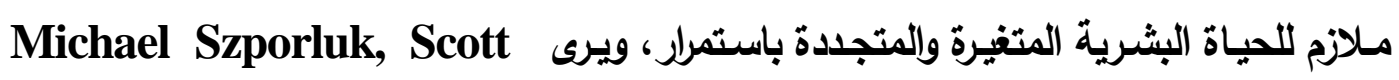
Dubin,(2006:2)

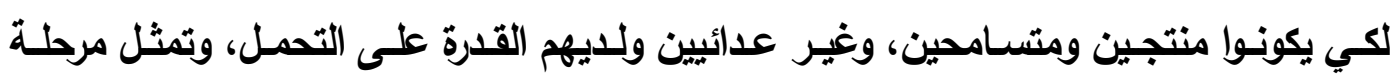

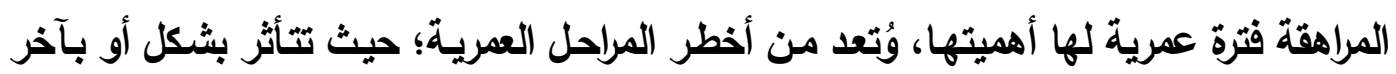

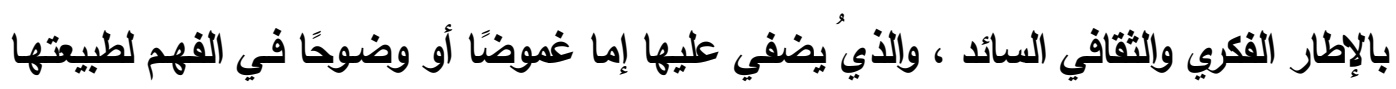
وما يمكن أن يعتري الفرد فيها من التحولات المختلفة. ويوصول الفرد إلى مرحلة المراهقة يبدأ في التفكير في ذاته والاهتمام بتحديد الصفات التهات أو الخصائص التي تتميز بها هذه الذات، والتي ترضي تقديره دون أن تغترب بـه اغترابًا جذريًا 
عن البيئة الاجتماعية التي يعيش فيها، ويمر المراهق في سبيل تحقيق ذلك بمرحلة مليئة

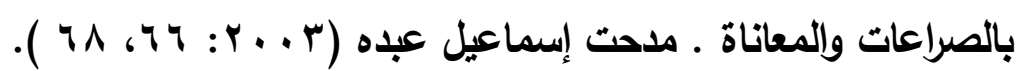
أ ) مفهوم إدارة الصراع :

تعددت تعريفات إدارة الصراع، واختلف الباحثون في تعريفه، ويعرض الباحث لبعض

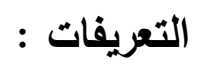

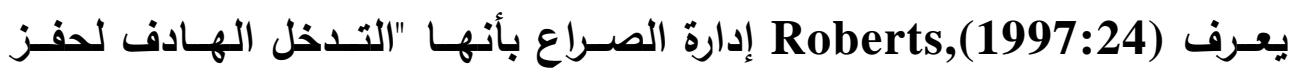

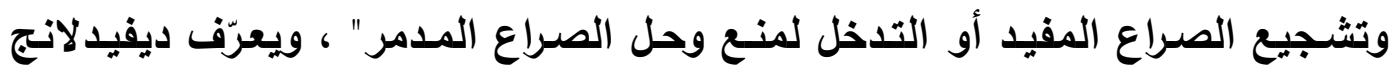

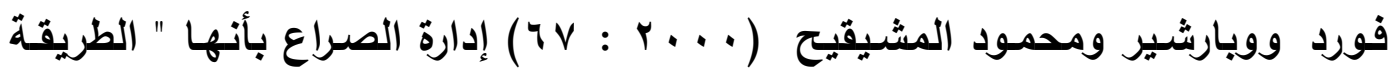

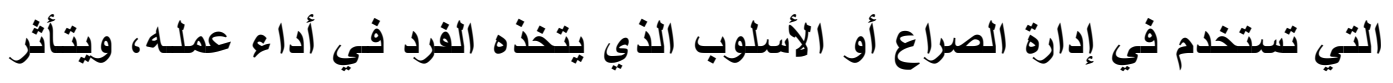

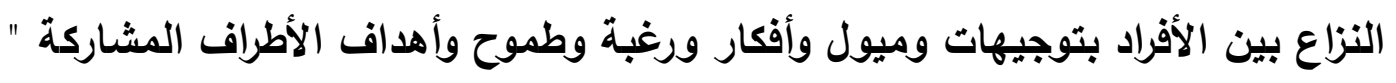

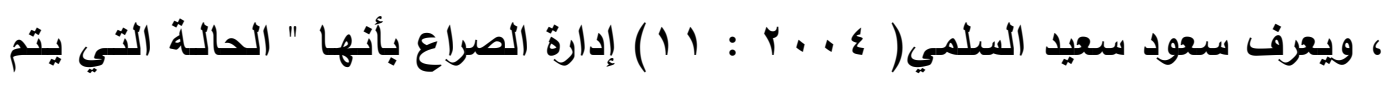

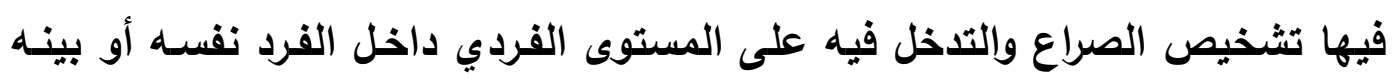

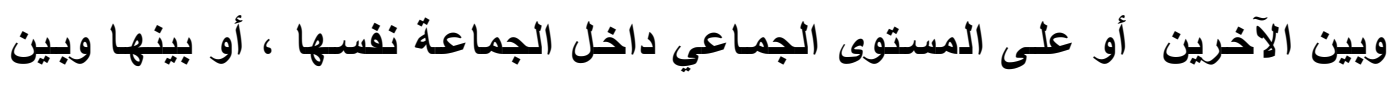

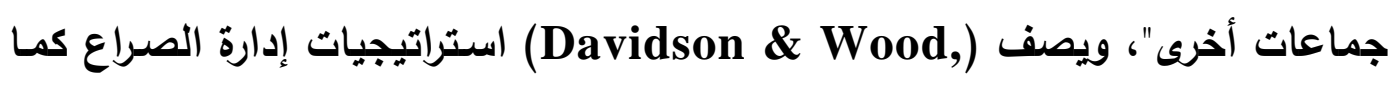

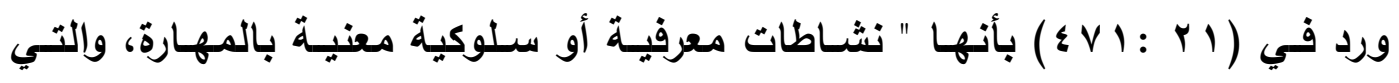

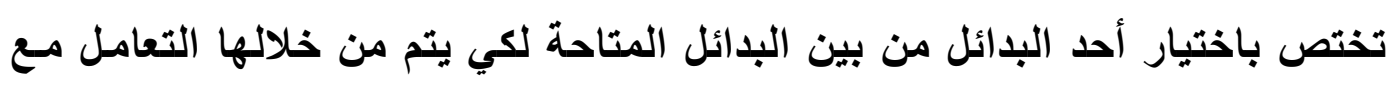

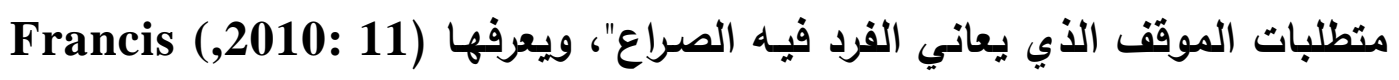

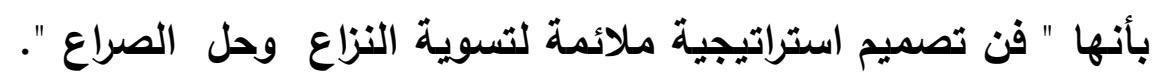

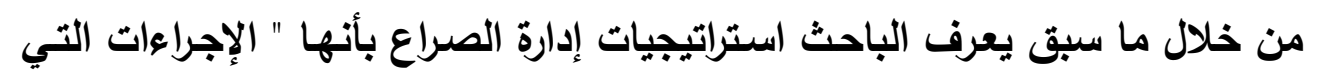

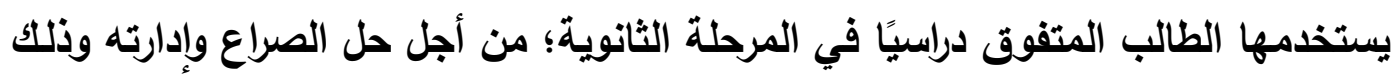

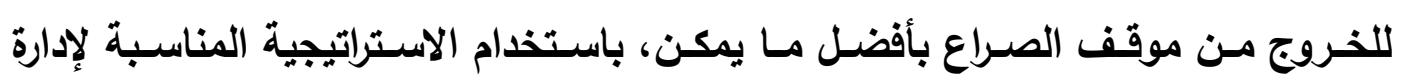

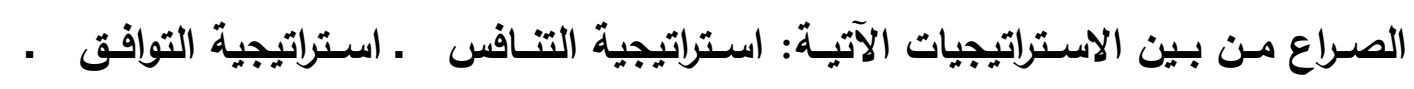

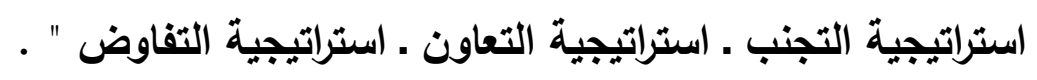
ب) أسباب الصراع : يرى Beebe\&Masterson,(1997:24) أن الصراعات يمكن أن تكون نتيجة الفروق الفردية بين الأفراد في المطلومات والاتجاهات والقيم والأهداف، والتنافس بينهم.

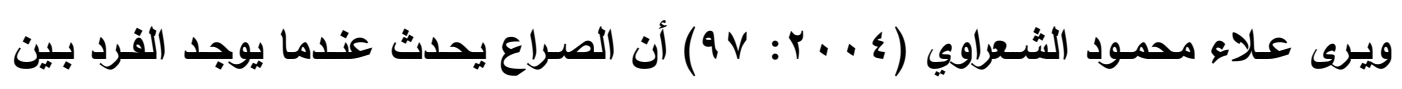


قوتين - على الأقل - تدفعانه، وعليه أن يختار أحدهما، كما يظهر الصراع عندما تختلف

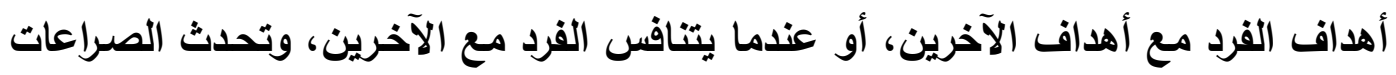

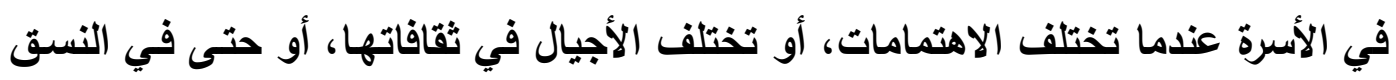

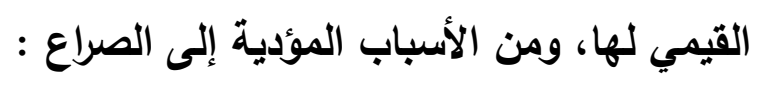

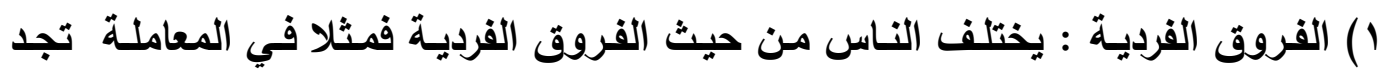

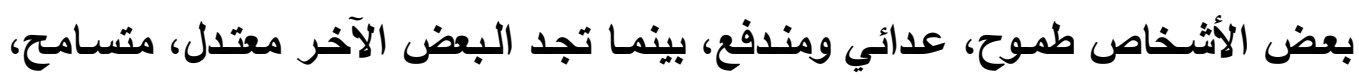

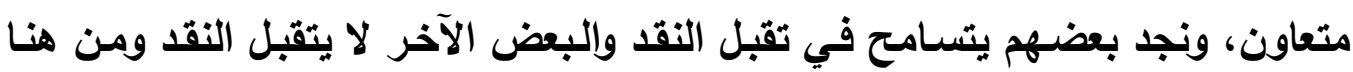

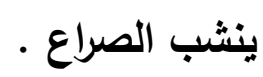

r) اختلاف القيم : اختلاف الأفراد من حيث القيم والتصورات تؤدي لحدوث الصراع .

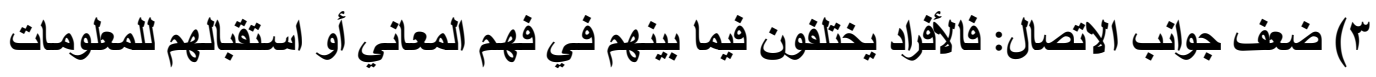

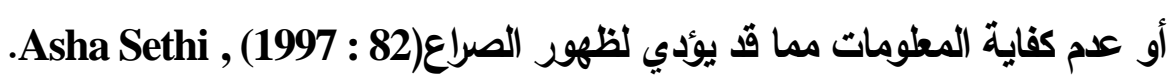
ج) الآثار الإيجابية لإدارة الصراع :

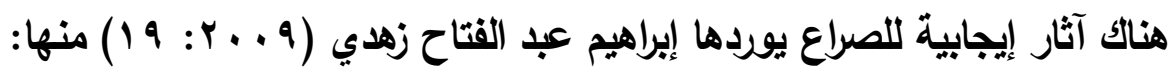

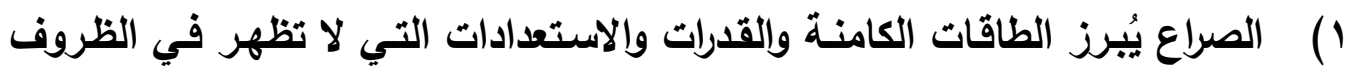
العادية.

r الصراع يساعد الفرد على البحث عن حل للمشكلة التي يتعرض لها.

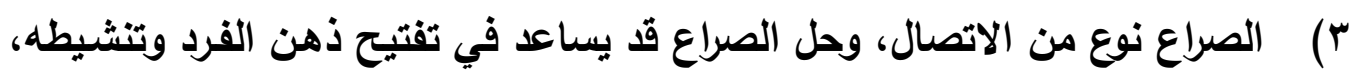
والتفكير الجيد للوصول إلى الحل. ؛) الصراع يساعد على إثباع حاجات الأفراد خاصةً الثخص العدواني.

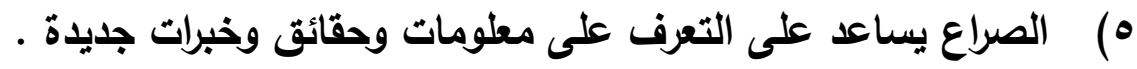

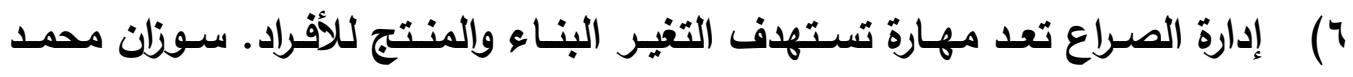

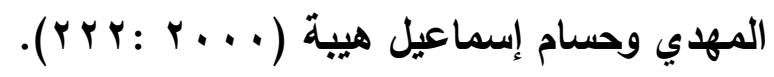

د) الآثار السلبية لإدارة الصراع :

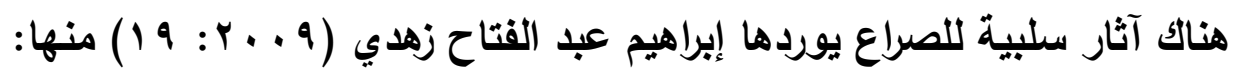

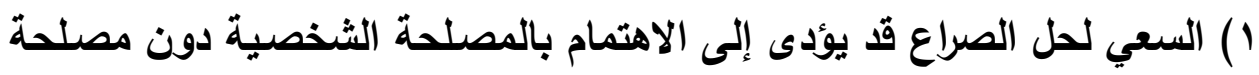
الجماعة. 
r) الصراع قد يهام المعنويات وُيهلدر الوقت والجهد ويؤدى إلى نقص الفاعلية والكفاءة.

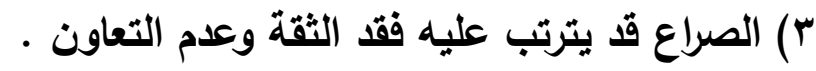

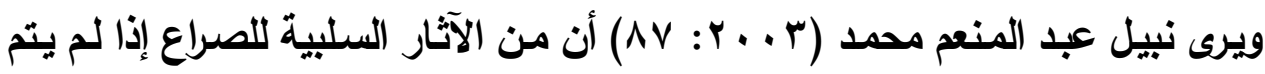

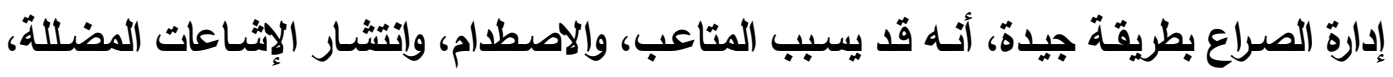

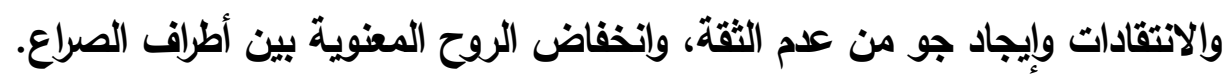

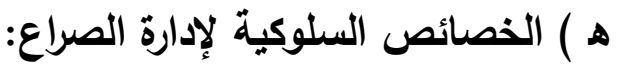
تتعد الخصائص السلوكية التي قد يستخدمها الفرد لإدارة صراعاته مع الذاتي، وهي:

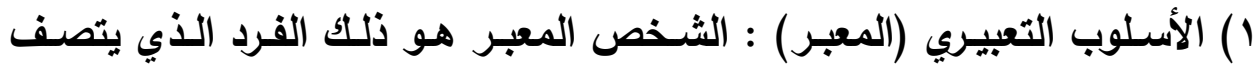

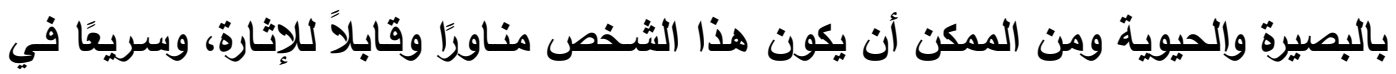

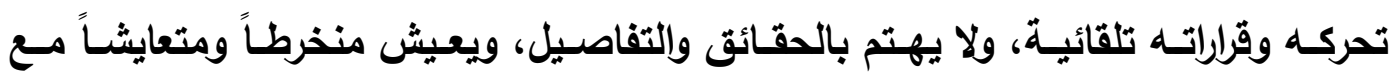

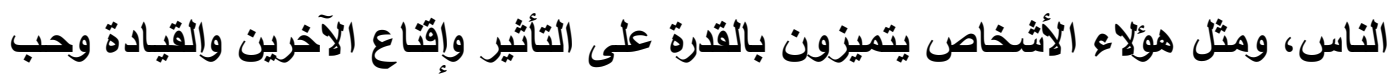

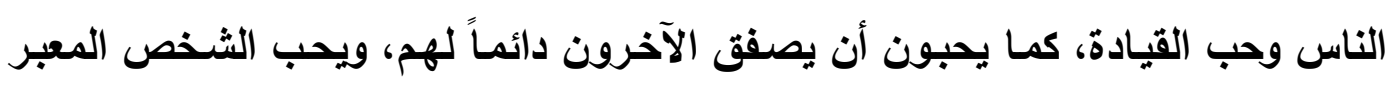

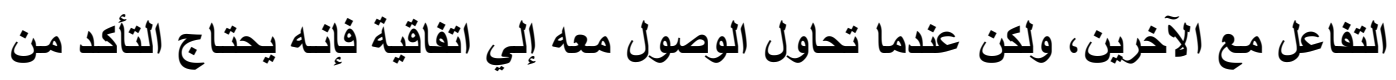

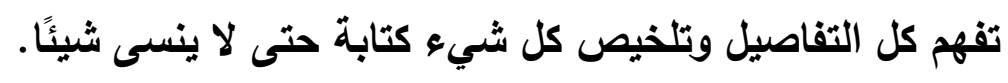

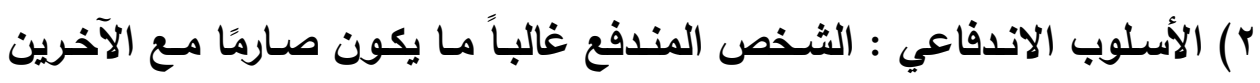

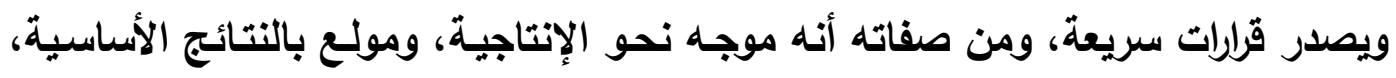

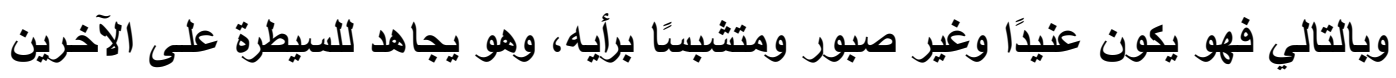

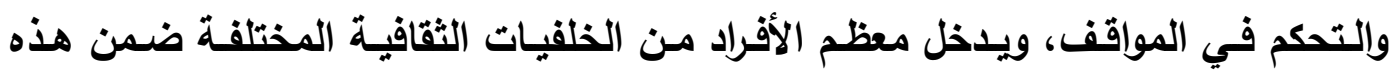

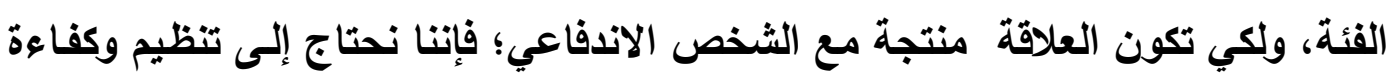

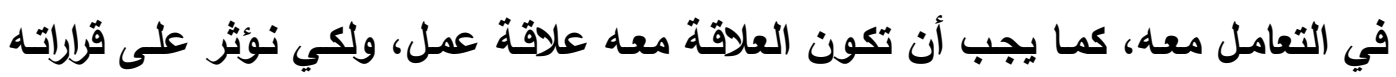
علينا أن نقام له خيارات ونتركه يصل إلى نتائج .

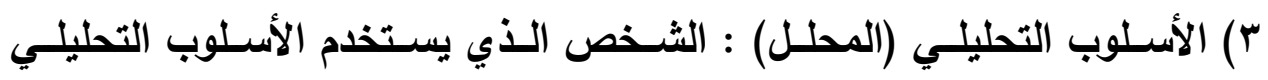

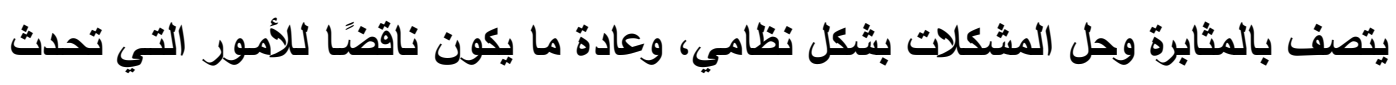

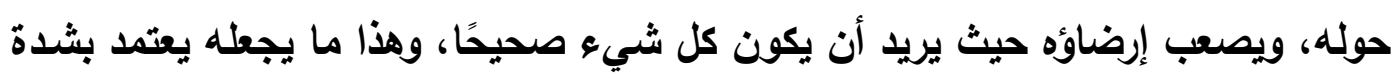

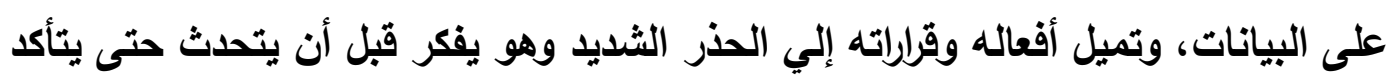


أن كل مـا يقولـه صحيح، ولكي تتوافق مـع هذا الثخص المحلل يجب عليك أن تكون

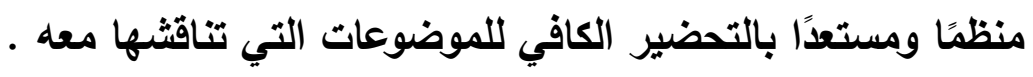

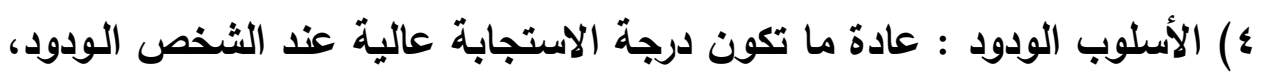

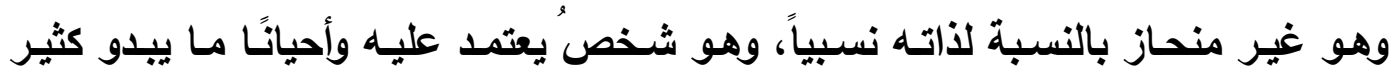

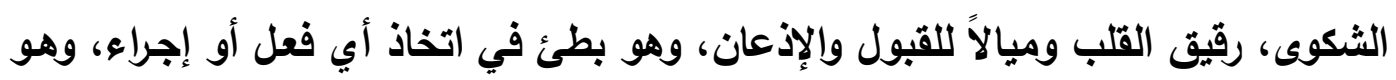

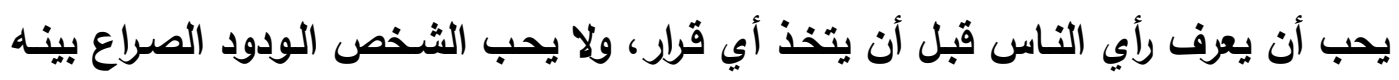

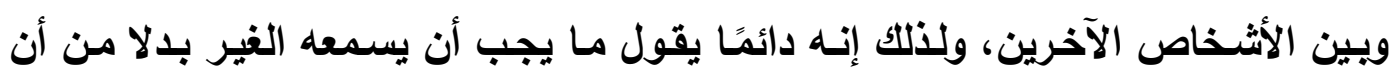

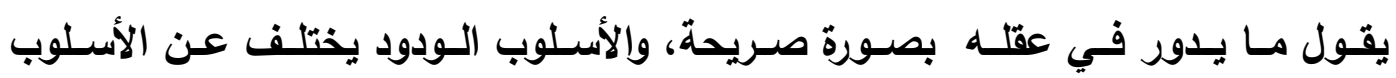

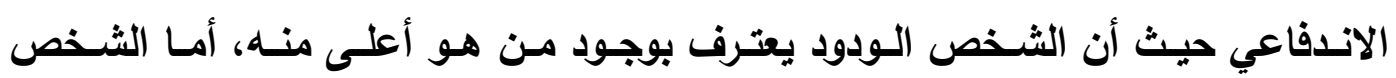

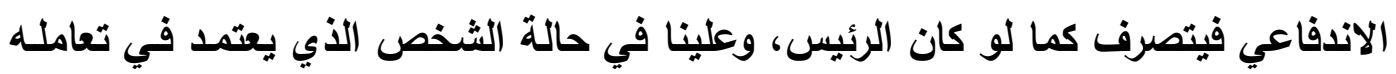

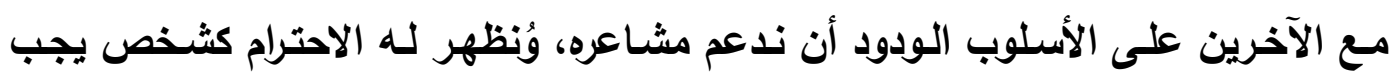

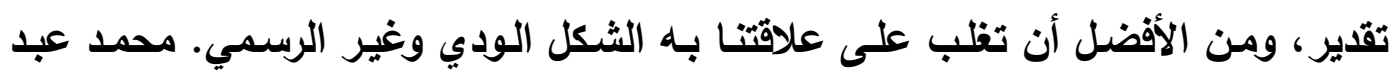

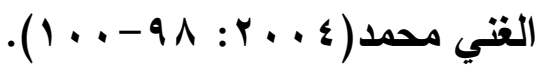

$$
\begin{aligned}
& \text { و) استراتيجيات إدارة الصراع : }
\end{aligned}
$$

إن الهـف الأساسـي مـن استراتيجيات إدارة الصـراع هو مسـاعدة الناس لكي يكونـوا

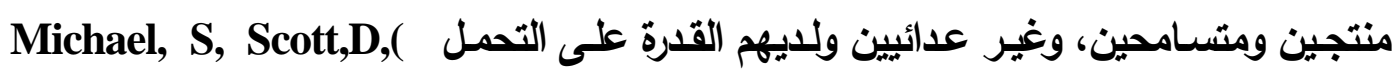

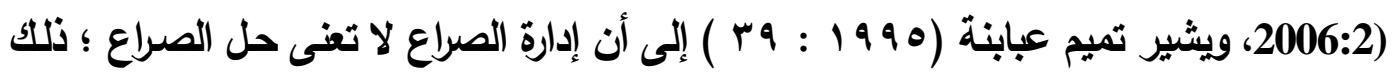

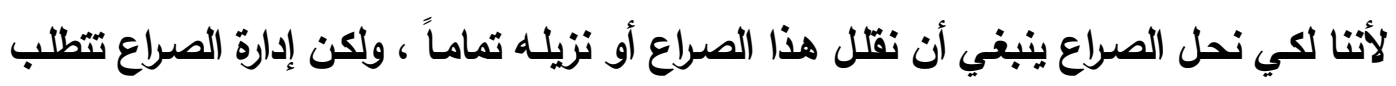

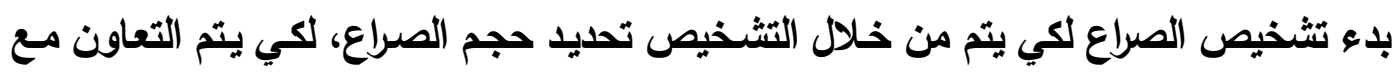

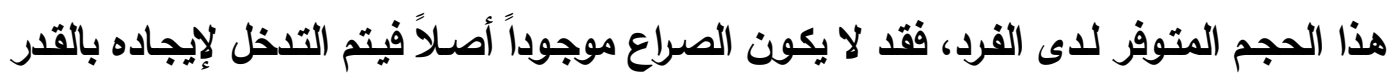

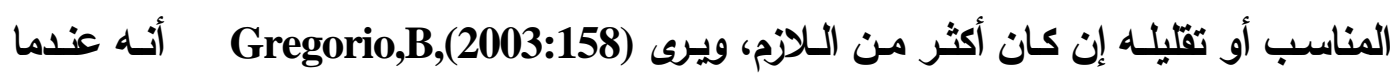
تتعدد الخيارات فلابد أن يوجد خلاف أو تعارض ومثل هذه الاند الاختلافات عندما يتم التعامل معها

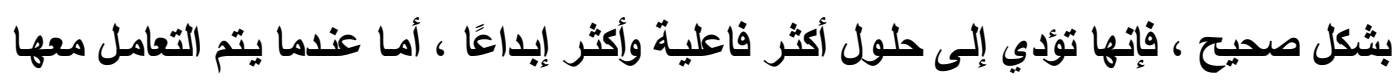

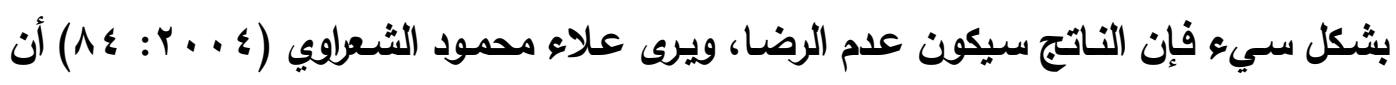

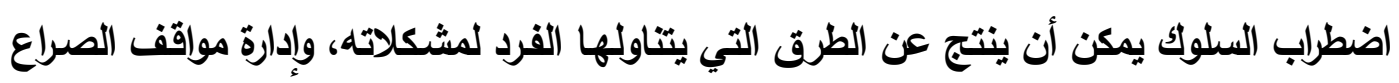

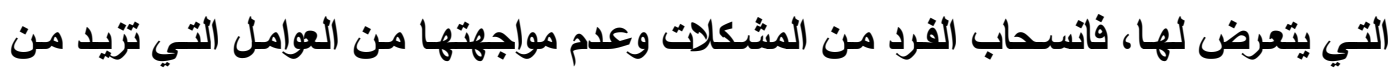

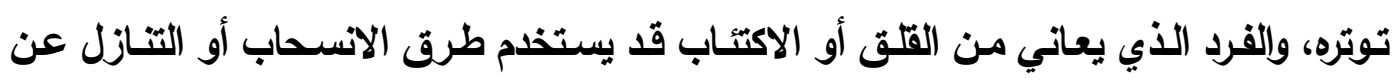


حقوقه، أمسا المتمرد أو الذي يميل للعنف فقد يستخلم كل منهما القوة للسيطرة على الآخرين

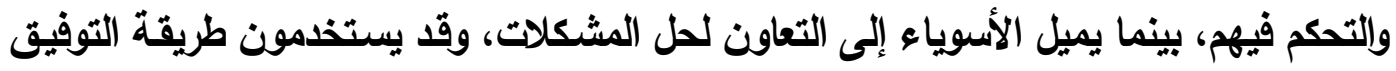
عندما تتفق أهدافهم مع أهداف الآخرين.

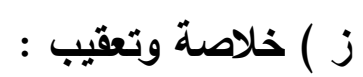

يتعرض الطالب في المرحلة الثانوية لإرهاق فكري نتيجة سعيه للبقاء والاستمرار،

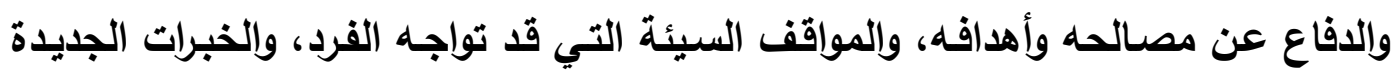

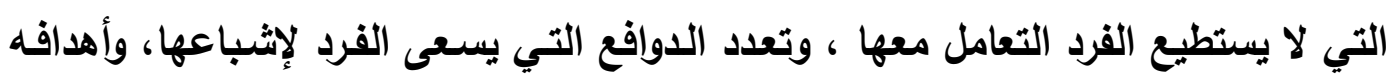

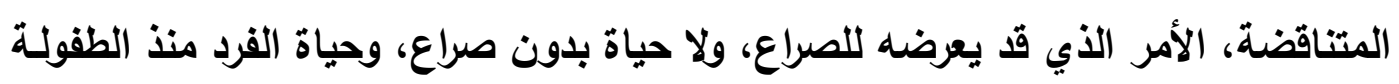

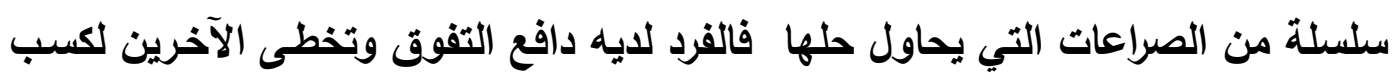
حبهم وتقديرهم، ولكي يحقق الفرد ذلك ويتكيف مع محيطه، ويحقق أهدافهـ كان لزامـاً عليه أن يحطم كل ما يعيقه لتحقيق أهدافه، إلا أن الناس يختلفون في قدراتهم على دئ تحمل

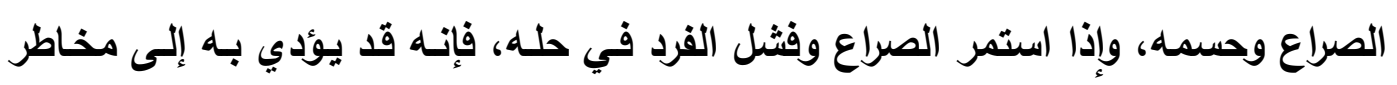

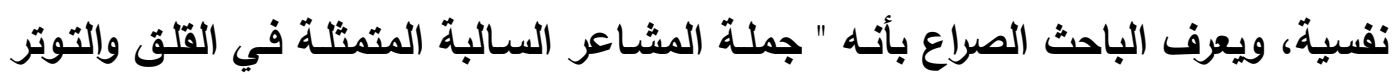

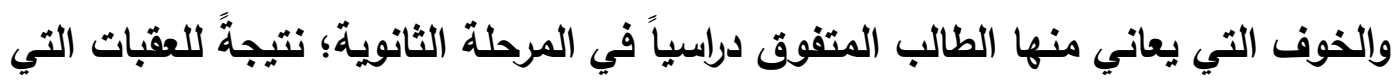

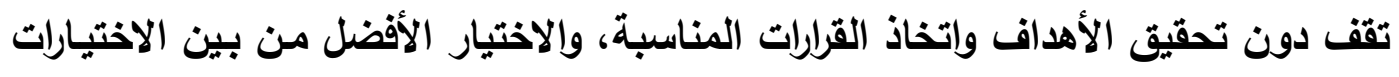

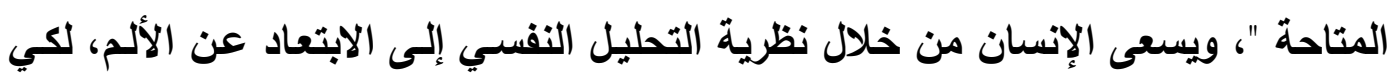

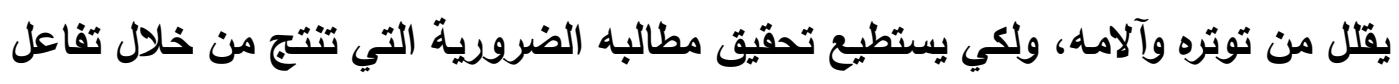

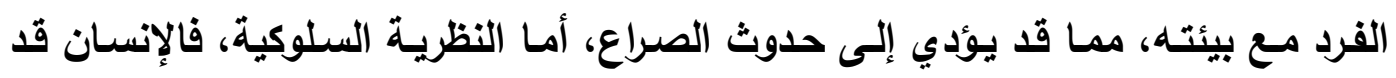

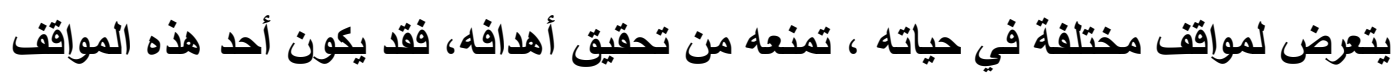
معارض لأهدافه، أو كلاهما مهم بالنسبة إليه وعليها أن يختار أحدهما فقط، أو كلاهما

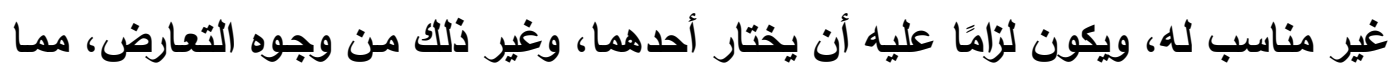

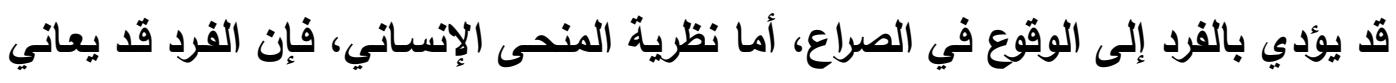

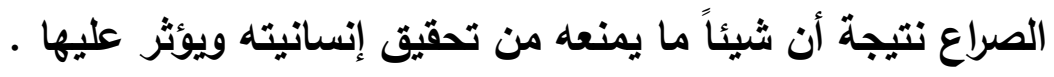

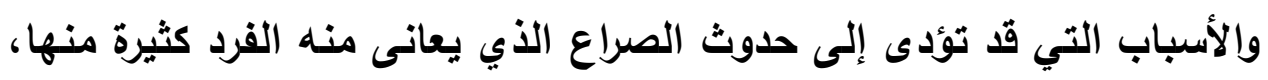

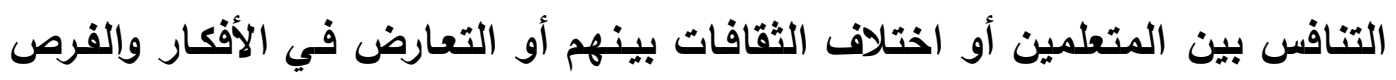

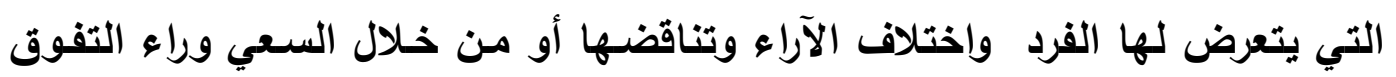


أو القوة أو الطموح للمستقبل المشرق بالمال أو السلطة أو التنافس على الحصول

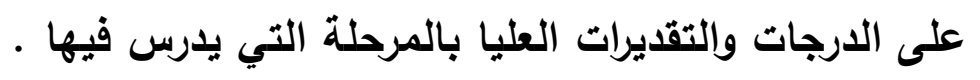

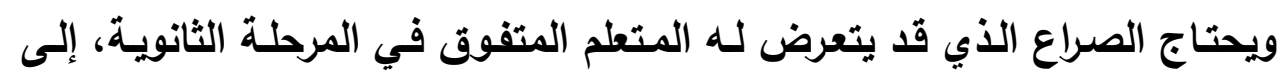

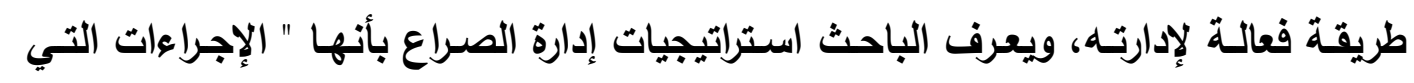

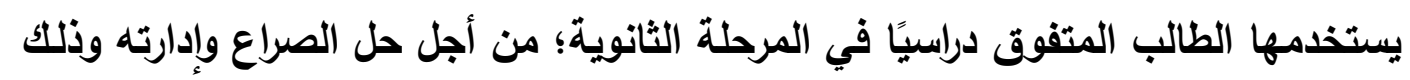

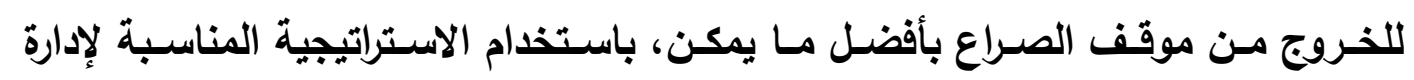
الصراع من بين الاستراتيجيات الآتية : استراتيجية التنافس ـ استراتيجية التوافق استراتيجية التجنب . استراتيجية التعاون . استراتيجية التفاوض .

وكل طالب لـه أسلوب خاص قد يتبعه عند إدارة الصراع ومن هذه الأساليب :

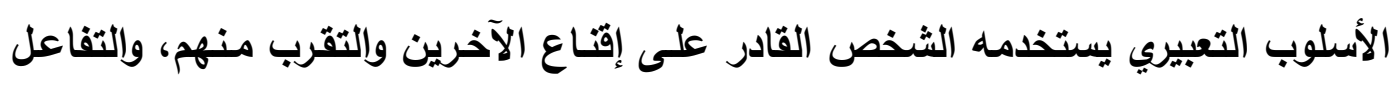

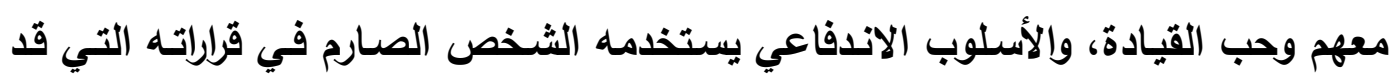

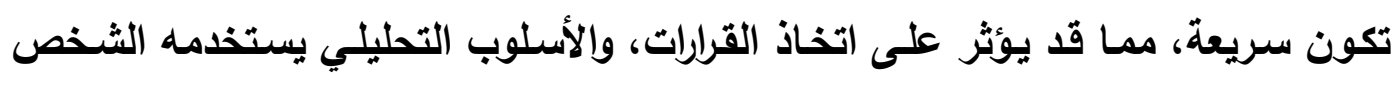

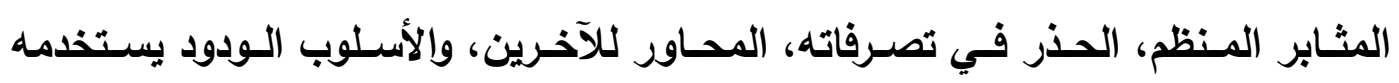

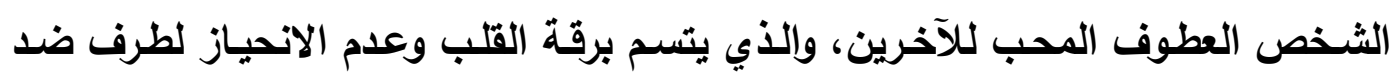

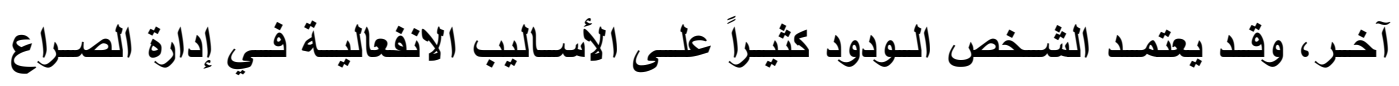

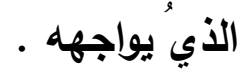

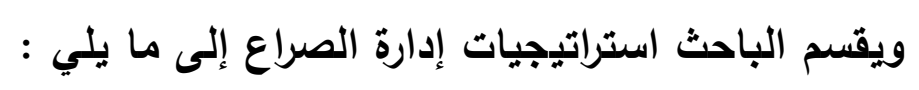

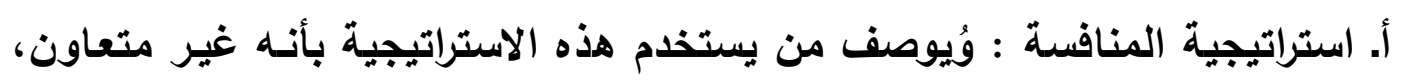

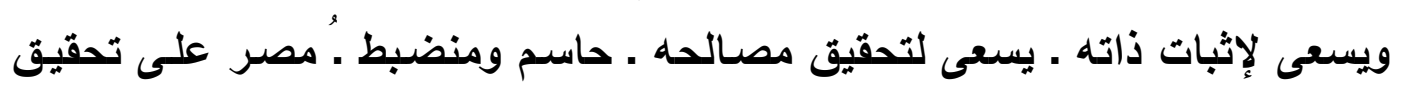

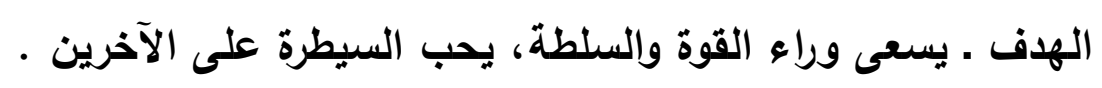

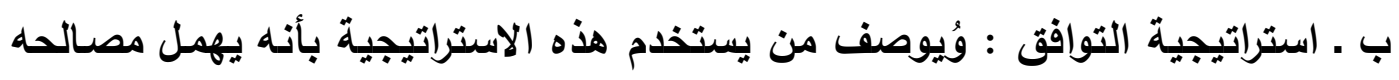

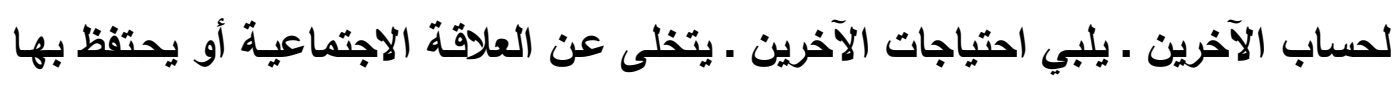

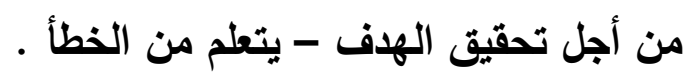

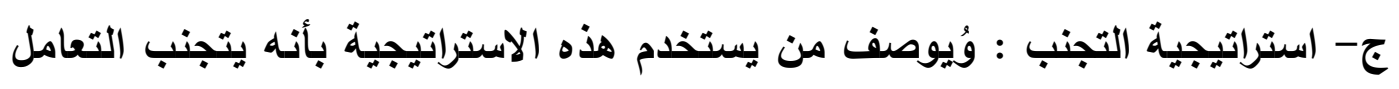

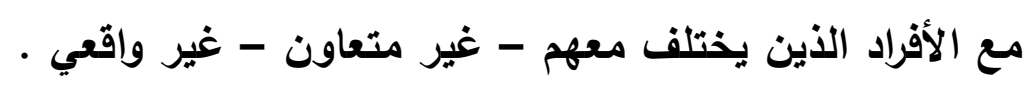


د - استراتيجية التعاون : وئيوصف من يستخدم هذه الاستراتيجية بأنه متعاون ـ متفتح الأهن ـ مستعد للنقاش وتبادل الحوار. هـ - استراتيجية التفاوض : وُيوصف من يستخدم هذه الاستراتيجية بالتفاهم ـ الحكمة .

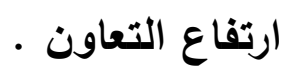

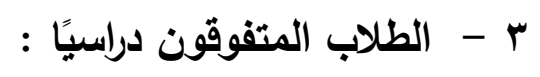
إن الاهتمام بالطالب المتفوق من أكثر الأمور المهمة والمتاوليًا : في في أروقة أكثر ونالات

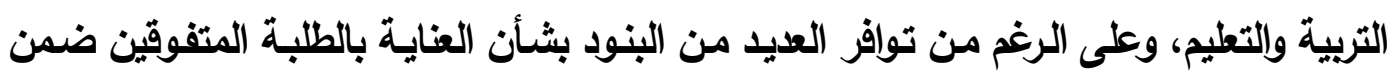

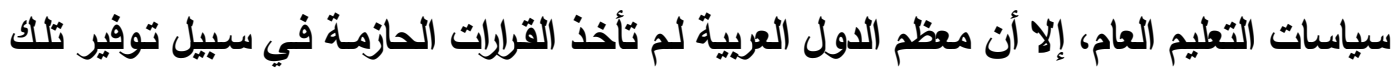

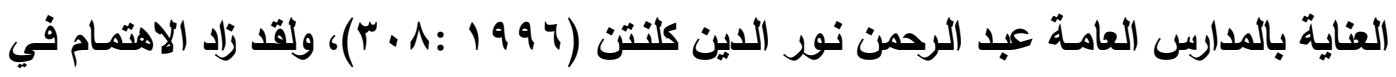

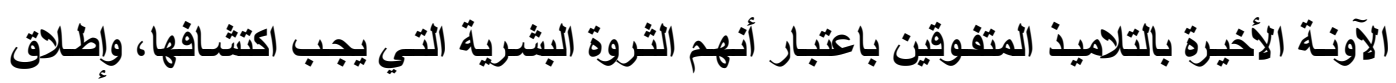

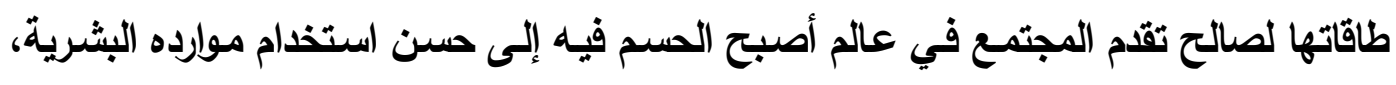

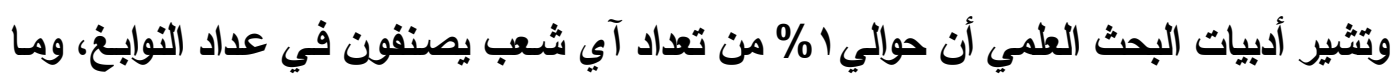

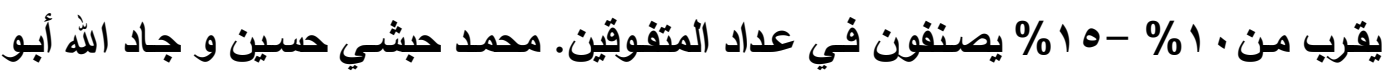

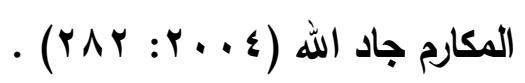

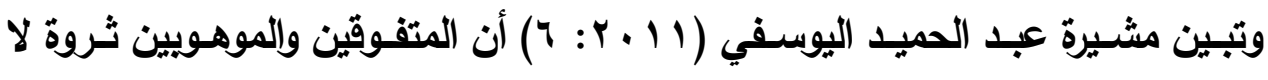

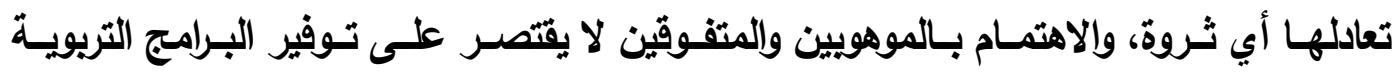

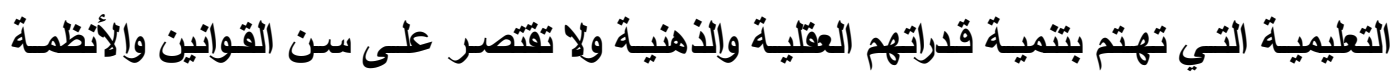
والتثريعات التي تنظم حياتهم وتسهل التعامل معهم بل ويتعدى ذلكت إلى رعايتهم نفسيًا وعقليًا

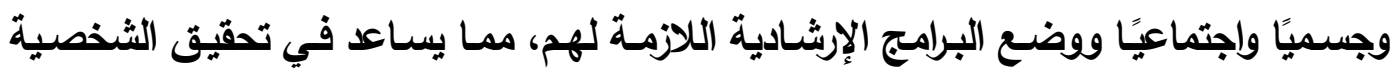

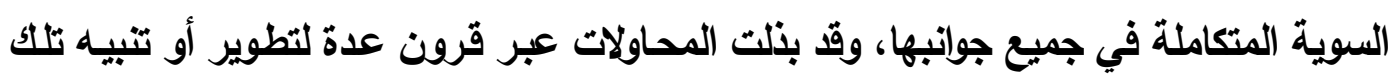

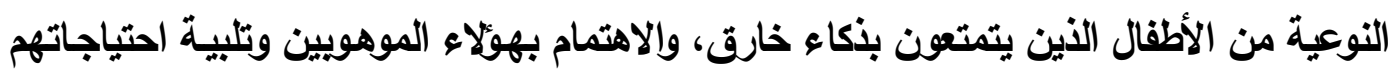

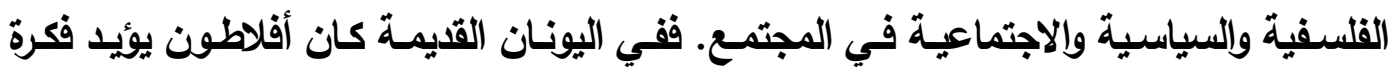

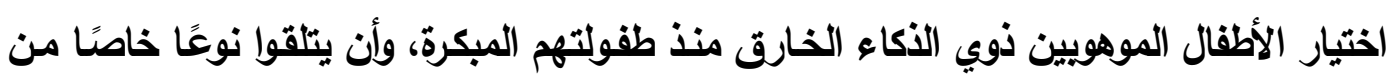

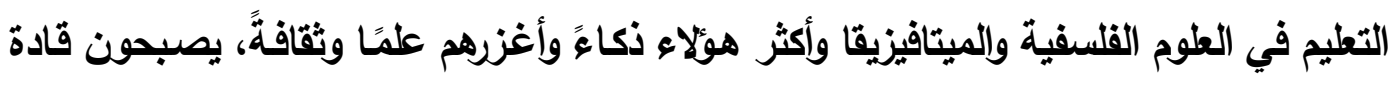

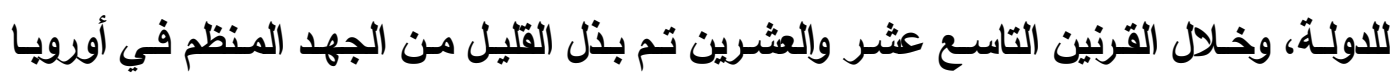

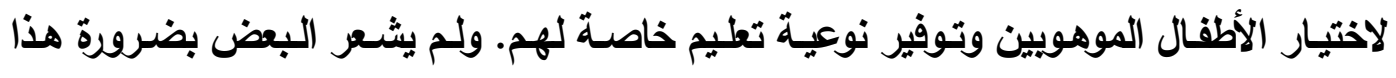


طالما أن المدارس الثانوية والجامعات كانت قاصرة على تعليم الطبقات الاجتماعية الراقيـة والتتي

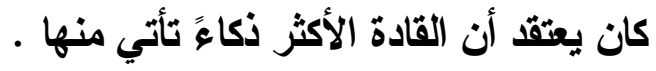

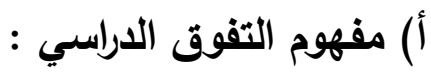

ولقد تعددت تعريفات التفوق الدراسي نذكر منها تعريف عبد الرحمن نور الدين

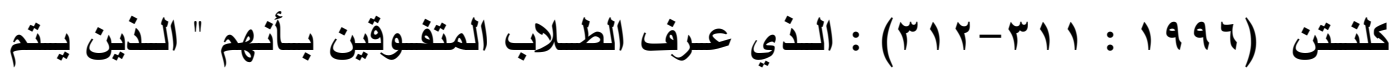
اختيارهم والتعرف عليهم من قبل الأفراد المتخصصين والمؤهلين علميًا، وهم ذوو قدرات

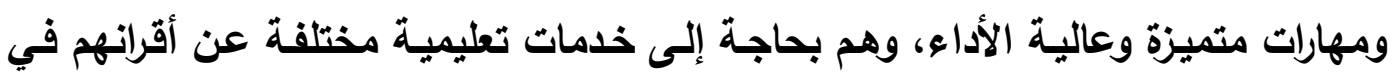

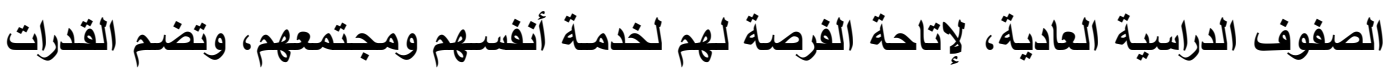

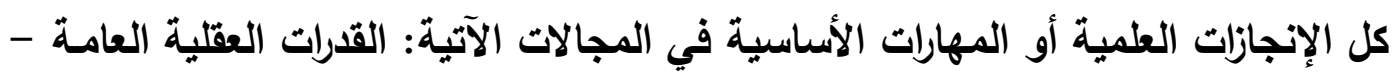

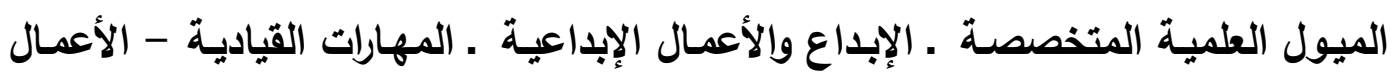

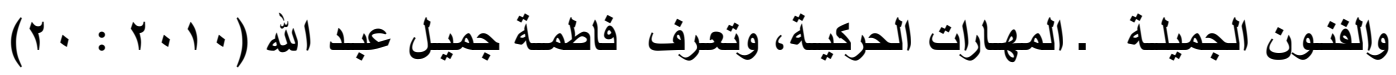

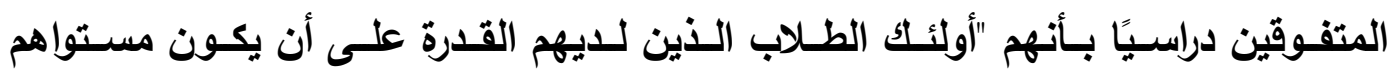

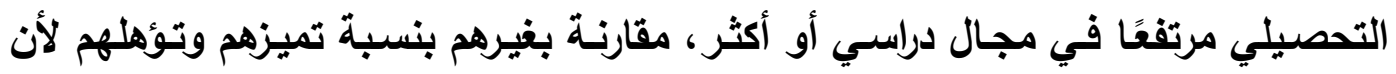

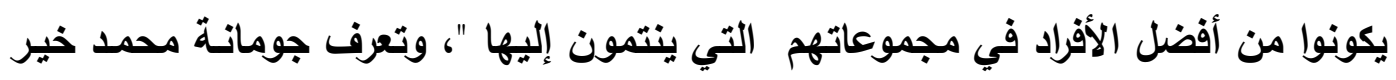

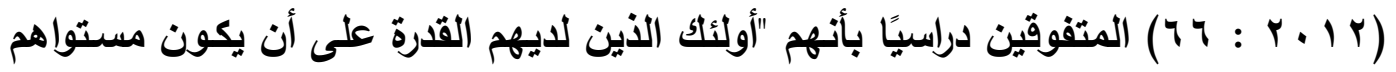

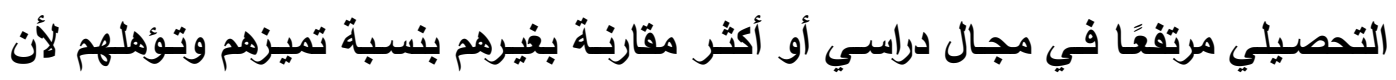
يكونوا من أفضل أفراد المجموعة التي ينتمون إليها".

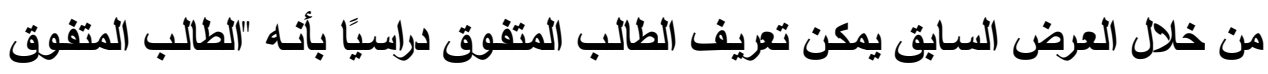

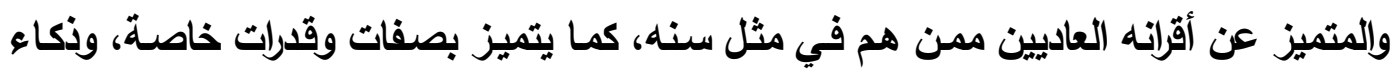

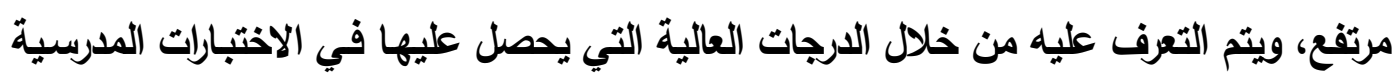

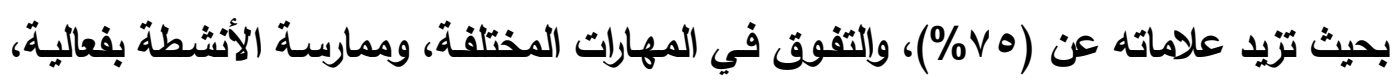

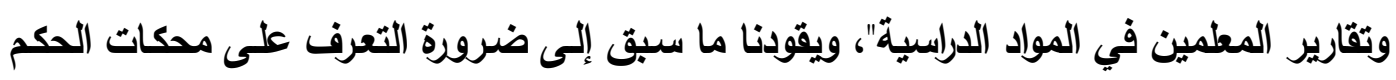

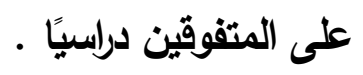

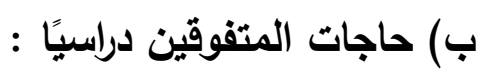
من خلال ما سبق يمكن القول بأن المتفوقين دراسيًا لابد وأن يتوفر لديهم ما 


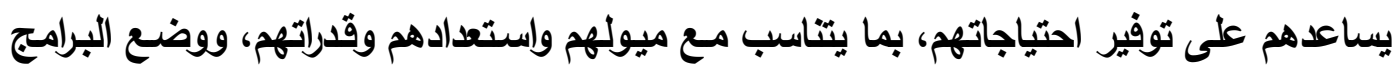

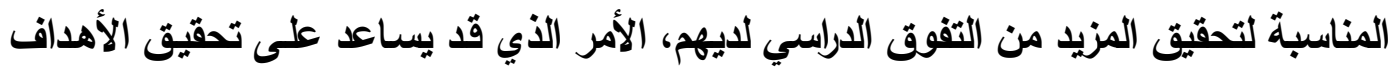
المنشودة وإنجاز الأعمال المختلفة . ج) جعاية الطلاب المتفوقين دراسيًا : من خلال العرض السابق يمكن أن يستنتج الباحث أن المتفوقين دراسيًا في

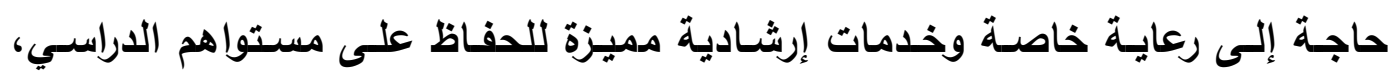

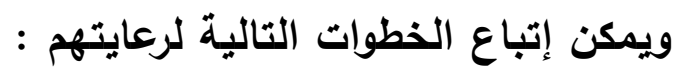

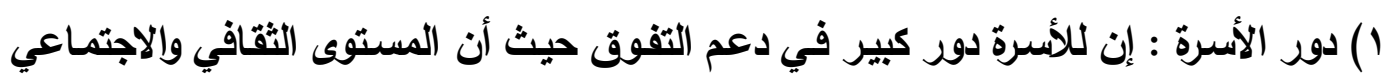
للوالاين يساء على تحقيق فرص النجاح والتفوق لأبنائهم، ونلك بالمشاركة الإيجابية الفعالة

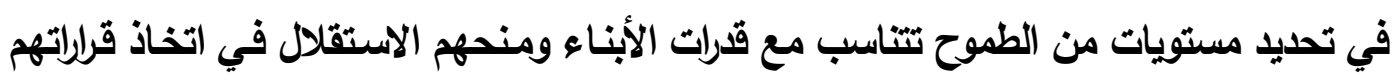
نحو الدراسة المناسبة لهم، وتهيئة الجو الملاثم للاستذكار وتوفير الإمكانات اللازيمة والمشئاركة

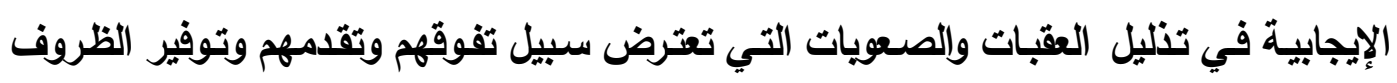
الملائمة للنمو السليم والتفاعل الأسري.

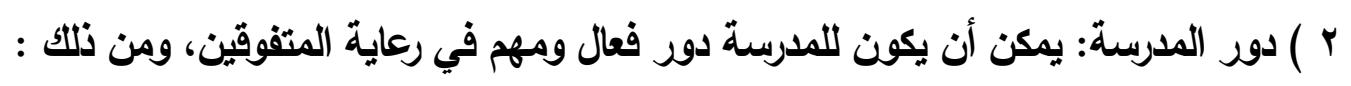

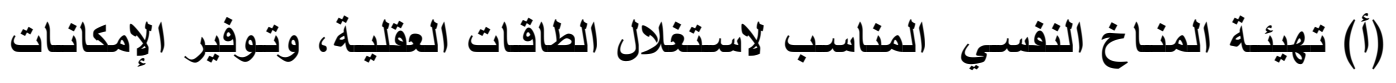

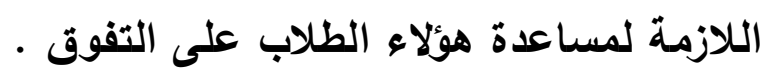

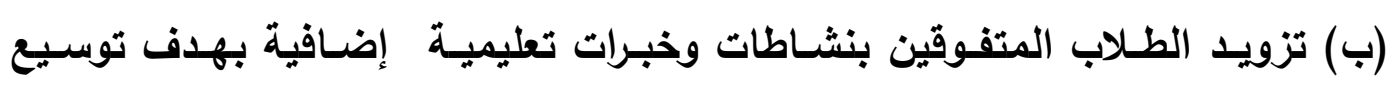

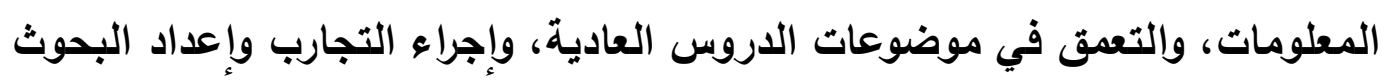

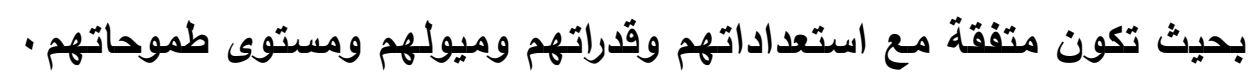

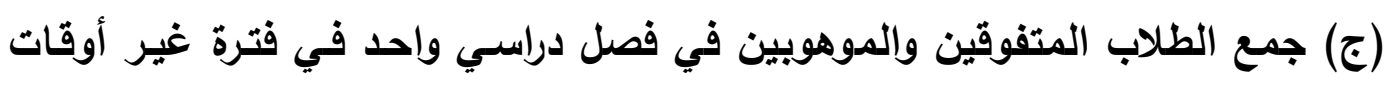

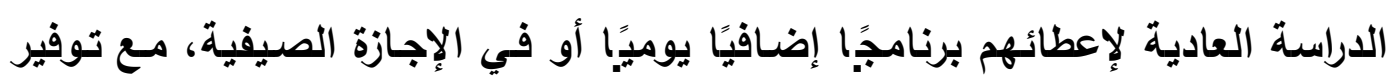

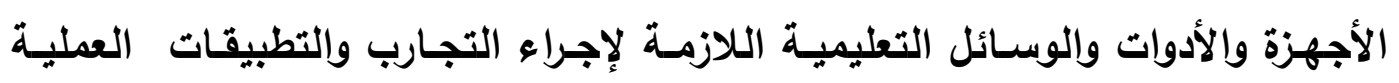
بمساعدة المتخصصين الأكفاء. (د) عدم تقييد الطلاب المتفوقين دراسيًا بالمرحلة الدراسية التي يمر بها على أساس السفاء

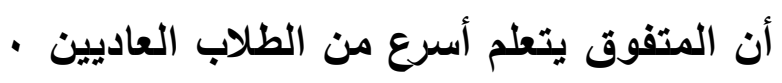


(هـ) تنظيم مسـابقات في البحث العلمي وكتابـة الثسعر والقصص وتثجيعهم على والقي

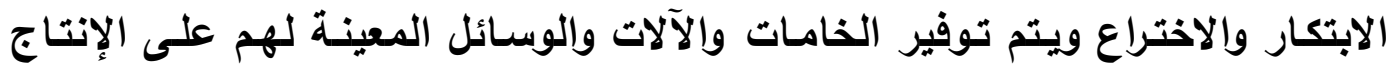

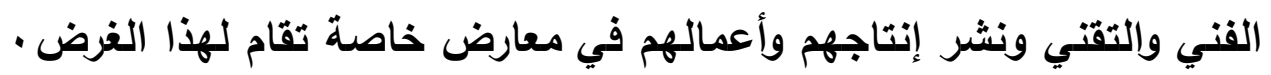

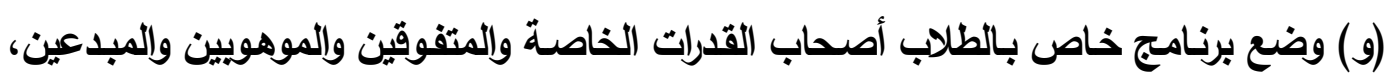
والتي تثير فيهم روح البحث الطمي وتتمي قدراتهم على التفكير والابتكار. إن توفير الرعاية المناسبة للطلاب المتفوقين دراسيًا يضمن تفاعلهم في الحياة بالقدر

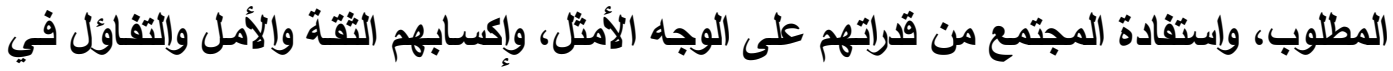

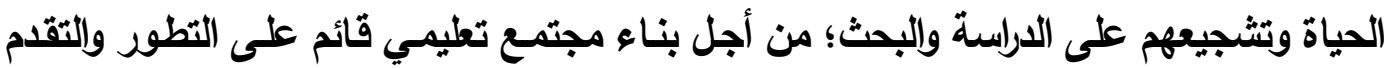

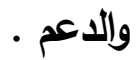

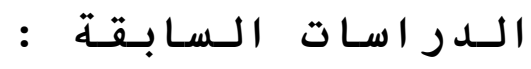

ومن الدراسات التي تناولت الذكاء الانفعالي في علاقته باستراتيجيات إدارة الصراع :

: Afzalur \& Clement,(2002) تعد هذه دراسـة عبر الثقافـات، وممـا هدفت إليه الاراسـة التعرف على العلاقة بين

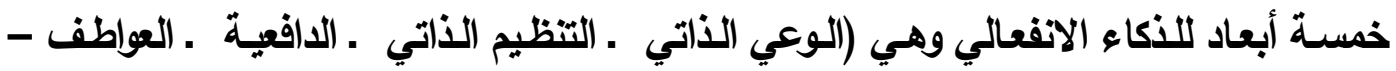

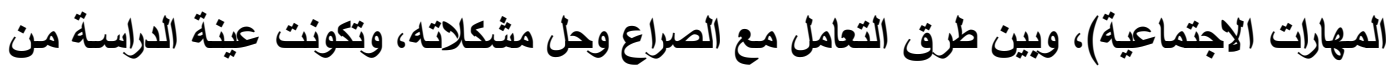

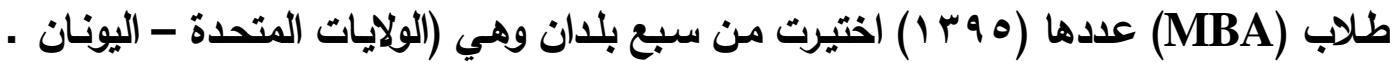

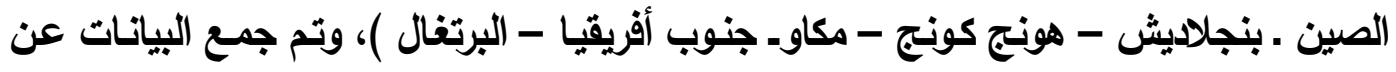

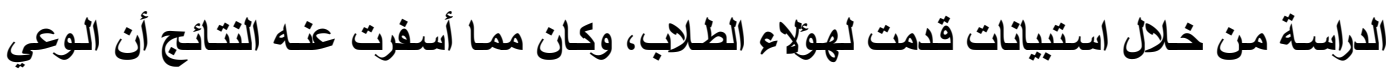
الذاتي يرتبط إيجابيًا بالتظيم الذاتي والعواطف والمهارات الاجتماعية، وأن المهارات الاجتماعية

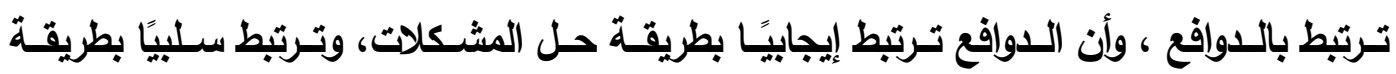
التفاوض والحوار.

: Ka Wai \& Miss,(2005) ب براسة

ومما هدفت إليه الاراسـة اكتشاف العلاقة بين الأكاء الانفعالي وأسـاليب إدارة الصراع

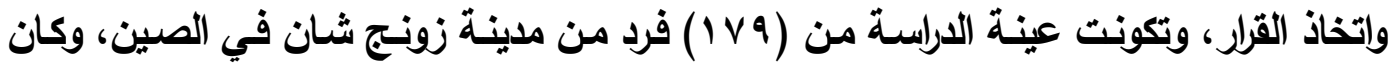

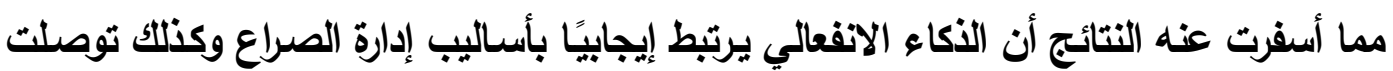

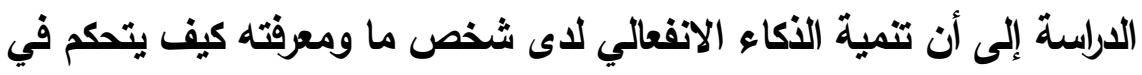
عواطفه ؟ وكيف يديرها ؟ مهم للغاية لجعل الحياة أفضل وأكثر. 
: Andrea,(2010) براسة

ومما هدفت إليه الدراسة التعرف على أهمية المهارات الثخصية والذكاء الانفعالي

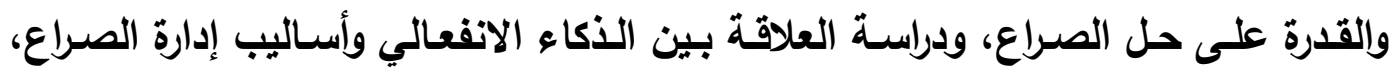
وتكونت عينة الدراسة من طلاب مدارس (MBA) في أمريكا، ومن المقاييس المستخدمة في الدراسـة مقياس (Thomas-Killman,1974) لقياس أسـاليب إدارة الصراع، وكان الصنان

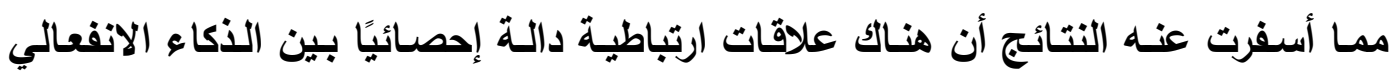

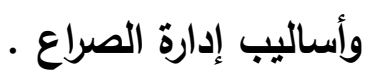

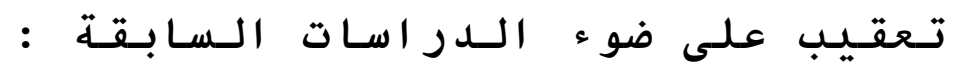

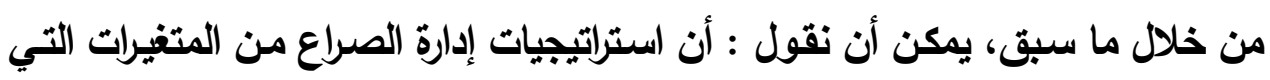

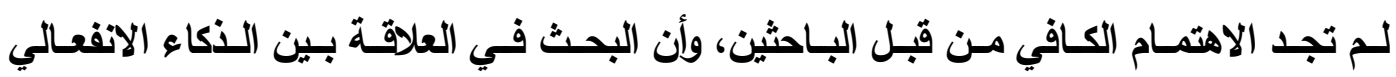

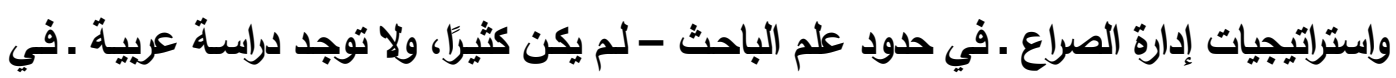

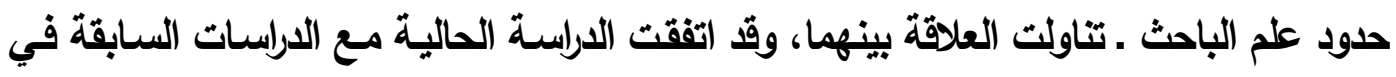

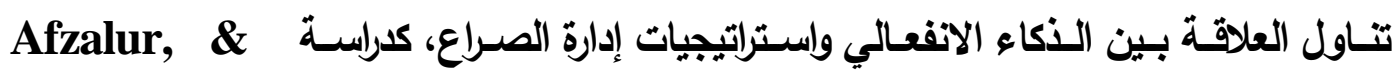
والتي هدفت مما هدفت إليه التعرف على العلاقة بين خمسة أبعاد للأكاء

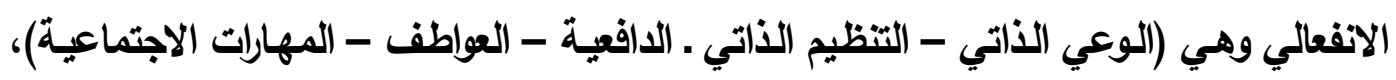

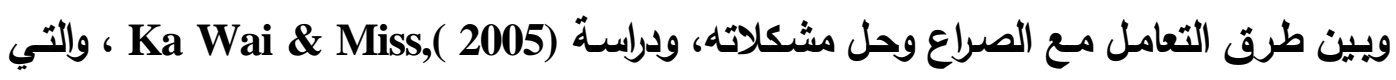

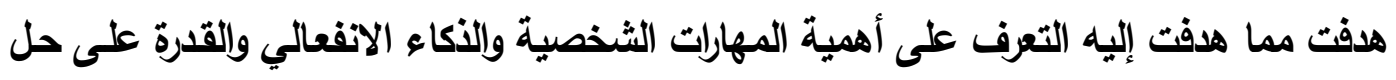
الصراع، ودراسة العلاقة بين الذكاء الانفعالي وأساليب إدارة الصراع، ودراسة ( Andrea Claire

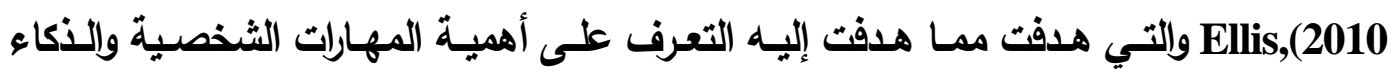

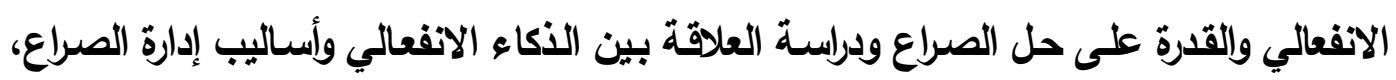

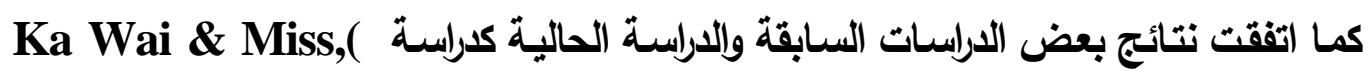

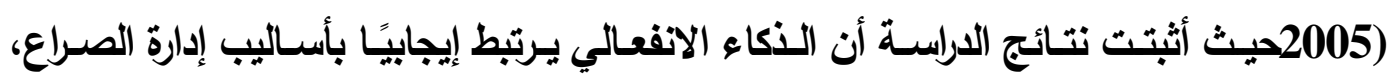
ودراسـة Andrea Claire Ellis,(2010) حيث مما أسفرت عنه نتائج الدراسـة وجود علاقات

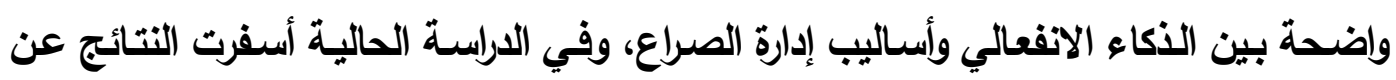

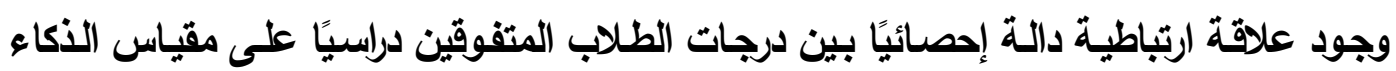

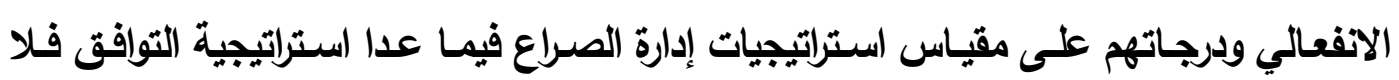

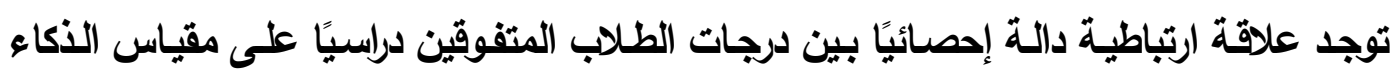


الانفعالي ودرجاتهم على استراتيجية التوافق، واختلفت الدراسة الحالية مـع الدارسات السابقة من

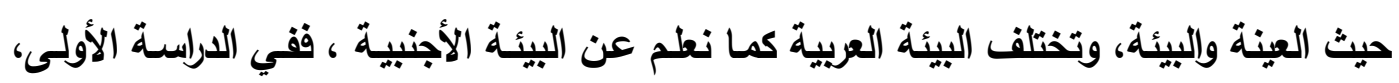

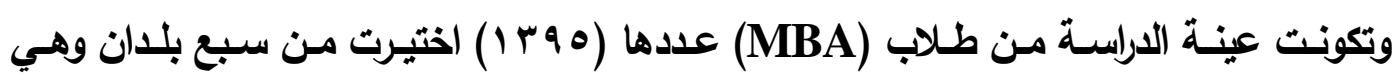
(الولايات المتحدة - اليونان - الصين - بنجلاديش - هونج كونج - مكاو - جنوب أفريقيا -

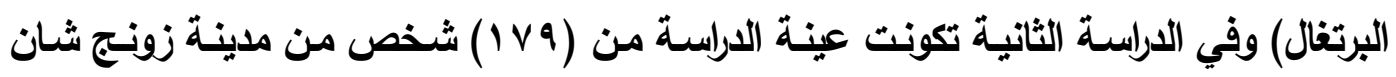

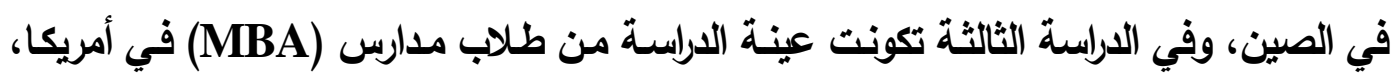

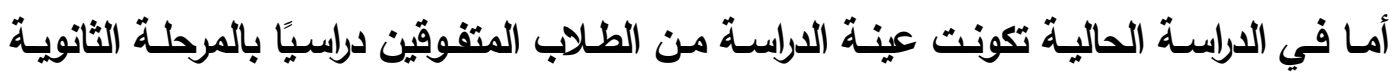
بالمنيا.

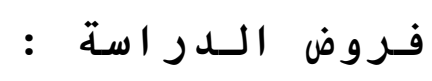
على ضوء ما سبق يمكن صياغة الفروض كما يلي:

1

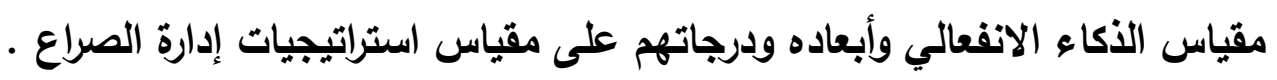

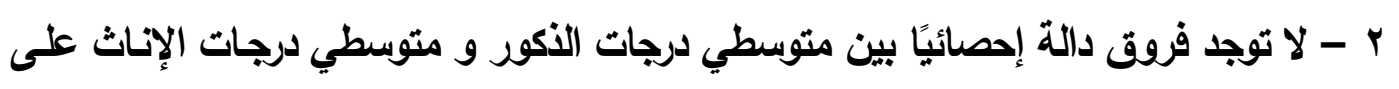
مقياس الأكاء الانفعالي وأبعاده.

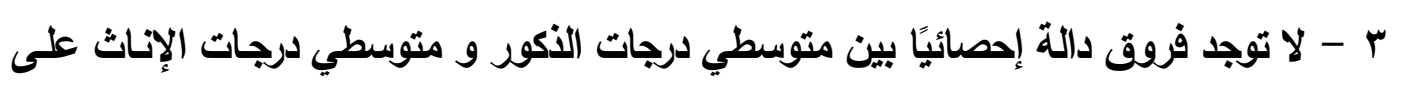

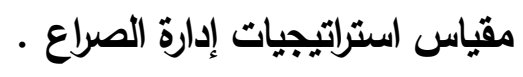
و - الإجراءات :

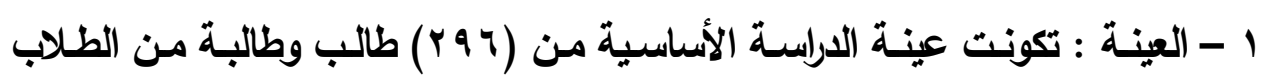

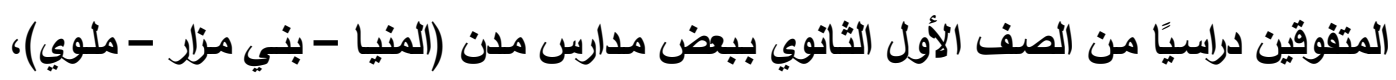

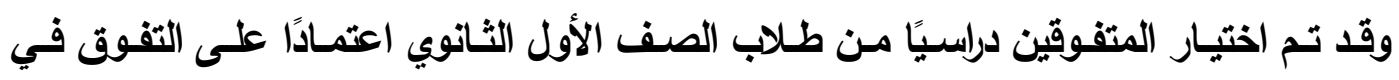

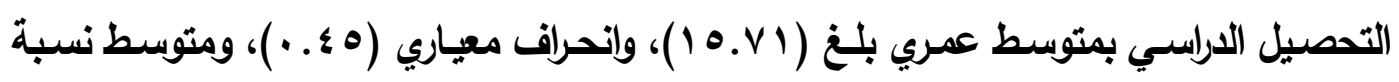

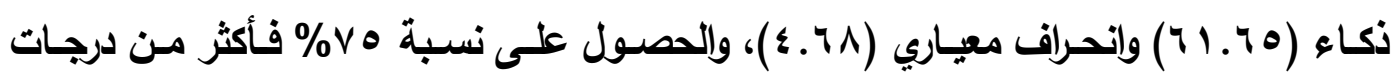

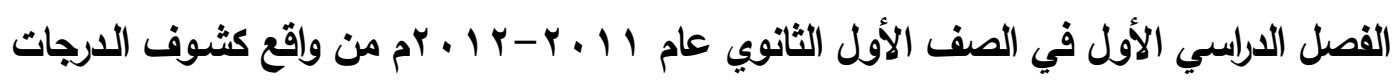
بكل مدرسة، وللتأكد من تفوق هؤلاء الطلاب دراسيًا قام الباحث بتطبيق اختبار الأكاء اللفظي

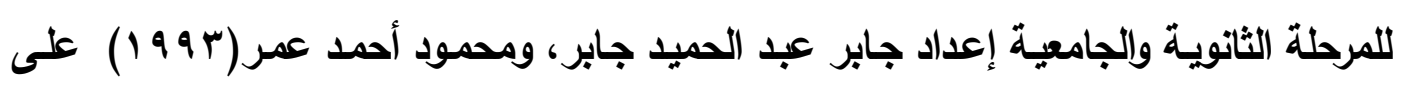

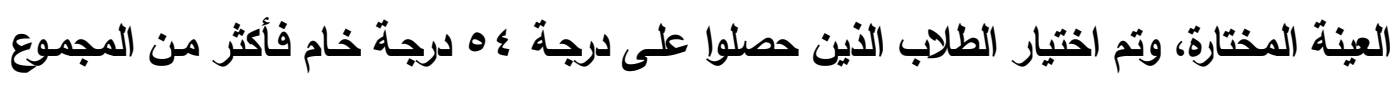
الكلي ـ 1 درجة خام بناءً على تعليمات المقياس. 
r- أدوات الدراسـة : لاختبـار صـحة فروض الدراسـة الحاليـة وللتأكلد مـن نتـائج الاراسات السابقة حول موضوع الاراسة وللوصول إلى نتائج الدراسـة، تم استخدام الأدوات التالية : 1 - اختبار الأكاء اللفظي للمرحلة الثانويـة والجامعية، إعداد جابر عبد الحميد جابر، و

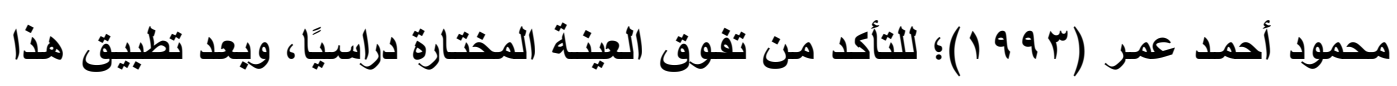
الاختبار تم استبعاد من لم تنطبق عليه نسبة الذكاء كما حددها معدا المقياس .

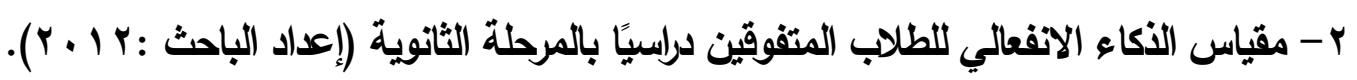

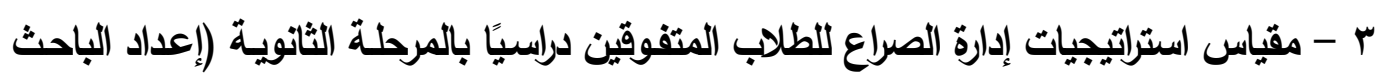
. (Y. I r:

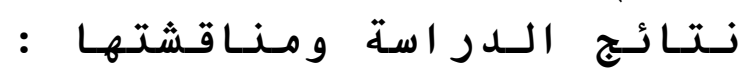
1 - نتيجة الفرض الأول وتفسيرها : ونصه " لا توجد علاقة ارتباطية دالة إحصائيًا بين درجات

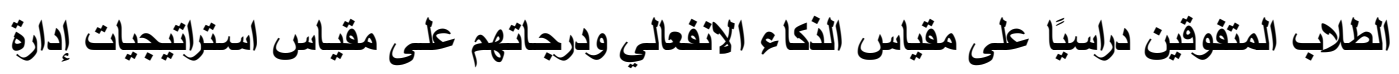

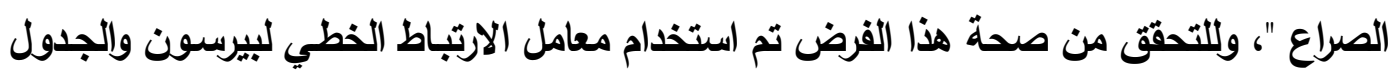
التالي يوضح معاملات الارتباط الخطي بين درجات الذكاء الانفعالي ودرجات استراتيجيات إدارة الصراع لاى عينة الدراسة.

جلول (1)

معاملات الارتباط الخطي بين درجتي الأكاء الاففعالي واستراتيجيات إدارة الصراع لاى عينة الداسة

\begin{tabular}{|c|c|c|c|c|c|}
\hline الكلية & والدارهارة: & الانفعالات) (إدارة & الاجتماعارية اتثاتف & (الألوعي & \\
\hline **. .५११. & $*_{0}^{*} .1 \leqslant \mu_{-}$ & ${ }^{* *}, ., Y Y=-$ & **. & **. $. Y \leqslant 7$. & 1- استراتيجية التتافس \\
\hline$\because \cdots \Lambda_{-}$ & $\because{ }^{\circ}$ & $\because$. TY. & $\because Y^{q}$ & $\because \cdots \varepsilon=$ & r- استراتيجية التوافق \\
\hline **. & ${ }^{* \star}, .1 \vee \Lambda_{-}$ & ${ }^{*}, . r \cdot V_{-}$ & **.,YTI- & $* *$. YVq. & "- استراتيجية التجنب \\
\hline$\star^{* \star}, . Y \wedge \varepsilon$ & $* * .179$ & $* \star . Y 01$ & $* \star ., Y \leqslant \Lambda$ & $* * ., 1 \Lambda$ & ــ استراتيجية التعلون \\
\hline **..IV0 & $\because \cdots 7$ & **..IAY & $* * .190$ & **. .174 & هـ استراتيجية التقاوض \\
\hline
\end{tabular}

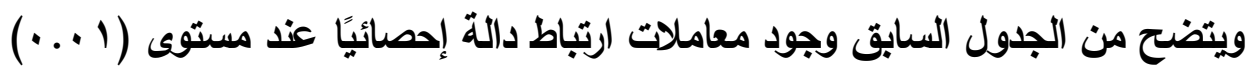

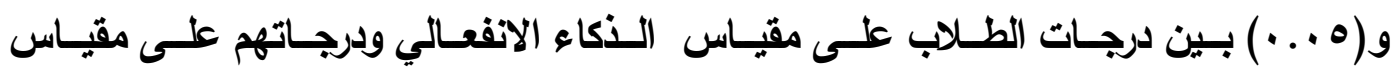
واستراتيجيات إدارة الصراع، مـا عدا استراتيجية التوافق فكانت غير مرتبطة بأي بعد من أبعاد الادئ 
النكاء الانفعالي واللدرجة الكلية له، كما يلاحظ وجود علاقة ارتباطيه سلبية دالة إحصائية عند

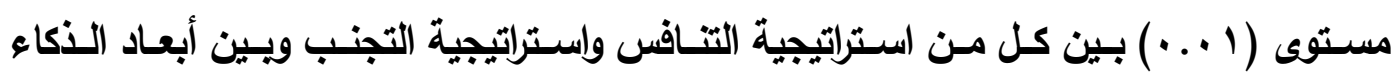
الانفعالي والدرجة الكلية، وهناك علاقة ارتباطيه موجبة دالة إحصائية عند مستوى (1 (1 ...) بين

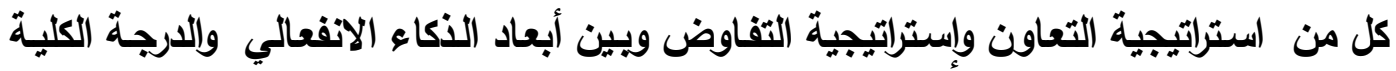

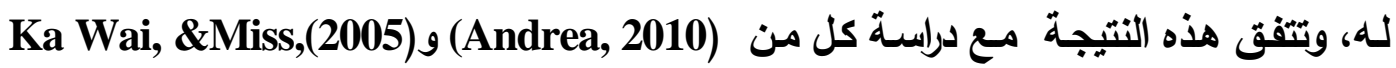

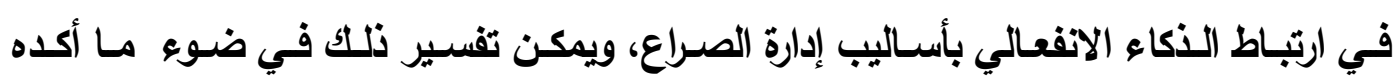
Reiff,(2001:66 ) ذللك من الدور المهم والفعال في حل المثكلات التي يواجهها الإنسان بجانب القدرات العقلية

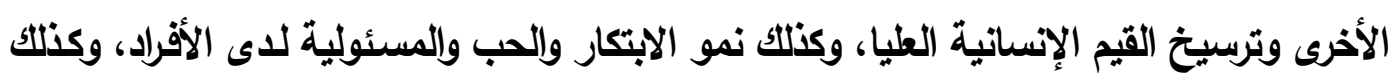

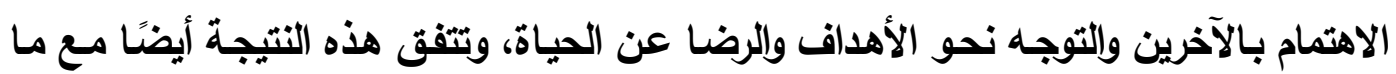

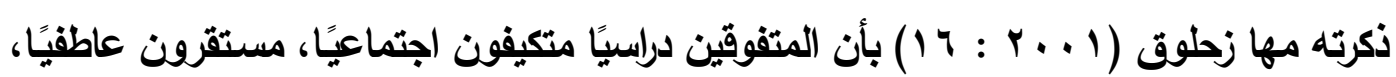

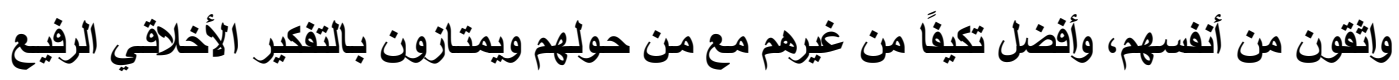

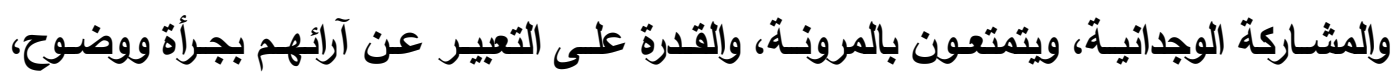
ويفضلون مناقثنة الأفكار والمشكلات.

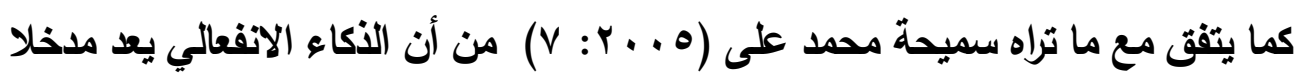

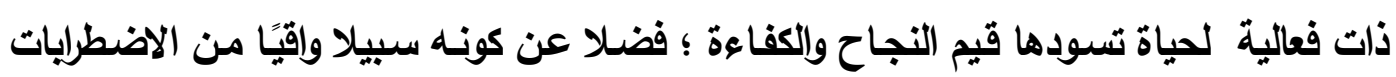
العاصفة التي تصيب الإنسان بتوتراتها في أمنه وإستقراره النفسي .

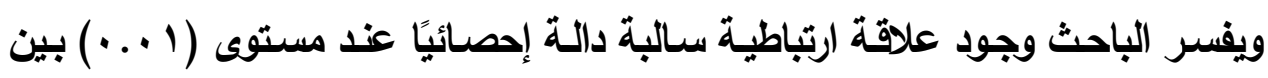

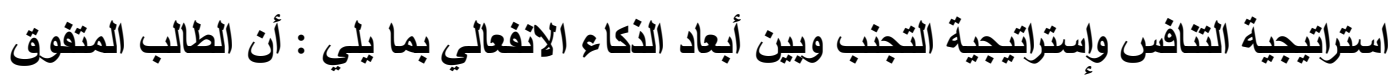

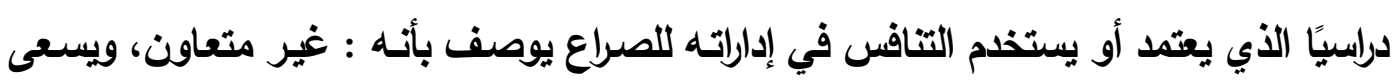

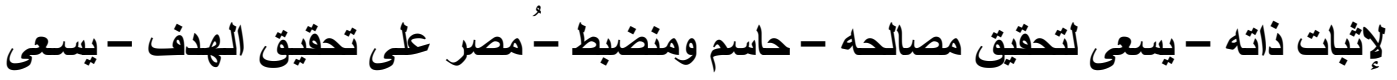

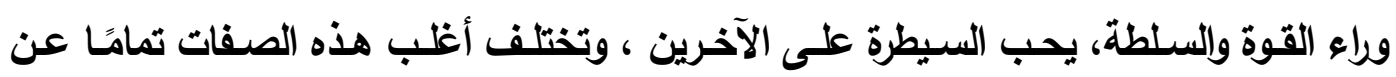

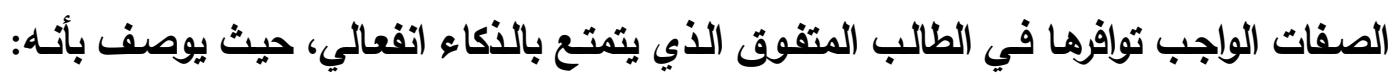

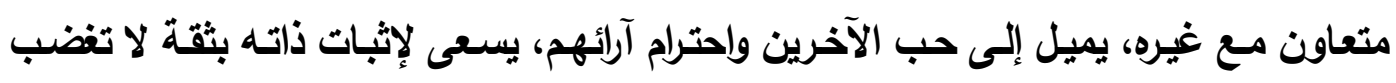

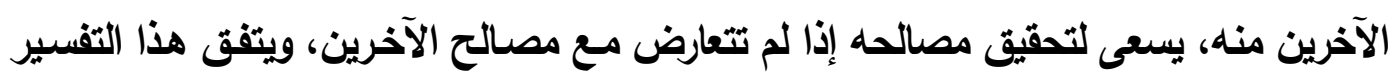

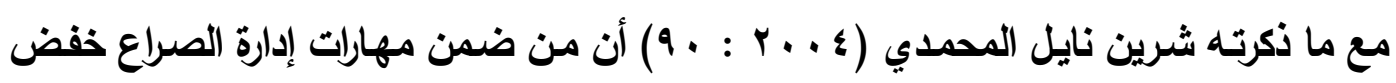
المنافسة عن طريق التعاون بروح الفريق الواحد ، بعيدًا عن العدوانية. 
كما يمكن تفسير وجود علاقة ارتباطية موجبة دالة إحصائيًا عند مستوى (1 ...)

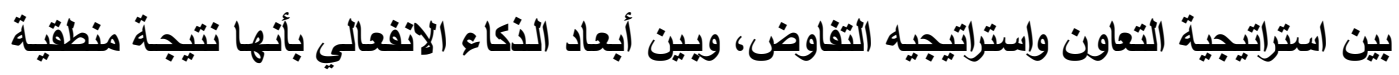

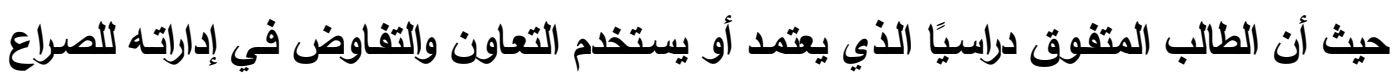

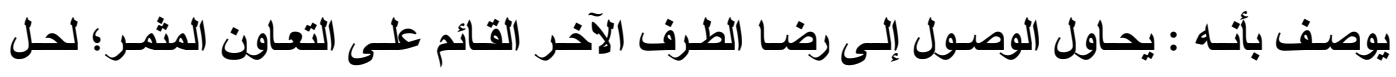

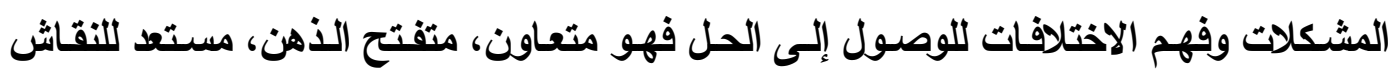

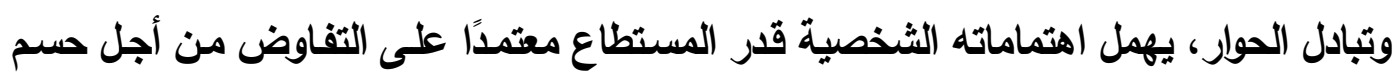

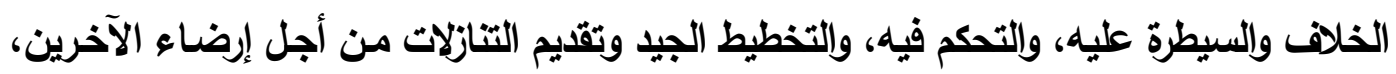

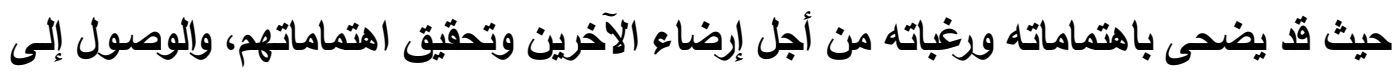

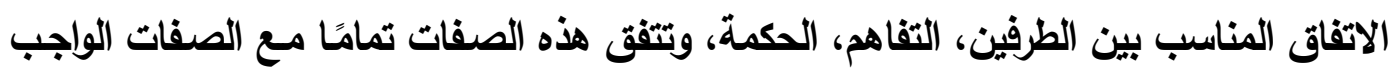

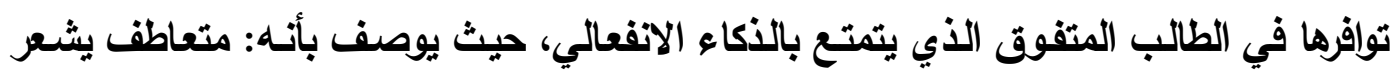

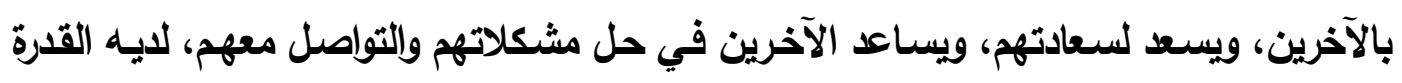

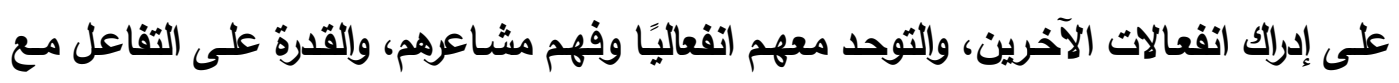

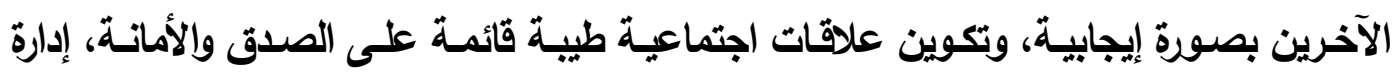

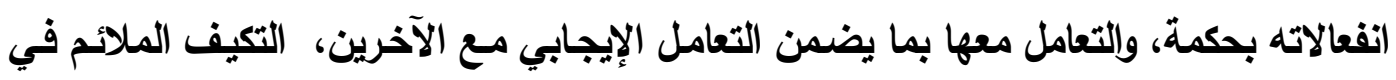

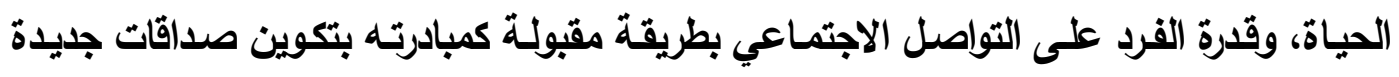

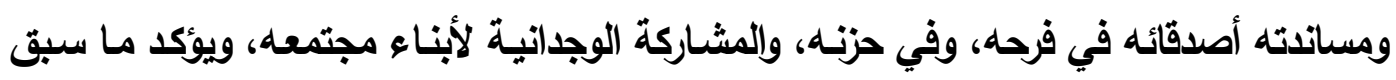

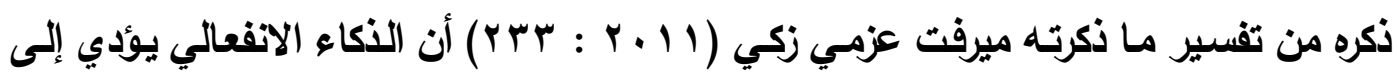

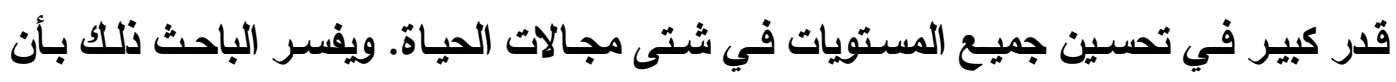

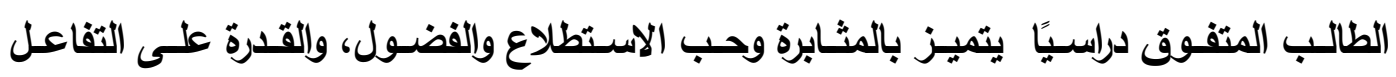

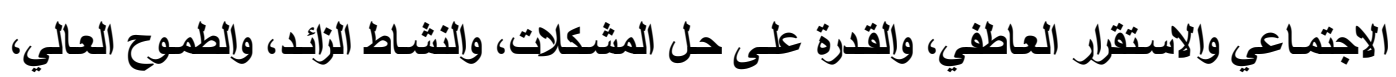

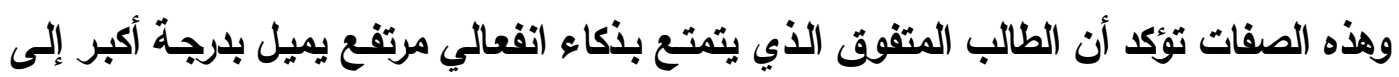

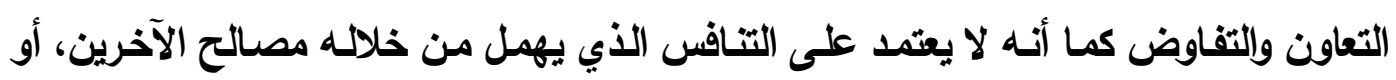
التجنب الذي يهرب من مواجهة المواقف الحياتية المختلفة، مما يدل على أن هناك همزة وصل التهل

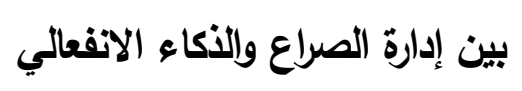

باعتباره يضم الكثير من المهارات الاجتماعية.

ويفسر الباحث عدم وجود علاقة ارتباطية دالة إحصائيًا بين استراتيجية التوافق ، وأبعاد التادئ

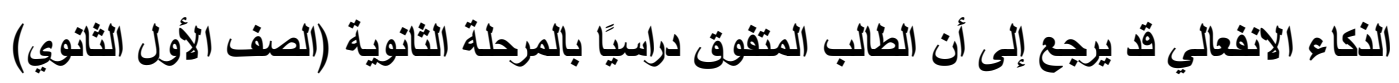


بأنه لا يعتمد على الحل الوسط - وُيوصف من يستخذم هذه الاستراتيجية بأنه يهمل مصالحه

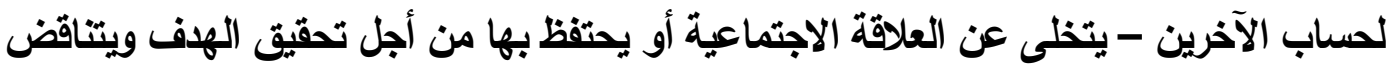

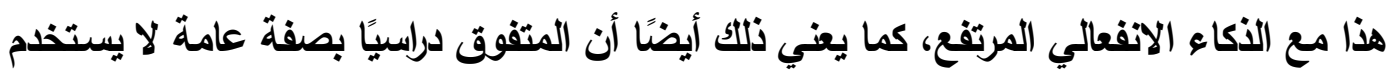
هذه الاستراتيجية أو يستخدمها في مواقف قليلة معينة.

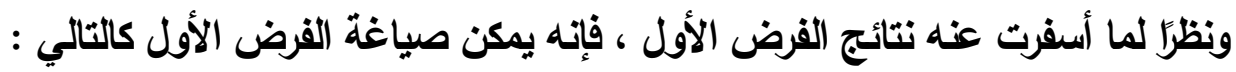

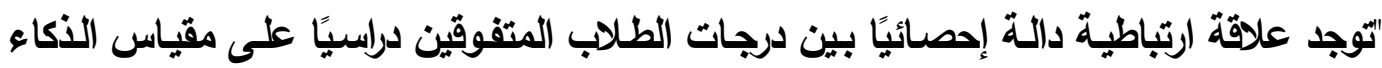

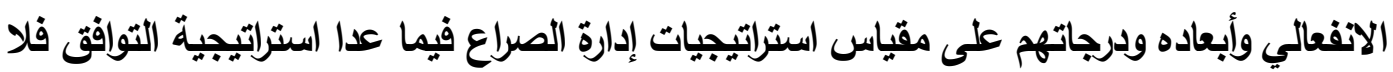

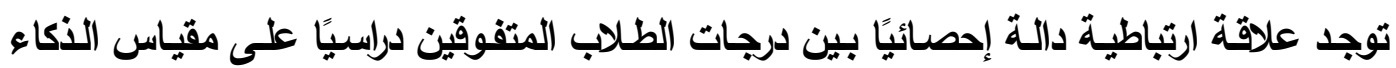
الانفعالي وأبعاده ودرجاتهم على استراتيجية التوافق".

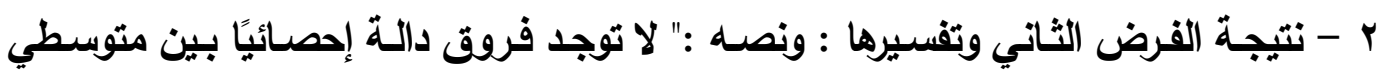

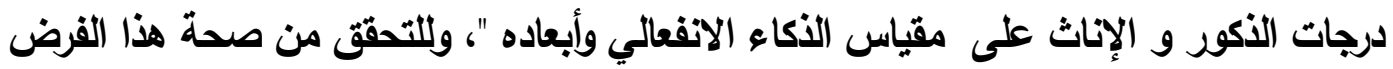

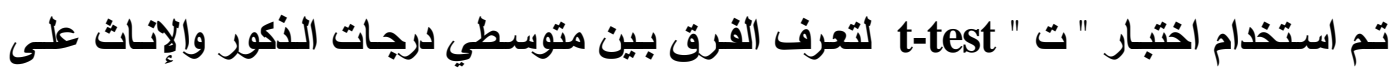

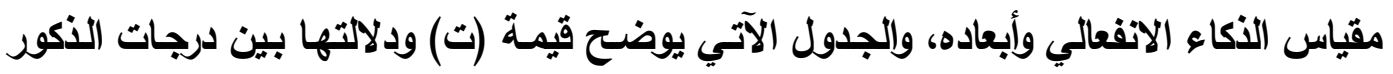
والإناث على مقياس الأكاء الانفعالي.

\section{جدول (ץ)}

قيم "ت" ودلالتها للفروق بين متوسطي درجات الذكور والإناث على مقياس الذكاء الانفعالي وأبعاده

\begin{tabular}{|c|c|c|c|c|c|c|}
\hline \multirow{2}{*}{ مستوى الدلاكة } & \multirow[t]{2}{*}{ قيم ت } & \multicolumn{2}{|c|}{ 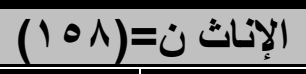 } & \multicolumn{2}{|c|}{ 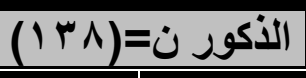 } & \multirow[t]{2}{*}{ الأبعاد } \\
\hline & & انميراف & الحسابي & انحرياري & الصسابي & \\
\hline غير دال - غ | غال & $\cdot .974$ & r.94 & ro.rE & $r .91$ & ro.TV & الأول (الوعي بالذات) \\
\hline دال & $T .1 \leq \leqslant-$ & 1.40 & 17.87 & 1.7 & 10.94 & والمهاراتِ الاجتماعية ) \\
\hline دال & 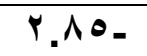 & 1.70 & $Y \cdot . \leqslant T$ & 1.74 & 19.94 & الثالث (إدارة الانفعالات) \\
\hline غير دال & $\because+1 \%=$ & 1.24 & 14.91 & $1 . \wedge$. & $1 \% .9 \mathrm{~V}$ & والتحفيزيز) (مهـارة الدافعيسة \\
\hline غير دال & $1 . \times 1=$ & 0.11 & V..Yo & $7 . \$ 1$ & $V 0 . \leqslant 9$ & اللارجة الكلية \\
\hline
\end{tabular}

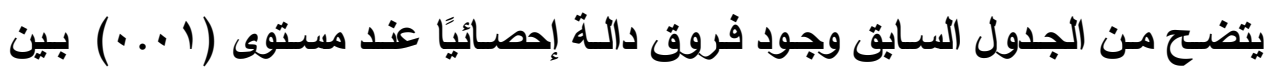
متوسطي درجات الأكور والإناث على بعدي (التعاطف والمهارات الاجتماعية)، (إدارة الانفعالات) 
لصالح الإناث، أي أن الإناث أكثر تعاطفًا وممارسة للمهارات الاجتماعية، وأكثر قدرة على إدارة

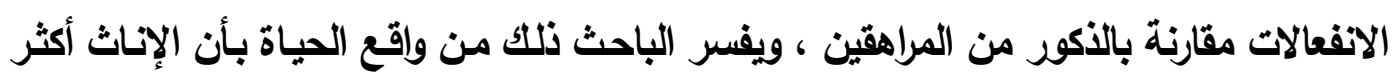

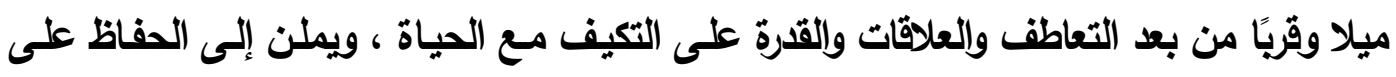

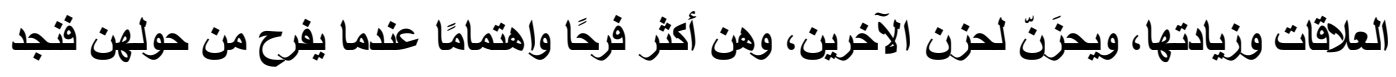

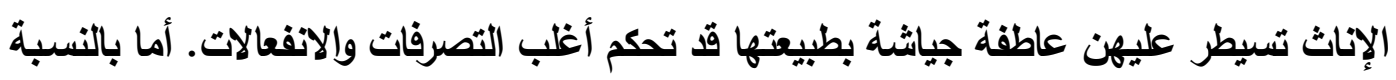

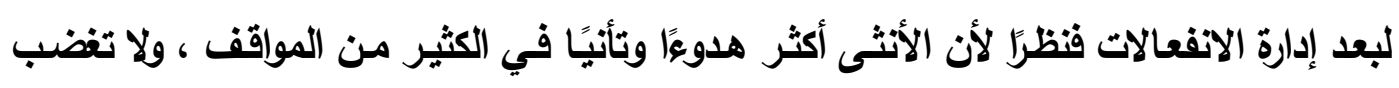
بسرعة كالذكور بفضل طبيعتها الإنسانية الرقيقة، وكنلك أعراف المجتمع وتقاليده الأي قد يجطانها في مواقق أخرى عاجزة بعض الثبء عن التعامل مع بعض المواقف، أو للحفاظ على مظهرها أمام الآخرين فلا يكون أمامها إلا التصرف الحكيم في إدارة الانفعالات .

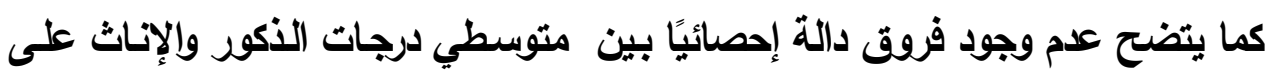

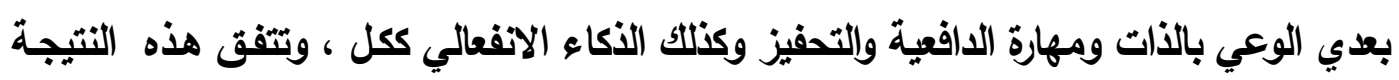

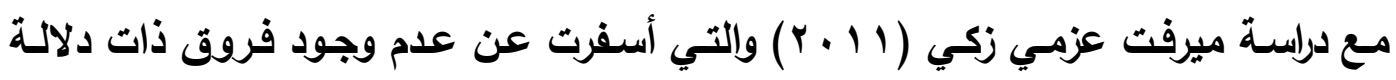

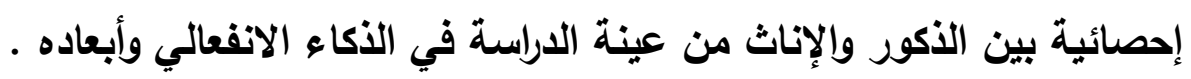

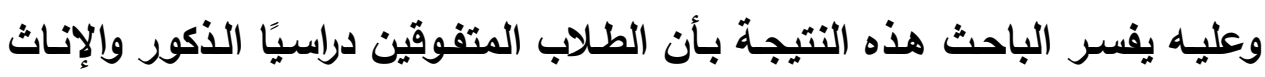

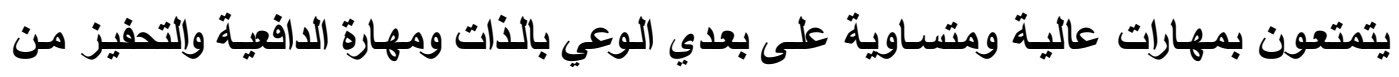

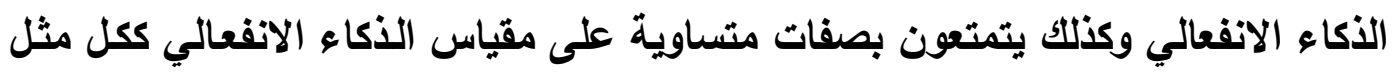

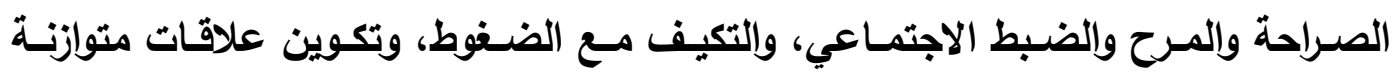

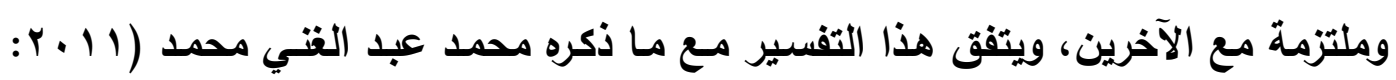

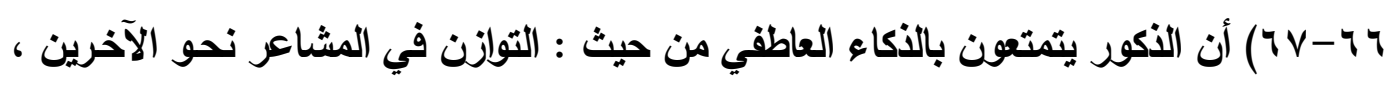

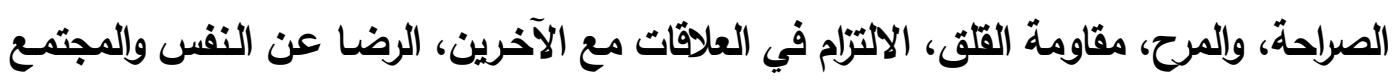

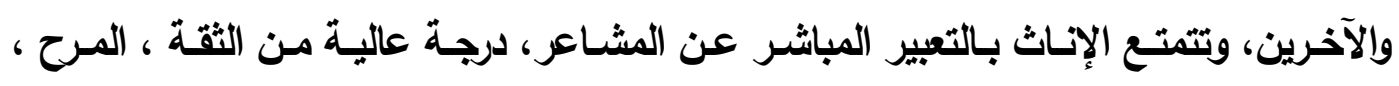

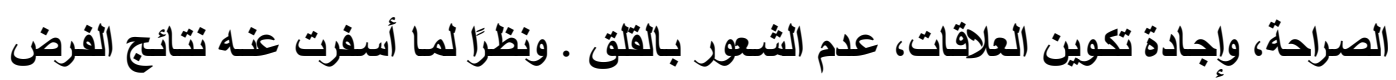

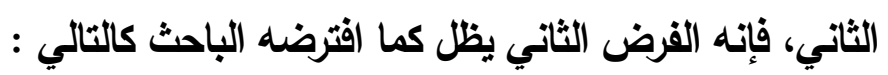

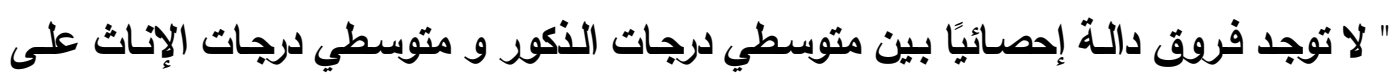
مقياس الذكاء الانفعالي وأبعاده " . ج- نتيجة الفرض الثالث وتقسيرها : 
ونصه :" لا توجد فروق دالة إحصائيًا بين متوسطي درجات الذكور والإناث على مقياس

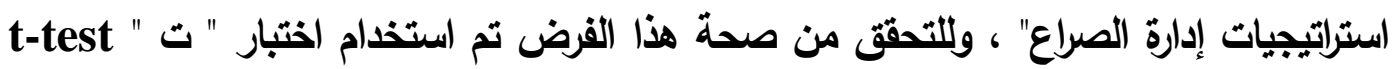
لتعرف الفروق بين متوسطي درجات الأكور والإناث على مقياس استراتيجيات إدارة الصراع ،

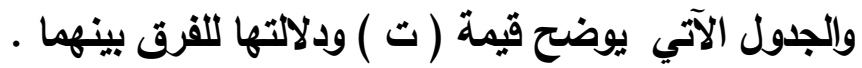
جدول (r)

قيم " ت " للفروق بين متوسطي درجات النكور و متوسطي درجات الإناث على مقياس استراتيجيات إدارة الصراع الناع

\begin{tabular}{|c|c|c|c|c|c|c|}
\hline \multirow{2}{*}{ الدلالة } & \multirow[t]{2}{*}{ قيم ت } & \multicolumn{2}{|c|}{ 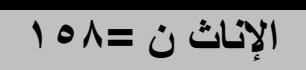 } & \multicolumn{2}{|c|}{ الأكور ن = = ا ا } & \multirow[t]{2}{*}{ الاستراتيجيات } \\
\hline & & |نحراف & الحسابي & أنحراف & |الصسابي & \\
\hline غير دال & $1 . r \wedge V$ & 1.11 & ז.r. & T.Y & r.70 & 1- إستراتيجية \\
\hline غير دال & . TYV & $r . r \Lambda$ & 0.07 & r.Mr & 0.70 & r- الته افتراتيجية \\
\hline غير دال &. $\mathrm{r}$ & 1.9. & 1.20 & 1.01 & $1 . r V$ & "- التتراتيجية \\
\hline غير دال & $\cdot r \leqslant 0$ & Y.TV & $v . \cdot 7$ & r.. 1 & $v .1 \leq$ & ـ التعاورن التيجية \\
\hline غير دال & $\because \cdots$ & r.\& & 7.59 & ఛ. \&. & 7.57 & هـ استراتيجية \\
\hline
\end{tabular}

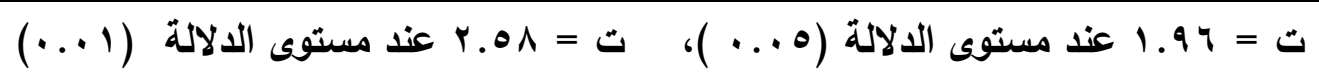
يتضح من الجدول السابق عدم وجود فروق دالة إحصائيًا بين متوسطي درجات الطلاب

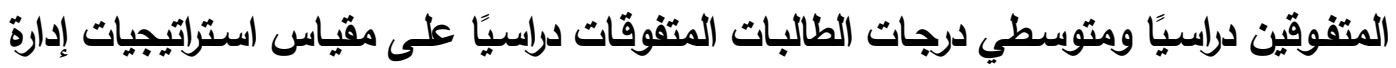
الصراع، ويفسر الباحث عدم وجود فروق بين الجنسين في استراتيجيات التنافس والتوافق والتجنب والتعاون والتفاوض في أن كلا الجنسين يستخدمان نفس الاستراتيجيات بنفس الكفاءة

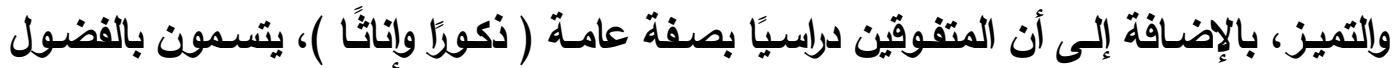
العلمي والثــف بـالتطلم، والمشـاركة الوجدانيـة الفعالتة، وحب المغامرة، والإصرار على تحقيق الأهداف، والطموح العالي، والانثـال كثيرً بالمستقبل والتخطيط الجيد لـه، وحب الاستطلاع، والتفاعل الاجتماعي والاستقرار العاطفي، والقدرة على حل المشكلات، والنشاط الزائد،

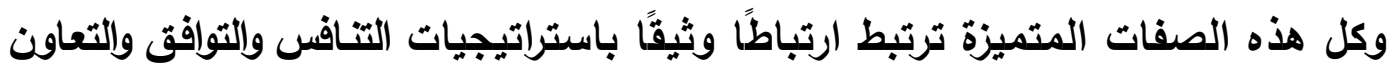
والتفاوض، كما أن المتفوقين دراسيًا من الجنسين يستخدمون التجنب في بعض المواقف التي تلئي 
يكون التجنب فيها نوعًا من الحكمة والتفاوض ويدعم هذا التفسير محمد عبد الغتي محمد

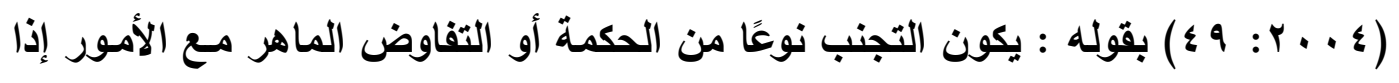

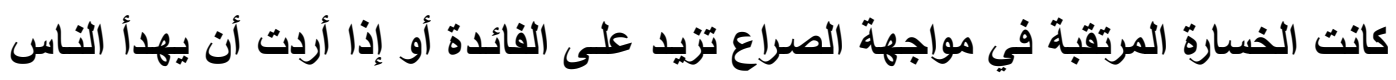

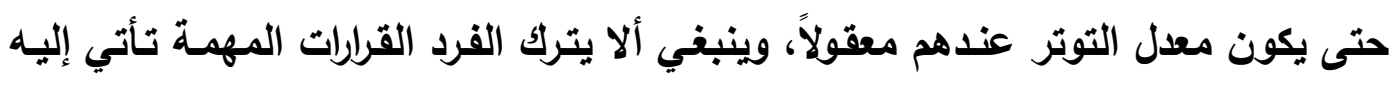

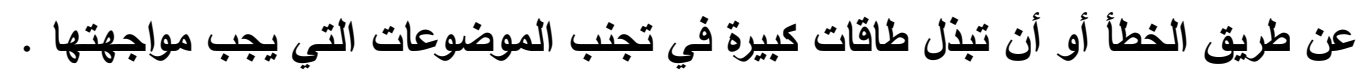

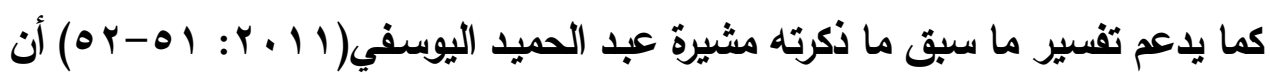

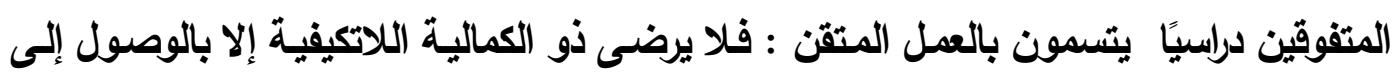

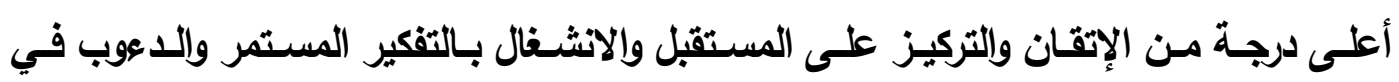

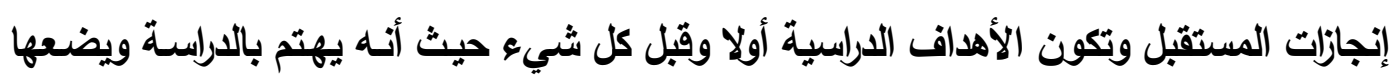

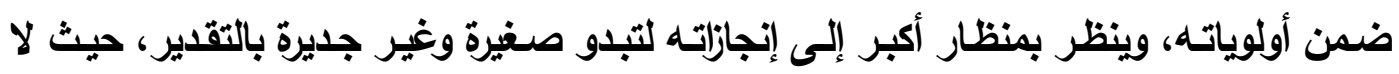

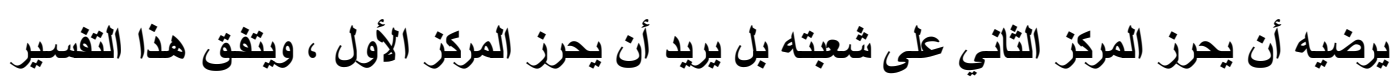

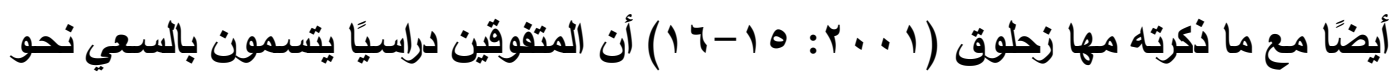

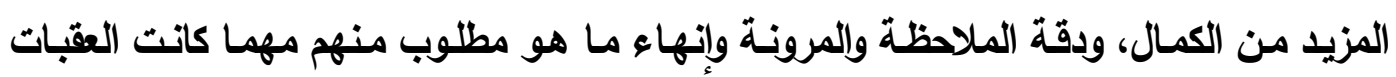

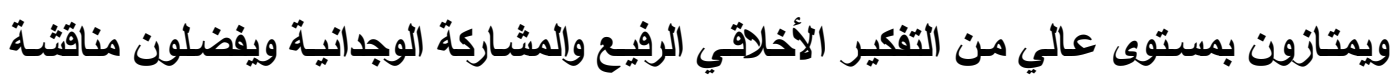
الأفكار والحب العالي للاستطلاع .

ونظرً لما أسفرت عنه نتائج الفرض الثالث، فإنه القرض الثالث يظل كما افترضه الباحث كالتالي : " لا توجد فروق دالة إحصائيًا بين متوسطي درجات الذكور ومتوسطي درجات الإناث على

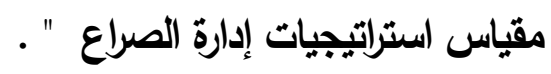

$$
\text { الـمـر اجع }
$$


1 إبراهيم عبد الفتاح زهدي (9 . . ؟) ـ استرتيجيات إدارة الصراع التظيمي وعلاقتها

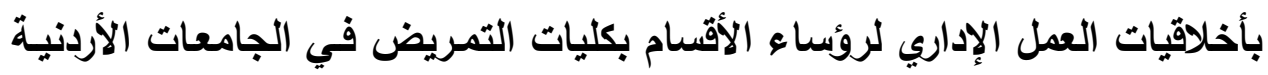

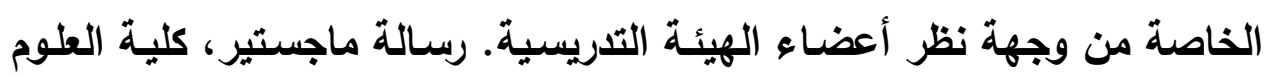
التريوية ، جامعة الثرق الأوسط للاراسات العليا .

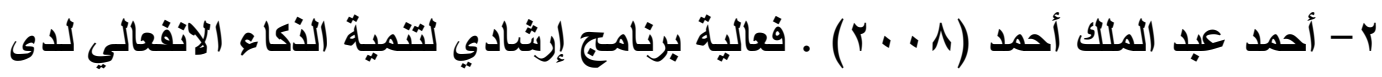
عينة من الصم بمدينة المنيا ـ رسالة دكتوراه، كلية التربية، جامعة المنيا.

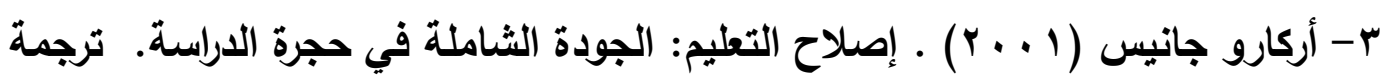

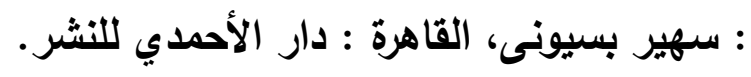

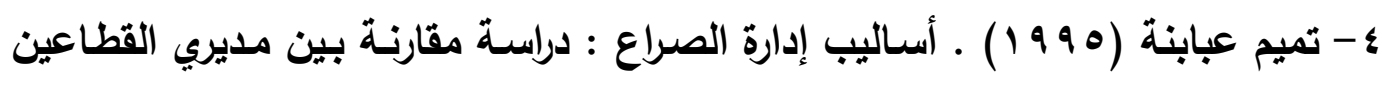

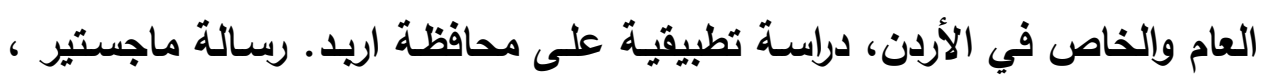

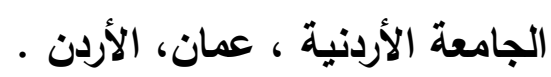

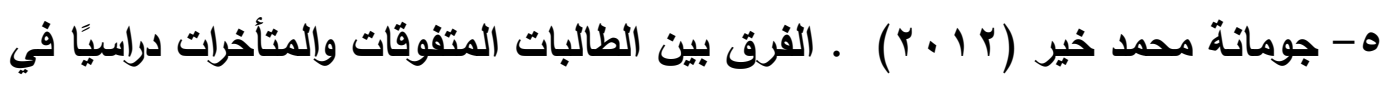

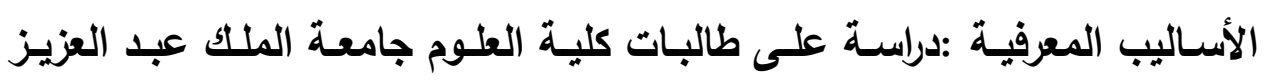

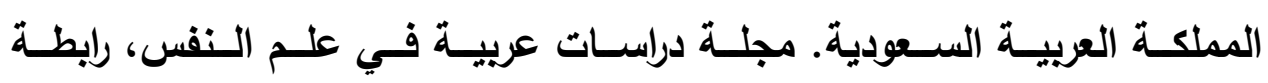

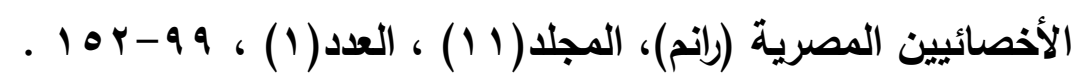

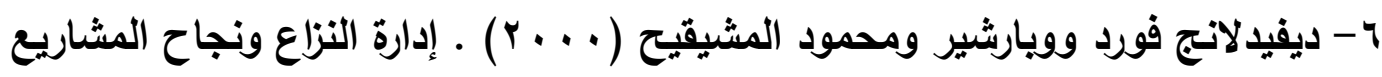

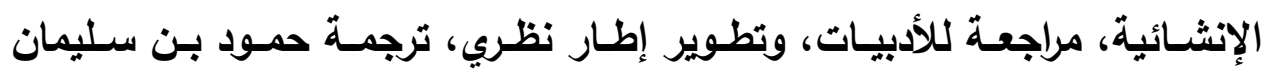

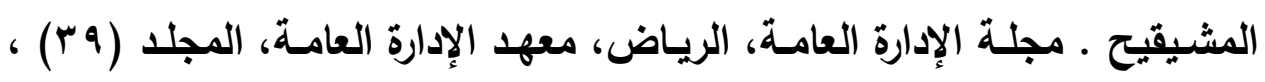

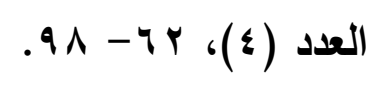

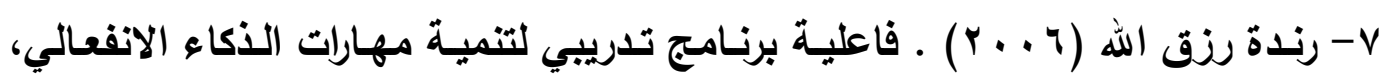

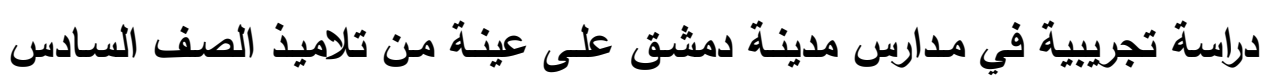

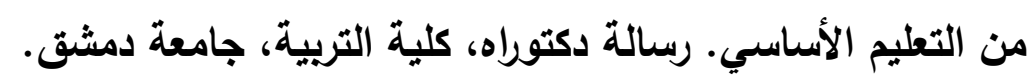

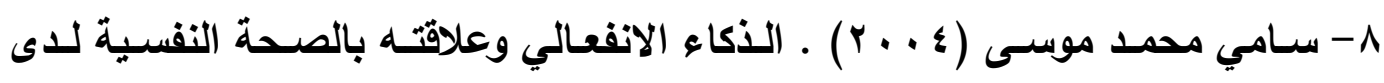

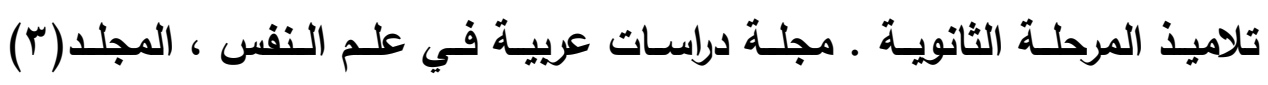

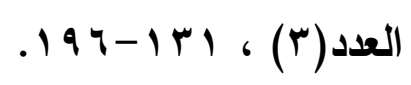

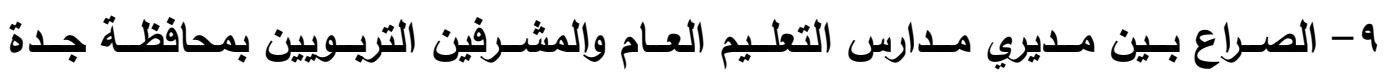

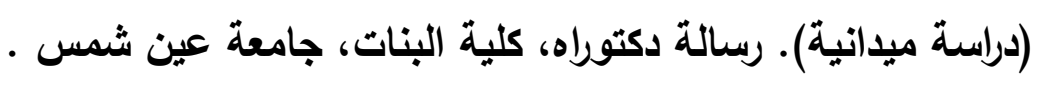


• 1 - سميحة محمد على (0 . . Y). الذكاء الانفعالي للدى الأطفـال في مرحله مـا قبل

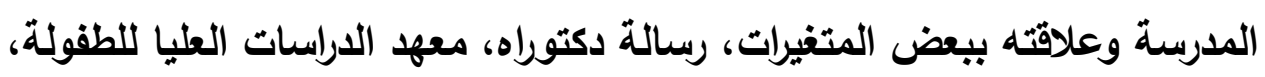
جامعة عين شمس .

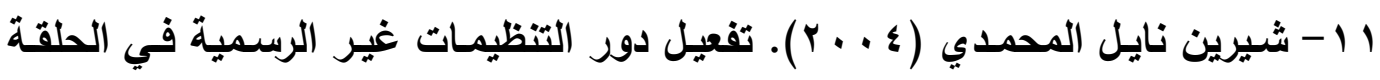

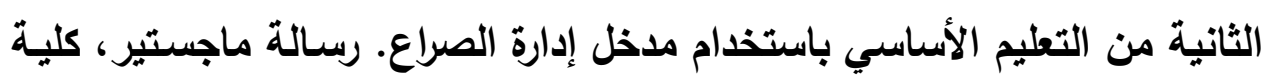

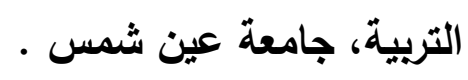

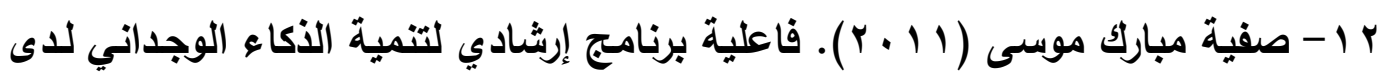

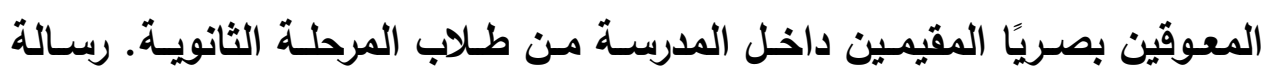

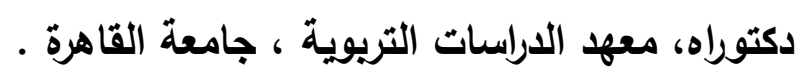

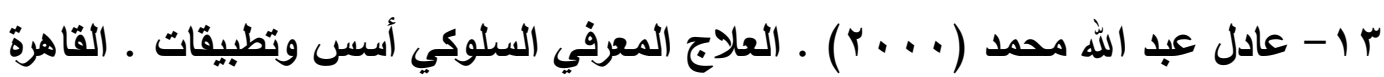

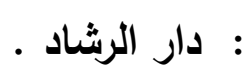

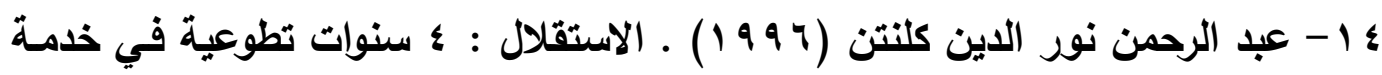

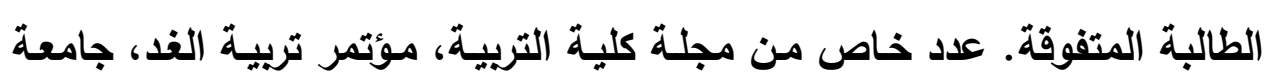

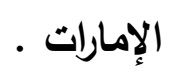

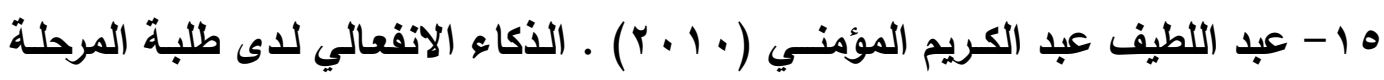

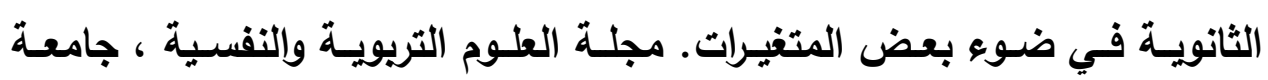

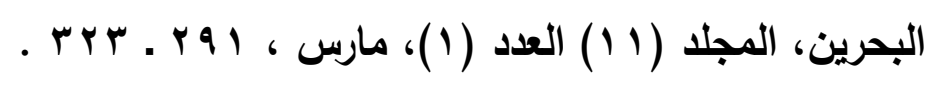

17

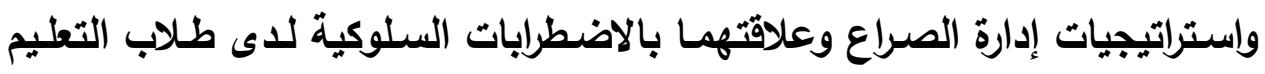

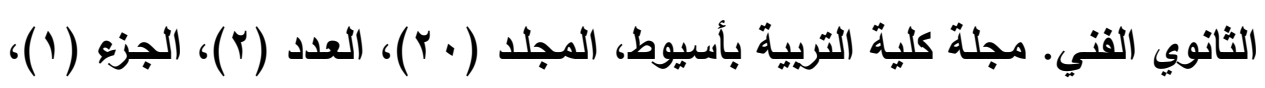
. Irr-v

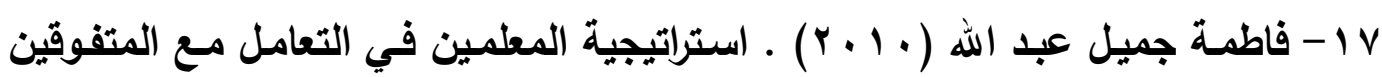

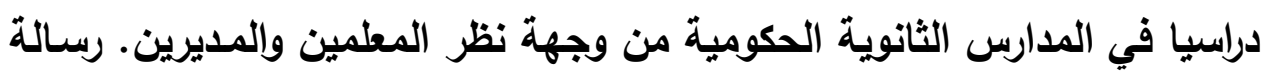
ماجستير، كلية الدراسات العليا، جامعة النجاح الوطنية .

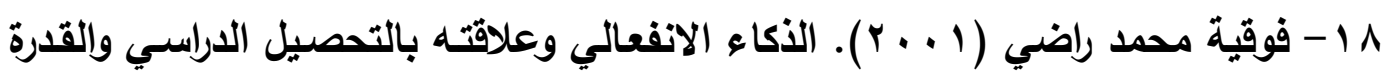

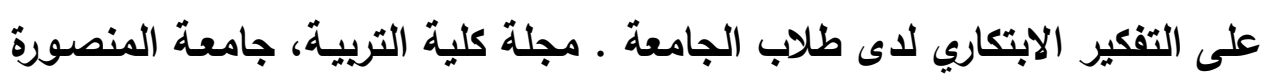

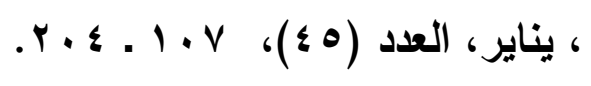


9 1 - محمد حبشي حسين و جاد الله أبو المكارم جاد الله (ع . . ץ) ـ المكونات العاملية

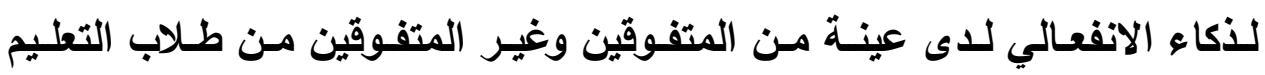

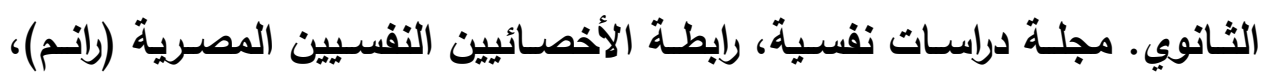

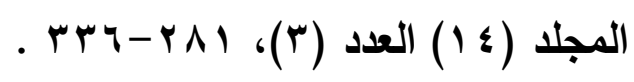

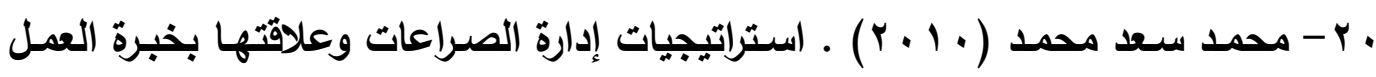

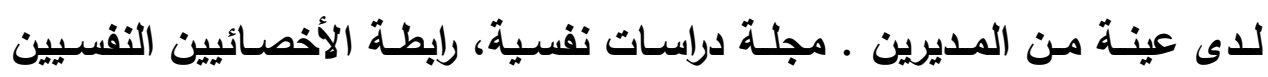

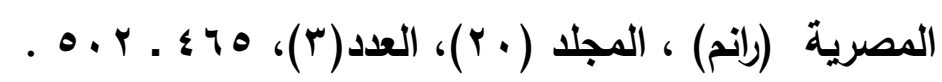

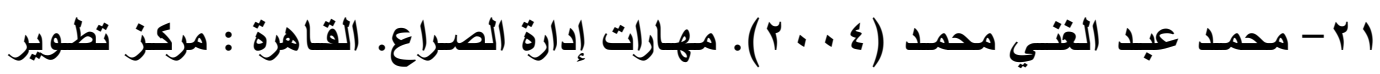

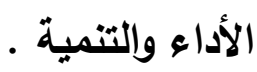

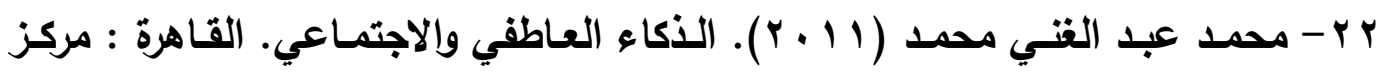

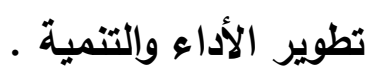

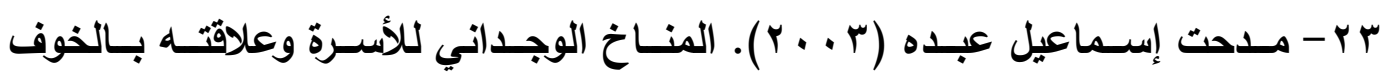

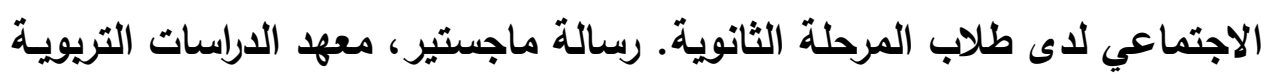
· مامعة القاهرة.

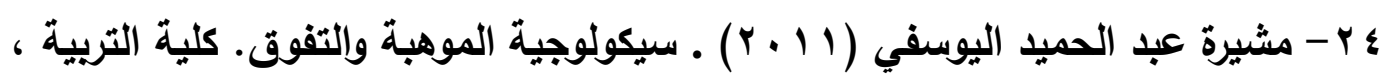

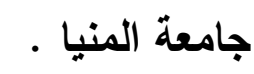

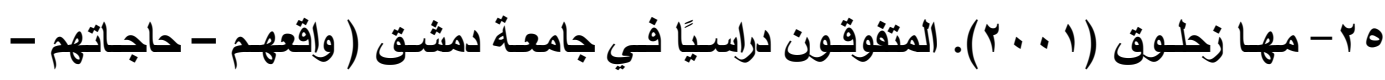

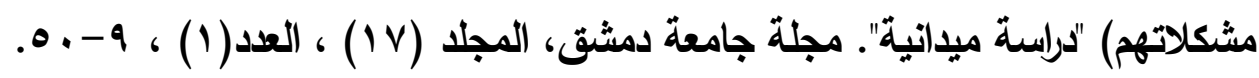

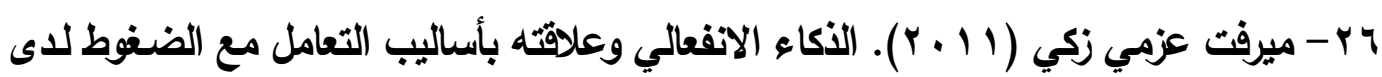

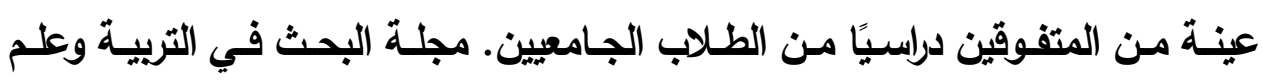

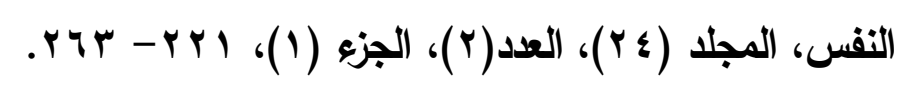

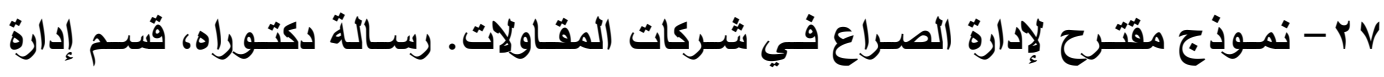

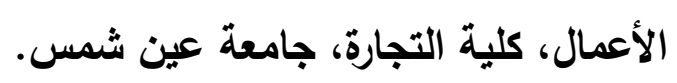

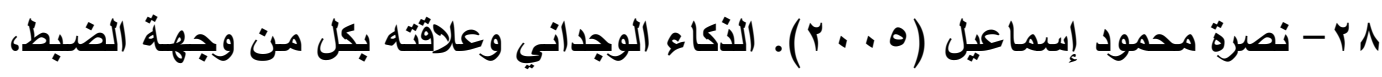
تقدير الذات والتحصيل الدراسـي لـى عينـة من تلاميذ المرحلة الإعداديـة بقتـا. رسالة ماجستير ، كلية التربية، جامعة المنيا.

29- Abraham, R. (2000). The Role of Job Control as a Moderator of Emotional Dissonance and Emotional Intelligence- 
Outcome Relation. Journal of Psychology Interdisciplinary and Applied , 134( 2), 169-189.

30- Afzalur, R.\& Clement,P. (2002) . Amodel of Emotional Intelligence and Conflict Management Strategies:A Study in Seven Countries. International Journal of Organizational Analaysis , 10 (4) , 302-326

31- Andrea, C. (2010). Exploring the Relationship of Emotional Intelligence and Conflict Management Styles. Doctor of Philosophy, the Faculty of The Graduate School at The University of North Carolina.

32- Asha, S. ( 1997). Control and Management of Conflict" in singh, H.M. "Foundamentals of Educational Management" Vikas publishing House Put Ltd.

33- Bar-On, R., Brown, J. Kirkcaldy, B., Thome, E. (2000). Emotional Expression and Implications for Occupational Stress : An Application of the Emotional Quotient Inventory (EQ- i). Personality and Individual Differences, 28 , 1107-1118.

34- Beebe, S., Masterson , J. (1997). Communication in Small Groups : Prinsiples and Practices (5th.) . New York .Longman.

35- Boyatzis, R., Goleman, D., . Rhee,k. S. (2000). Clustering Competence in Emotional Inteiligence Insights From the Emotional Competence Inventory. In: Bar-on \& J. Parker (Eds.), The Handbook of Emotional Intelligence , San Francisco, A Wiley Company, ,343-362.

36- Danielle, C. \& Adelheid, A. (2002). Emotional Intelligence and Leadership in Adolescents. Department of Military Psychology and Leadership, Royal Military College of Canada PO Box 17000, Station Forces, Kingston, ON, Canada K7K 7B4, Personality and Individual Differences ,33, 1101-1113.

37- Francis, W. (2010). Human Security and Conflict Management Post-Conflict Reconstruction in Sierra Leone 2002 to 2009. Doctor of Philosophy ، Faculty of The Graduate School, Howard University .

38- Garnefeski, N. (2000). Age Differences in Depressive Symbtoms, Antisocial Behavior, and Negative Perceptions of Family, School , and Peers Among Adolescents. J of Child and Adoles Cent Psychiatvy, 39(9), 1175-1181.

39- Goleman ，D. (1995a). Emotional Intelligence. New York: Bantam Books. 
40- Greenberg, J., Bar-on, r. (2000). Behavior in Organization.

New Jersey: Prentice Hail , Inc.Upper Saddle River.

41- Gregorio, B. (2003). Conflict Management Skills . California:

University, Chapter, 13, 157-174.

42- Kazdin, A. (2000): Encyclopedia of Psychology. Oxford: Oxford University Press.

43- Ka Wai, C., Miss, C. (2005). Emotional Intelligence and Conflict Management Styles . University of Macau , 7 (239) , 1-27.

44- Maurice, e. (2004). The Connection Between Social- Emotional Learning and Learning Disabilities. Implications for Intervention, Learning Disability Quarterly, The Council for Learning Dis abilities. Maurice,27, (1), 53 Win.

45- Mayer , J. Salovey, P. (1997). What is Emotional Intelligence?. In P. Salovey \& DJ. Sluyter (Eds.), Emotional Development and Emotional Intelligence: Implication for Educators. New York: Basic Books , 1 , 3-31 .

46- Mayer , j. (2001). Emotional Intelligence and Giftedness. Roeper Review, 23,131-137.

47- Mayer, J,. Salovey, P. (1993) . The Intelligence of Emotional Intelligence. Journal of Intelligence, $17,433-442$.

48- Mehrabian, A. (2003). Emotional Intelligence Test \& Optional Software - Available on the Web at http:// www.kaaj.com/ psych/scalaslei. htm.

49- Michael, S., Scott, D, ( 2006). The Bridge- New Civil Society and Conflict Management Strategy. Mercy Corps Civil Society \& Conflict Management Team Newsletter Vol. VI Third Quarter.

50- Parker, J., Creque, R., Barnhart, D., Harris, J., Majeski, S.(2004). Wood Laura, Bond, Barbara \& Hogan, M. Academic Achievement in High school: Does Emotional Intelligence Matter?. Personality\& Individual Differences, 37 (7), 1321-1331.

51- Petrides, k., Furnham .(2004) . The Role of Trait Emotional Intelligence in Academic Performance and Deviant Behavior at School. Journal of Personality and Individual Differences, 36, 267-276.

52- Reiff, h. (2001). the Relation of Idand Gender with Emotional Intellingence in College Students Journal of Learning Disabilities,34, (1), 66-100. 
53- Roberts , W. (1997). An Investigation of the Relationship Between Principals Self-Efficacy Beliefs and Their Methods of Management Conflict with Teachers. Disseration ،Abstracts International ,57(6), 14-42.

54- Seyfarth, J. (1999). The Principal New Leadership for New Challenges, Englewood Cliffs, NewJersy : Prentice Hall International, Inc.

55- Ting-Toomey, S., Takai, J. (2006). Explaining Intercultural Conflict: Promising Approaches and Future Directions. In J. G. Oetzel \& S. Ting-Toomey (Eds.), The Sage Handbook of Conflict Communication: Integrating Theory, Research, and Practice, 691-723.

56- Ting-Toomey, S., Yee-Jung, K., Shapiro, R., Garcia, W., Wright, T., Oetzel, J. ( 2000). Ethnic/Cultural Identity Salience and Conflict Styles in Four US Ethnic Groups. International Journal of Intercultural Relations, 24, 47-81.

57- Todd, H. (1992). Supervision First Line Management.(5th ed) Boston : R.R. Donnelley \& sons, Inc.

58- Tosi, H. (1995). Managing Organizational Behavior, 3rd Edition , Oxford : Blackwell Publishing Inc.

59- Tzu-Wen, (2011). schools for Children of Taiwanese Businesspeople in Mainland China: A Multi-Site Case Study of the Chinese Approach to Conflict Management and Resolution. Doctor of Philosophy in the Steinhardt School of Culture, Education, and Human Development, New York University.

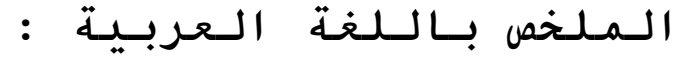$$
\text { هافت الدراسة إلى التعرف على طبيعة العلاقة بين الذكاء الانفعالي واستراتيجيات }
$$

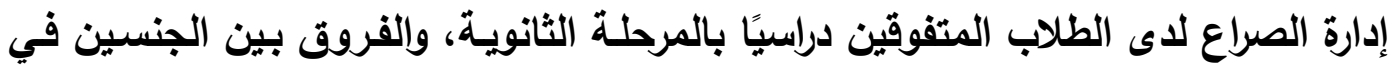$$
\text { الذكاء الانفعالي، والفروق بين الجنسين في استراتيجيات إدارة الصراع، وتكونت عينـة }
$$

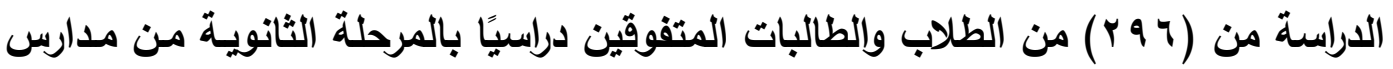


(مدينة بني مزار - مدينة المنيا - مدينة ملوي) بمحافظة المنيا r ا ب بم خلال الفصل

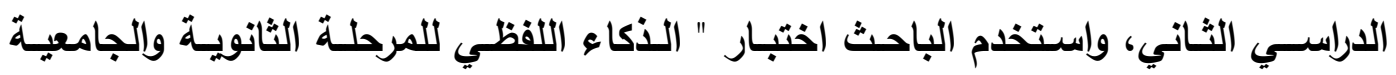

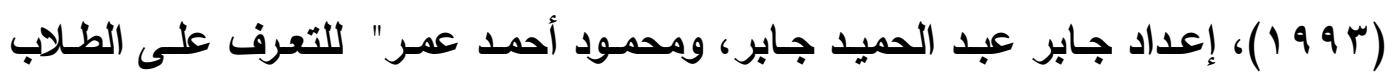

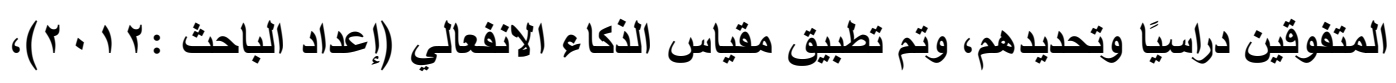

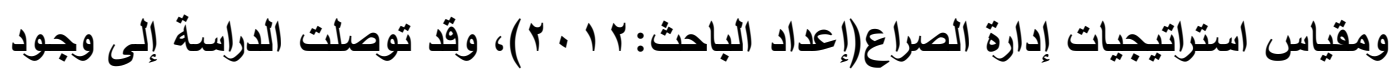

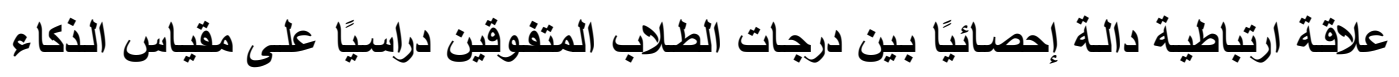

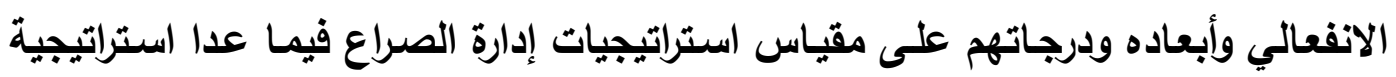
التوافق حيث لم توجد علاقة ارتباطية دالة إحصائيًا بين درجات الطلاب المتفوقين التئي دراسيًا

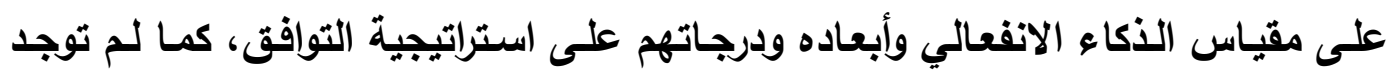

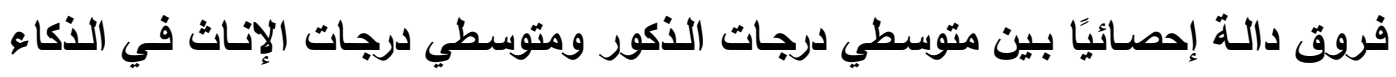

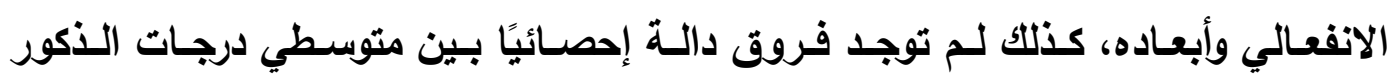

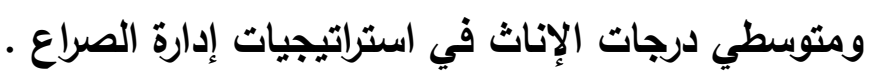

\section{Summary}

The current study aims at recognizing the relation between emotional intelligence and strategies of conflict management for the superior students and the difference between the ratio of marks of males and females in emotional intelligence and in the strategies of conflict management, .The sample consists of (296)student :138 males and 158 females from the toppers (superiors) in the first year of secondary school in the second term $2012 \mathrm{AC} / 1433 \mathrm{H}$. The research has handled some of Minia 
schools in Bani Mazar city, Minia city, Mallawy city during the school year 2012 in the second term. The researcher has used the Oral Intelligence test for the secondary and university stages (1993) ,prepared by Gabber Abdel-Hammed Gabber ,\& Mahmoud Ahmed Omar and he also applied the scale of emotional intelligence and the scale of strategies of conflict management ,both prepared by the researcher (2012) .Among the findings revealed by the current study are:

*There is a statistic significant correlative relationship between the scores of the superiors on the scale of emotional intelligence and their scores on the scale of the conflict management strategies expect for adaptability strategy.

*There are no statistically significant differences between the scores ratio of males and females in emotional intelligence

*There no statistically significant differences between the scores ratio of males and females in strategies of conflict management 